\title{
Nanostructured Solid Oxide Fuel Cell Electrodes
}

\author{
By
}

Tal Zvi Sholklapper

B.A. (University of California, Berkeley) 2004

M.S. (University of California, Berkeley) 2006

A dissertation presented in partial satisfaction of the

requirements for the degree of

Doctor of Philosophy

in
Engineering-Materials Science and Engineering
and the Designated Emphasis
in

Nanoscale Science and Engineering

in the

Graduate Division

of the

University of California, Berkeley

Committee in charge:

Professor Lutgard C. De Jonghe, Chair

Professor Oscar Dubón

Professor Robert G. Jacobsen

Fall 2007 
Nanostructured Solid Oxide Fuel Cell Electrodes

(C) 2007

by Tal Zvi Sholklapper 
Abstract

Nanostructured Solid Oxide Fuel Cell Electrode

by

\author{
Tal Zvi Sholklapper
}

Doctor of Philosophy in Materials Science and Engineering and the Designated Emphasis in Nanoscale Science and Engineering

University of California, Berkeley

Professor Lutgard C. De Jonghe, Chair

The ability of Solid Oxide Fuel Cells (SOFC) to directly and efficiently convert the chemical energy in hydrocarbon fuels to electricity places the technology in a unique and exciting position to play a significant role in the clean energy revolution. In order to make SOFC technology cost competitive with existing technologies, the operating temperatures have been decreased to the range where costly ceramic components may be substituted with inexpensive metal components within the cell and stack design. However, a number of issues have arisen due to this decrease in temperature: decreased electrolyte ionic conductivity, cathode reaction rate limitations, and a decrease in anode contaminant tolerance.

While the decrease in electrolyte ionic conductivities has been countered by decreasing the electrolyte thickness, the electrode limitations have remained a more difficult problem. Nanostructuring SOFC electrodes addresses the major electrode issues. The infiltration method used in this dissertation to produce nanostructure SOFC 
electrodes creates a connected network of nanoparticles; since the method allows for the incorporation of the nanoparticles after electrode backbone formation, previously incompatible advanced electrocatalysts can be infiltrated providing electronic conductivity and electrocatalysis within well-formed electrolyte backbones. Furthermore, the method is used to significantly enhance the conventional electrode design by adding secondary electrocatalysts. Performance enhancement and improved anode contamination tolerance are demonstrated in each of the electrodes. Additionally, cell processing and the infiltration method developed in conjunction with this dissertation are reviewed. 


\section{Dedication}

This thesis is dedicated to my parents, Michael and Liora, for their constant support through out my studies. 


\section{Table of Contents}

$\begin{array}{lll}\text { Chapter 1: } & \text { Introduction } & 1\end{array}$

1.1 Why Fuel Cells? 1

1.2 Basic Operating Principles of SOFCs 2

1.3 Structure of a SOFC 5

$\begin{array}{llr}1.4 & \text { Electrolyte } & 8\end{array}$

$\begin{array}{lll}1.5 & \text { Cathode } & 9\end{array}$

$\begin{array}{lll}1.6 & \text { Anode } & 13\end{array}$

$\begin{array}{lll}1.7 & \text { SOFC Stack and System } & 13\end{array}$

$1.8 \quad$ Metal Supported Solid Oxide Fuel Cell (mSOFC) 15

$\begin{array}{lll}1.9 & \text { Summary and Scope } & 16\end{array}$

$\begin{array}{ll}\text { References } & 17\end{array}$

$\begin{array}{ll}\text { Chapter 2: } & \text { Infiltrated Electrolyte Backbone }\end{array}$

$\begin{array}{lll}2.1 & \text { Introduction } & 19\end{array}$

$\begin{array}{ll}2.2 & \text { Single Component }\end{array}$

2.2.1 LSM Electrodes $\quad 22$

2.2.2 Alternative Electrodes 25

2.3 Nanocomposite Electrodes $\quad 31$

$\begin{array}{lll}2.4 & \text { Stability } & 33\end{array}$ 
$\begin{array}{lll}2.5 & \text { Summary } & 42\end{array}$

$\begin{array}{ll}\text { References } & 43\end{array}$

Chapter 3: $\quad$ Enhancing Composite LSM-YSZ Cathodes 45

$\begin{array}{lll}3.1 & \text { Introduction } & 45\end{array}$

$\begin{array}{llr}3.2 & \text { Performance } & 48\end{array}$

$\begin{array}{ll}3.3 & \text { Enhancement Mechanism }\end{array}$

$\begin{array}{lll}3.4 & \text { Stability } & 53\end{array}$

$\begin{array}{llr}3.5 & \text { Summary } & 54\end{array}$

$\begin{array}{ll}\text { References } & 56\end{array}$

Chapter 4: $\quad$ Enhancing Composite Ni-YSZ Anodes 57

$\begin{array}{lll}4.1 & \text { Introduction } & 57\end{array}$

$\begin{array}{llr}4.2 & \text { Performance } & 58\end{array}$

$\begin{array}{lll}4.3 & \text { Sulfur Tolerance and Stability } & 60\end{array}$

$\begin{array}{lll}4.4 & \text { Summary } & 68\end{array}$

$\begin{array}{ll}\text { References } & 70\end{array}$

$\begin{array}{ll}\text { Chapter 5: } & \text { Conclusions }\end{array}$

Appendix 1: Cell Processing \& Testing Procedure 73

$\begin{array}{lll}\text { A1.1 Introduction } & 73\end{array}$

$\begin{array}{lll}\text { A1.2 Processing } & 73\end{array}$ 
A1.2.1 Supports: Compaction or Tape Cast 74

A1.2.2 Thin Film Electrodes and Electrolytes 74

A1.2.3 Pt Current Collectors $\quad 76$

$\begin{array}{lll}\text { A1.2.4 Infiltration: Nanostructuring } & 77\end{array}$

$\begin{array}{lll}\text { A1.3 Cells } & 77\end{array}$

A1.3.1 Electrolyte Supported Cells (ESC) 77

A1.3.2 Anode Supported Cells (ASC) 78

A1.3.3 Cathode Supported Cells (CSC) 78

A1.4 Measurement and Testing Procedure 79

A1.4.1 Cell Mounting/ Heating 79

$\begin{array}{lll}\text { A1.4.2 Electrochemical Testing } & 79\end{array}$

$\begin{array}{lll}\text { A1.4.2.1 Performance Characteristics } & 80\end{array}$

A1.4.2.2 AC Impedance Spectroscopy 82

$\begin{array}{lll}\text { A1.4.3 Microscopy } & 85\end{array}$

$\begin{array}{lll}\text { A1.4.4 XRD } & 85\end{array}$

$\begin{array}{lll}\text { A1.4.5 DSC-TGA } & 86\end{array}$

$\begin{array}{lll}\text { A1.5 Summary } & 86\end{array}$

$\begin{array}{ll}\text { References } & 87\end{array}$

$\begin{array}{llr}\text { Appendix 2: } & \text { Infiltration } & 88\end{array}$

$\begin{array}{llr}\text { A2.1 Introduction } & 88\end{array}$

A2.2 Method and Science of Infiltration $\quad 88$

$\begin{array}{lll}\text { A2.3 Difficulties } & 95\end{array}$ 
$\begin{array}{ll}\text { A2.3.1 Salt } & 95\end{array}$

$\begin{array}{ll}\text { A2.3.2 Phase } & 96\end{array}$

A2.3.3 Electrode Density 96

A2.3.4 Volume of Infiltrated Material 97

$\begin{array}{lll}\text { A2.4 Scale-up } & 98\end{array}$

$\begin{array}{lll}\text { A2.5 Summary } & 99\end{array}$

$\begin{array}{lr}\text { References } & 101\end{array}$ 


\section{Acknowledgements}

I would like to thank my advisors academic and otherwise, Lutgard De Jonghe, Steven Visco, Craig Jacobson and Velimir Radmilovic, for their support and constant mentoring during the course of my research. I would also like to thank Grace Lau, Hideto Kurokawa, Chun Lu, Keiji Yamahara and Michael Tucker for being great co-workers and for their constant encouragement.

Additionally, I would like to thank the U.S. Department of Energy's (DOE) Solid State Energy Conversion Alliance (SECA) and by the U.S. Department of Energy under Contract \# DE-AC02-05CH11231, for supporting this research. 


\section{Chapter 1: Introduction}

\subsection{Why Fuel Cells?}

Fuel Cells allow for the direct electrochemical conversion of fuel to electricity, where as much of today's standard power generation relies on combustion processes, making fuel cells in theory more efficient. At the turn of the century the "Hydrogen Economy" powered by fuel cells operating on clean hydrogen was touted as the answer to future energy needs and the United States and the European Union resolved to make its development a top priority. ${ }^{1}$ However, recently interest in the "Hydrogen Econmy" has faded since there are major technological hurdles in each step when using hydrogen as the fuel, from low efficiencies during hydrogen production through low energy densities and difficulty in storage. As of August 2007, market capitalization for non-hydrogen fuel cell makers has topped that of hydrogen fuel cell makers. ${ }^{2}$ Since Solid Oxide Fuel Cells (SOFCs) operate at elevated operating temperatures $\left(500^{\circ} \mathrm{C}-1000^{\circ} \mathrm{C}\right)$, they allow for the possibility of direct reforming most hydrocarbon fuels, giving them a distinct advantage over other fuel cell technologies.

Another significant benefit of SOFCs is that their efficiency scales well, due to the modular nature of the SOFC unit, making SOFCs attractive for a wide variety of applications and markets, from small scale automotive, and cogenerative use as a power source and water heater for homes ${ }^{3}$ to large scale hybrid SOFC / turbine units which can compete with current grid sources. ${ }^{4}$ In Figure 1, a graph of the efficiency vs. rate power 
for fuel cells is compared to other competing technologies and it is evident that fuel cells are superior from an efficiency standpoint in all rated power ranges. It is now a matter of decreasing cell costs and increasing cell lifetimes to the levels that make them commercially viable.

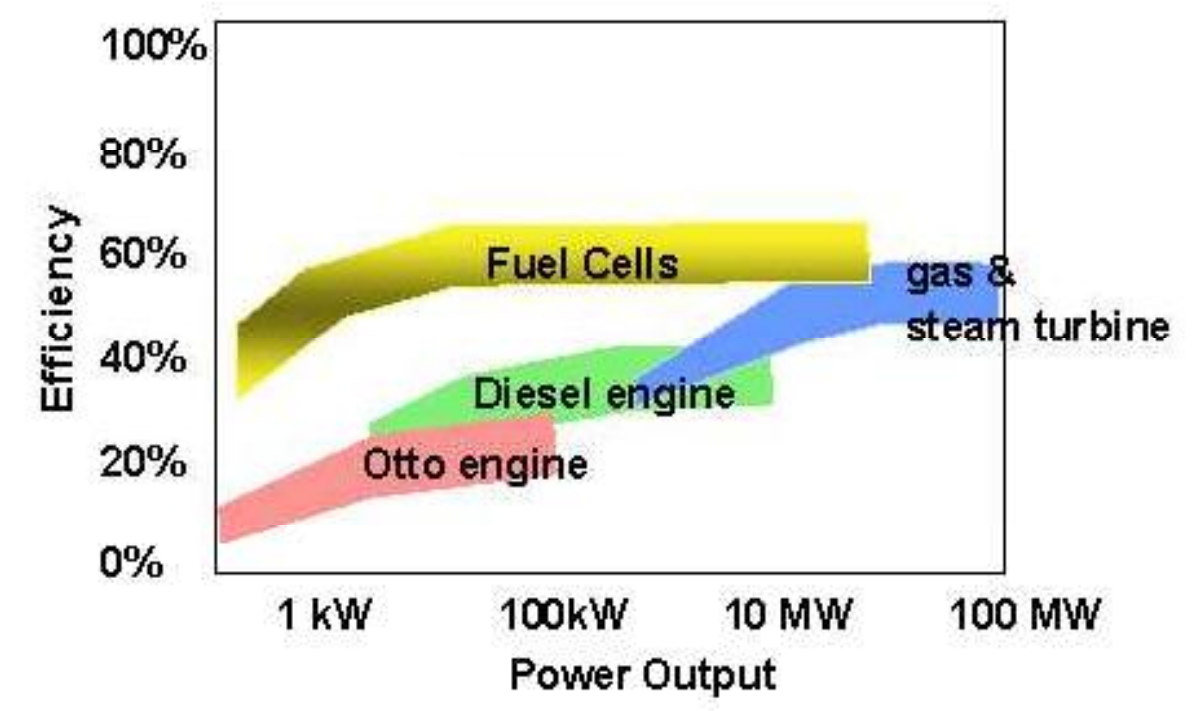

Figure1 Efficiency vs. rated power for Fuel Cells and competing technology. ${ }^{5}$

With the decrease inoperating temperature of SOFCs from the approximately $1000{ }^{\circ} \mathrm{C}$ systems initially developed to approximately $600-700^{\circ} \mathrm{C}$, ceramic components within the stack can be substituted with much less costly ferritic steel interconnect plates, thus increasing the probability of commercialization of the SOFC technology ${ }^{6-7}$ While the lowered operating temperatures successfully decrease cell and system costs a number of cell issues come in to play. This dissertation will present solutions to problems encountered when attempting to meet commercial viability.

\subsection{Basic Operating Principles of SOFCs}

The efficiency of system is given as: 


$$
\eta=\frac{\text { Work }}{\text { Heat }}
$$

In a conventional thermal power system the chemical energy of the fuel is transformed first to thermal energy, then to mechanical energy, and finally to electrical energy. The theoretical efficiency of such a system is governed by the Carnot limitation. For a combustion system the Carnot efficiency is determined by the difference in temperature between the high temperature of combustion to the low temperature of the sink and is given as

$$
\eta_{\text {Combustion }}=1-\frac{T_{\text {Low }}}{T_{\text {High }}}
$$

On the other hand in a fuel cell, chemical energy is converted directly to electricity and can thus yield a higher theoretical efficiency, which is given by the ratio of the Gibbs free energy and enthalpy for the fuel

$$
\eta_{\text {Combustion }}=\frac{\Delta G^{\circ}}{\Delta H^{\circ}}
$$

At an operating temperature of $700{ }^{\circ} \mathrm{C}$ the efficiency for the production of water from its constituents yields a theoretical efficiency of $78 \%$, while the Carnot efficiency of a heat engine operating at the same temperature with a sink at $100{ }^{\circ} \mathrm{C}$ the efficiency is only $62 \%$.

The theoretical voltage obtained from fuel cell is termed Open Circuit Voltage $(\mathrm{OCV})$ and is the equilibrium difference in potential or electromotive force (emf) between the fuel $\left(\mathrm{H}_{2}\right)$ and air electrodes of the fuel cell. It is given by the Nernst equation for the formation of water as

$$
E=\frac{R T}{4 F} \ln \left(\frac{P_{O_{2}(\text { Cathode })}}{P_{O_{2}(\text { Anode })}}\right) \text { and } P_{O_{2}(\text { Anode })}=\frac{P_{\left.H_{2} \text { O(Anode }\right)}}{P_{H_{2}(\text { Anode })} \cdot K}
$$




$$
E=E^{o}+\frac{R T}{4 F} \ln \left(P_{\mathrm{O}_{2}(\text { Cathode })}\right)+\frac{R T}{2 F} \ln \left(\frac{P_{\mathrm{H}_{2}(\text { Anode })}}{P_{\mathrm{H}_{2} \mathrm{O}(\text { (Cathode })}}\right) .
$$

where $E^{o}=\frac{R T}{4 F} \ln (K)$ is the standard cell voltage $\left(E^{o}=\frac{-\Delta G^{o}}{z F}=\frac{-\left(\Delta H^{o}-T \Delta S^{o}\right)}{z F} \approx 1.1 V\right)$, $\mathrm{R}$ is the gas constant, $\mathrm{T}$ is the temperature, $\mathrm{F}$ is the Faraday constant, $\mathrm{K}$ is the equilibrium constant of the reaction, and $\mathrm{P}$ is the partial pressure at each electrode.

In a SOFC the fuel $\left(\mathrm{H}_{2}\right)$ and oxidant $\left(\mathrm{O}_{2}\right)$ for the reaction are separated by a dense oxygen ion conducting electrolyte. A difference in activities between the fuel and oxidant gas gives rise to an electrochemical potential across the cell. When a load is applied a flow of electrons $\left(\mathrm{e}^{-}\right)$is induced and oxygen $\left(\mathrm{O}_{2}\right)$ is reduced at the cathode (Equation 5). Oxygen ions $\left(\mathrm{O}^{2-}\right)$ flow through the electrolyte in order to try and re-establish the electrochemical potential, and finally hydrogen $\left(\mathrm{H}_{2}\right)$ is oxidized at the anode producing water $\left(\mathrm{H}_{2} \mathrm{O}\right)$ (Equation 6). The overall reaction gives rise to the production of water from its constituents (Equation 7). A schematic Illustration of a SOFC with the above reactions listed is shown in Figure 2.

Reduction: $1 / 2 \mathrm{O}_{2}+2 \mathrm{e}^{-} \Rightarrow \mathrm{O}^{2-}$
$+\quad$ Oxidation: $\mathrm{O}^{2-}+\mathrm{H}_{2} \Rightarrow \mathrm{H}_{2} \mathrm{O}+2 \mathrm{e}^{-}$

Overall: $1 / 2 \mathrm{O}_{2}+\mathrm{H}_{2} \Rightarrow \mathrm{H}_{2} \mathrm{O}$ 


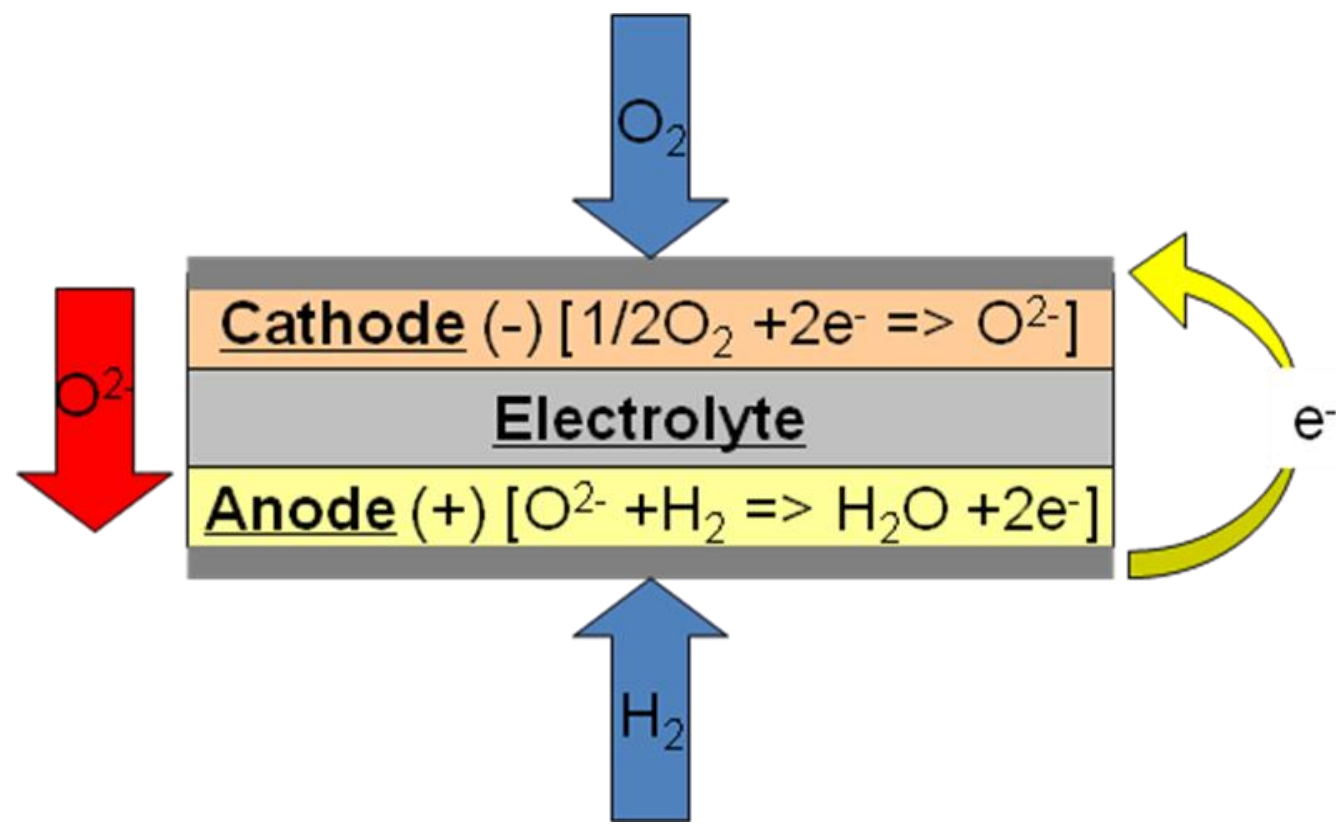

Figure 2. SOFC Schematic Diagram with electrode reactions and gas and charge carrier pathways illustrated.

\subsection{Structure of a SOFC}

As described in the previous section the basic electrochemical unit of the SOFC is comprised of an electrolyte sandwiched between oxidant and fuel electrodes. The current standard cell utilizes a yittria stabilized zirconia (YSZ) electrolyte sandwiched between a strontium doped lanthanum manganite (LSM) - YSZ cathode and Ni - YSZ anode. Each of the electrodes must maintain sufficient porosity to allow for gas flow through the electrode. An SEM micrograph of a fractured standard cell is shown in Figure 3. Note that scandia yittria stabilized zirconia (SYSZ) is exchanged for YSZ in this cell. Additionally, a layer of platinum is seen on top of the LSM-YSZ cathode, the platinum is used for current collection on both electrodes. 


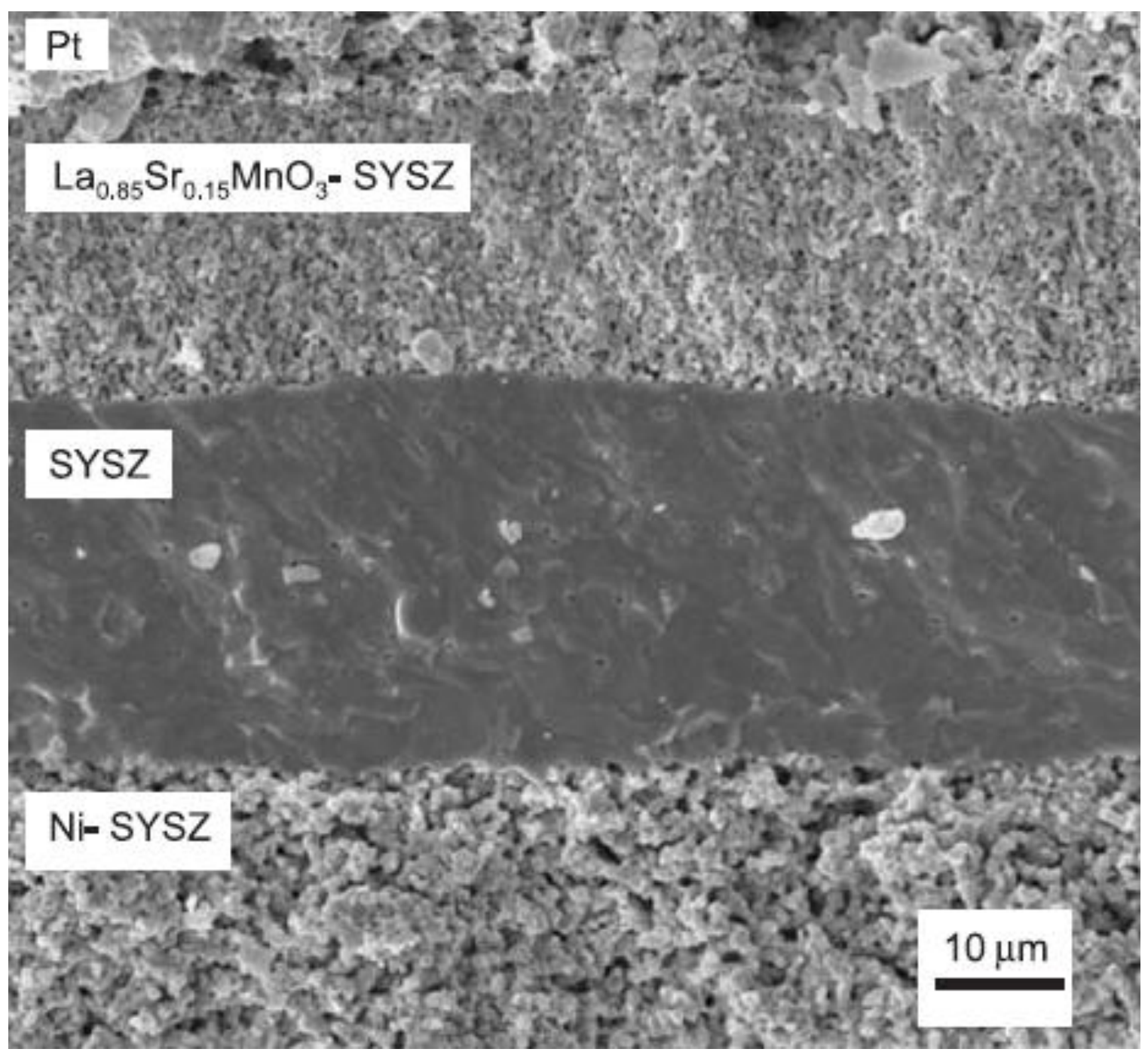

Figure 3. SEM cross-section of fractured SOFC.

Within the electrodes the electrochemical reaction requires conduction channels for electrons $\left(\mathrm{e}^{-}\right)$, oxygen ions $\left(\mathrm{O}^{2-}\right)$ and gas $\left(\mathrm{O}_{2}\right.$ or $\left.\mathrm{H}_{2}\right)$ for the reaction to occur. Hence the reaction occurs at the triple phase boundary (TPB) between electronic conducting $\mathrm{Ni}$ or LSM grains, ionic conducting YSZ grains and the pores.

A schematic of the TPB reaction area within an electrode is shown in Figure 4. The $1 \mu \mathrm{m}$ size electrode grains provide for percolation channels through the electrode for electrons and oxygen ions while the open pore structure supplies the gas for the reaction 
to occur. Once the reaction occurs, the oxygen ions flow through the $\sim 10 \mu \mathrm{m}$ thick dense electrolyte.

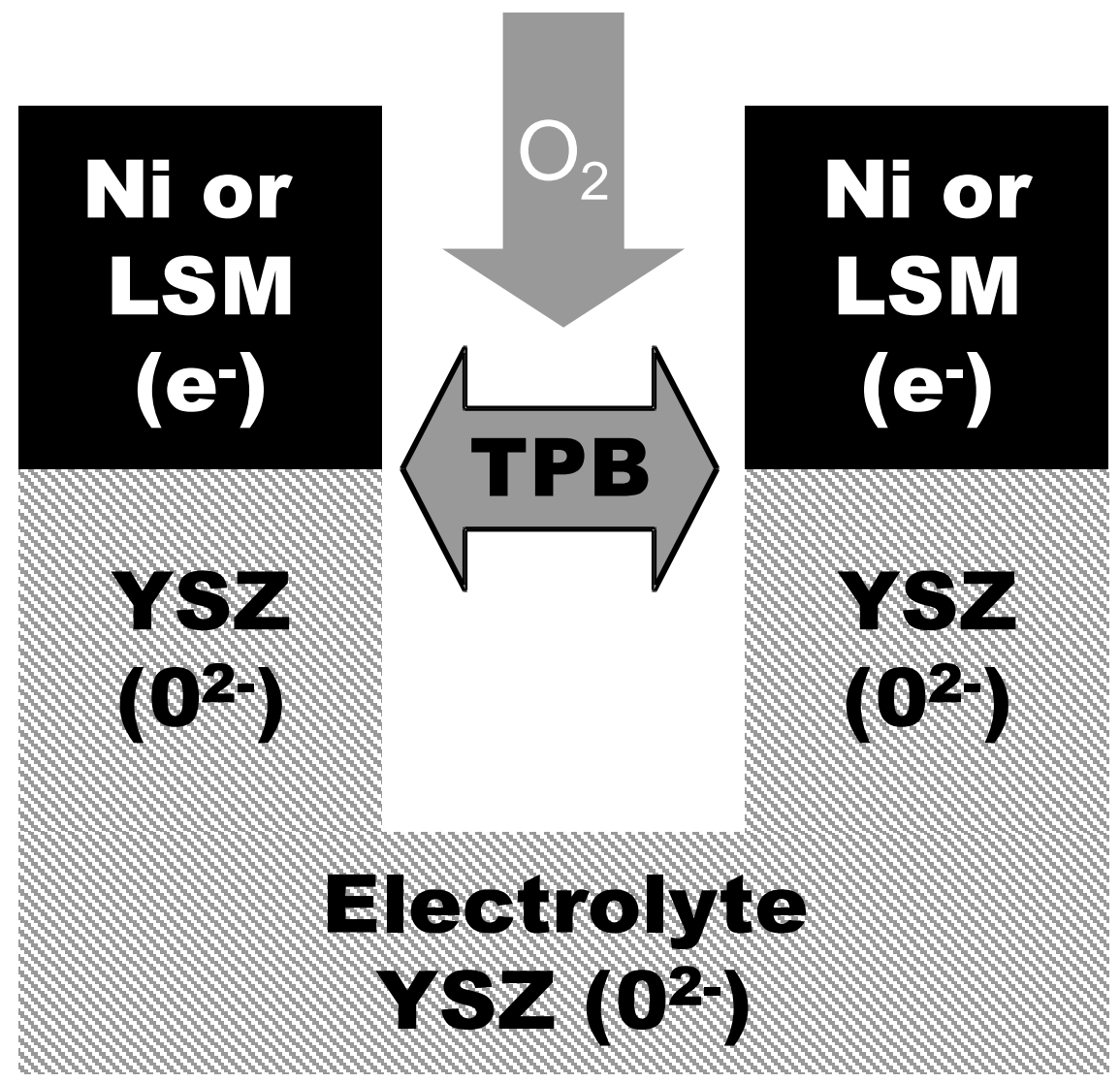

Figure 4. Schematic of electrode triple phase boundary (TPB) reaction area.

In order to discuss the conduction mechanism within each of SOFC materials, Kröger-Vink Notation will be introduced. The notation was developed by F.A. Kröger and H.J. Vink ${ }^{8}$ to describe electrical charge and lattice position of defects in crystals.

$\left(M_{S^{C}}^{C}\right)^{B}$

$\mathrm{M}^{\mathrm{C}}: \quad$ corresponds to the defect species or vacancy created and its charge. 
$\mathrm{S}^{\mathrm{C}}: \quad$ corresponds to the lattice position and its charge.

B: $\quad$ indicates the charge of the defect. $(\mathrm{x}=$ neutral, $\bullet=$ a single positive charge, ' = a single negative charge)

Following each of the cells layers will be introduced more specifically and conduction mechanisms will be addressed. Electrode problems that will be addressed in the dissertation will be introduced.

\subsection{Electrolyte}

As stated in section 1.2, the dense electrolyte must allow for oxygen ion $\left(\mathrm{O}^{2-}\right)$ mobility between each of the electrodes. Additionally, the electrolyte must have low electronic conductivity so as not to "short" the cell. Hence, the essential requirements for the electrolyte material are: high oxygen ion conductivity, low electronic conductivity, ease of densification and of course stability. The most commonly used material meeting these requirements is stabilized zirconia. Oxygen ion conductivity is induced by introducing oxygen ion vacancies in zirconia $\left(\mathrm{ZrO}_{2}\right)$ by doping with an aliovalent material, typically with yittria $\left(\mathrm{Y}^{3+}\right)$. Yittria with valance $3+$ is substituted for zirconia $\left(\mathrm{Zr}^{4+}\right)$ with valance $4+$. In order to maintain charge neutrality an oxygen vacancy $\left(V_{O^{2-}}\right)$ is created for every $2 \mathrm{Y}$ atoms substituted. The substitution reaction follows. The large density of oxygen vacancies provides the pathway for oxygen ion mobility.

$$
Y_{2} O_{3}+2\left(Z_{Z r^{4+}}^{4+}\right)^{\times}+\left(O_{O^{2-}}^{2-}\right)^{\times}=2\left(Y_{Z r^{4+}}^{3+}\right)^{\prime}+\left(V_{O^{2-}}\right)^{\cdots}+2 O_{2}
$$

One key characteristic that makes YSZ suitable as an electrolyte material is that it maintain low electronic conductivity in both oxidizing and reducing atmospheres. ${ }^{9}$ 
Another material that has been evaluated as an electrolyte material because of its high oxygen ion conductivity is ceria. However ceria develops substantial electronic conductivity in the reducing atmospheres, seen in the anode, thus shorting the cells and limited its use as an electrolyte to low temperatures $\left(\leq 600^{\circ} \mathrm{C}\right)$ in which less electronic conductivity is induced. In the case of ceria, both oxygen ion conductivity and electronic conductivity are created when ceria is reduced from a valance of $4+$ to $3+$ in the reducing atmospheres. While oxygen vacancies are created to maintain charge neutrality, the reduced ceria additionally serves as an electron hopping sites. The defect chemistry for ceria is show bellow.

$$
\frac{1}{2} \mathrm{O}_{2}+2\left(\mathrm{Ce}_{\mathrm{Ce}}^{3+}{ }^{4+}\right)^{\prime}+\left(V_{\mathrm{O}^{2-}}\right)^{\cdots}=\left(\mathrm{O}_{\mathrm{O}^{2-}}^{2-}\right)^{\times}+2\left(C e_{C e^{4+}}^{4+}\right)^{\times}
$$

\subsection{Cathode}

The TPB reaction area within each of the electrodes, illustrated in section 1.3, states that the electrodes must provide both electronic and oxygen ion conductivity, while maintaining sufficient porosity for gas flow to the reaction sites. In the composite electrode structure illustrated earlier the oxygen ion conductivity is provided by YSZ. Thus the essential requirements for the cathode materials are: high electronic conductivity, high catalytic activity for oxygen reduction, sufficient porosity after sintering and compatibility with the electrolyte. The typical cathode material of choice is doped lanthanum manganite. High electronic conductivity is induced in lanthanum manganite by doping with an aliavalent material, typically with strontium (Sr). Strontium $\left(\mathrm{Sr}^{2+}\right)$ with valance $2+$ is substituted for lanthanum $\left(\mathrm{La}^{3+}\right)$ with valance $3+$. In order to maintain charge neutrality manganese donates an electron by changing from a $3+$ valance 
to $4+$. The electron conduction mechanism is considered to be a small polaron hoping mechanism due to the localized manganese sites. The reaction is illustrated bellow.

$$
\mathrm{SrO}+\left(\mathrm{Mn}_{\mathrm{Mn}^{3+}}^{3+}\right)^{\times}=2\left(\mathrm{Sr}_{\mathrm{La}^{3+}}^{2+}\right)^{\prime}+2\left(\mathrm{Mn}_{\mathrm{Mn}^{3+}}^{4+}\right)^{\bullet}+\frac{1}{2} \mathrm{O}_{2}
$$

Even though LSM provides above adequate electronic conductivity it is not a good electrocatalyst for the oxygen reduction reaction since it has insufficient oxygen ion conductivity at lower temperatures. Even when YSZ is added to provide the oxygen ions for the reaction, the cathode typically limits cell performance.

While lowering of SOFC operation temperatures decreases overall cell costs, it also lowers the ionic conductivity of the electrolyte and the electrochemical performance of the electrodes. ${ }^{10}$ The decrease in electrolyte conductivity can be negated by switching to thin film electrolyte design to minimize losses. However, as can be seen in Figure 5, measured using a thick electrolyte fuel cell (so that a reference can be used to separate the electrode losses) at $800^{\circ} \mathrm{C}$, it is specifically the cathode kinetics that limits cell performance. 


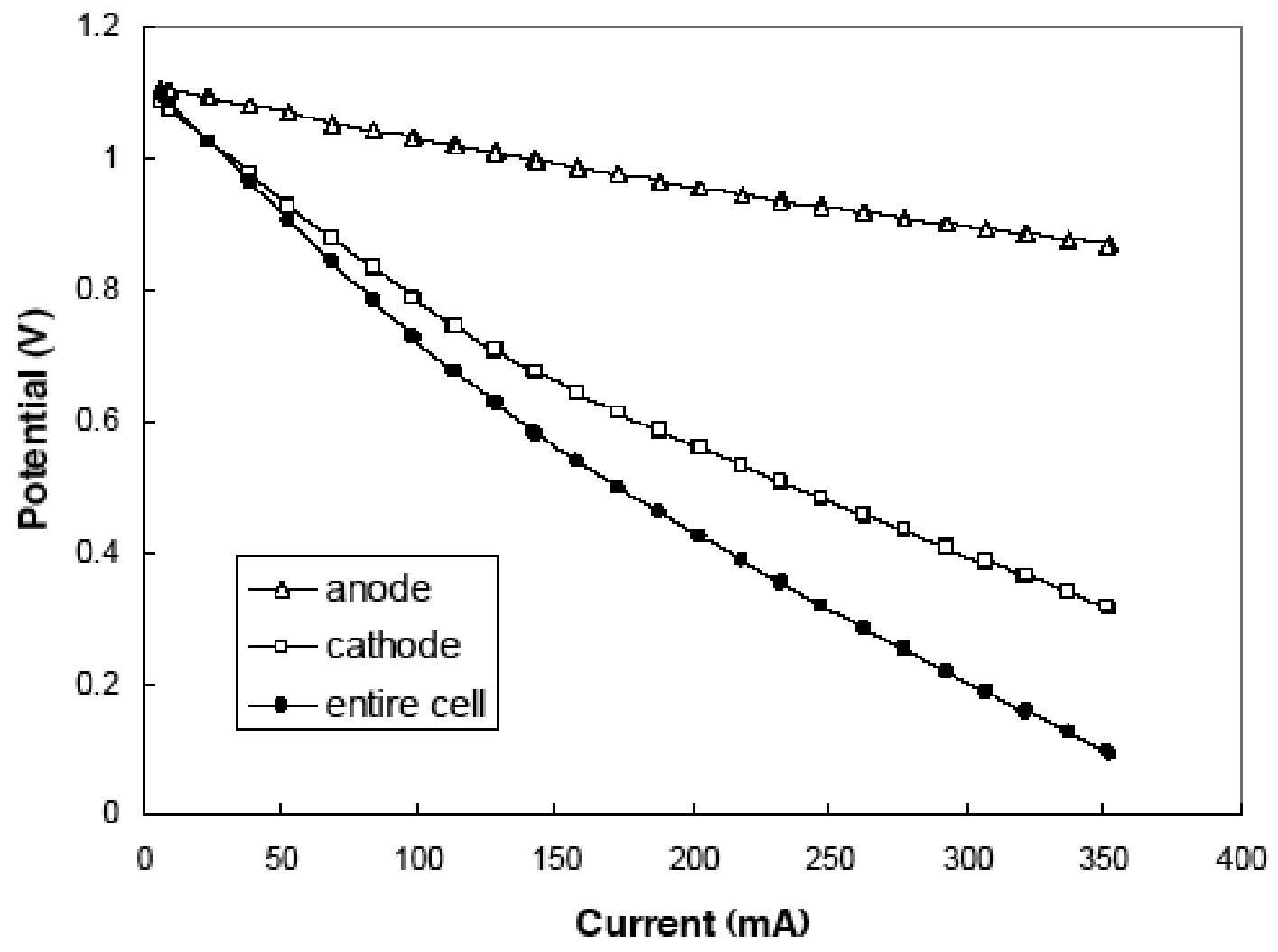

Figure 5. I-V characteristics of an electrolyte supported SOFC at $800{ }^{\circ} \mathrm{C} .{ }^{11}$

The overall drop in cell potential can be attributed to both IR losses, due to oxygen ion conduction through the electrolyte, and polarization losses $(\eta)$, due to slow electrode kinetics. The overall drop in cell potential is given in the following equation. As current is drawn and the cell is activated the rate of decrease in cell potential approaches the IR limit and becomes linear as current is drawn and the electrodes are activated. It is clear that the majority of the non-linear polarization losses $(\eta)$ are due to the cathode ( $\left.\eta_{\text {Cathode }}\right)$.

$$
\text { Cell Potential }=\mathrm{IR}+\left(\eta_{\text {Cathode }}+\eta_{\text {Anode }}\right)
$$

An approach of improving cathode performance has been to use doped lanthanum cobaltites or doped lanthanum ferrites. These materials have good oxygen ion 
conductivity as well as electronic conductivity, because some of the substituted strontium can additionally be compensated by oxygen vacancies, as show bellow.

$$
2 \mathrm{SrO}+\left(\mathrm{O}_{\mathrm{O}^{2-}}^{2-}\right)^{\times}=2\left(\mathrm{Sr}_{\mathrm{La}^{3+}}^{2+}\right)^{\prime}+\left(V_{\mathrm{O}^{2-}}\right)^{\bullet \bullet}+\frac{3}{2} \mathrm{O}_{2}
$$

Due to the ready availability of both electrons and oxygen ions, these materials make good electrocatalysts. However they are extremely reactive with YSZ, forming resistive products upon sintering. ${ }^{12}$ Luckily their intrinsic ionic conductivity allows them to be used as single component electrodes. However, since they must still be in contact with a YSZ electrolyte sintering temperatures must be kept to a minimum, and often a barrier layer is needed.

Since it is difficult to sinter the advanced catalysts, it would be advantageous to add them as low temperature sintered $\left(<900^{\circ} \mathrm{C}\right)$ nanoparticles on top of a preformed backbone. An approach was developed to depositing a continuous layer of nanoparticles within porous electrodes as is discussed in Appendix 3. This approach for creating nanostructured SOFC electrodes is utilized for not only advanced catalyst infiltration (Section 2.3), but also of LSM infiltration into a YSZ backbone (Section 2.1-2.3). It was shown that when sintering YSZ-LSM composite electrodes, structural factors, such as network connectivity during co-firing, limit YSZ's oxygen ion conductivity. ${ }^{13}$ By forming the YSZ backbone before the addition of the electrode material, a wellconnected oxygen ion-conducting network can be formed which can then be infiltrated with electrocatalysts, well bellow the usual co-firing temperatures. This concept was first reported in the patent literature in $1966,{ }^{14}$ and also exploited by Isenberg. ${ }^{15}$ An additional advantage of the process is that it allows for the incorporation of a composite electrocatalyst systems, producing a further enhanced electrode (Section 2.3). 
The ability to create nanostructured electrodes also facilitates the enhancement of traditional LSM-YSZ electrodes. By adding a mixed ionic electronic conductor such as doped ceria, extension can be achieved along each of the single type charge carrying grains in the composite (Chapter 3).

\subsection{Anode}

Just as in the case for the cathode, the anode material requirements are: high electronic conductivity, high catalytic activity for oxygen reduction, sufficient porosity after sintering and compatibility with the electrolyte. The typical anode material of choice is $\mathrm{Ni}$, which provides high electronic conductivity, while the YSZ supplies the oxygen ions for the oxidation reaction.

While lowering the operating temperature yields significant cost benefits, the performance and especially the sulfur tolerance of traditional Ni-YSZ anodes, drops drastically. At intermediate temperature $\left(600^{\circ} \mathrm{C}-800^{\circ} \mathrm{C}\right)$, Ni-based anodes tolerate only $\sim 0.1 \mathrm{ppm}$ of sulfur. ${ }^{16}$ By using a nanostructuring approach similar to that used in the cathode - infiltrating with ceria — the performance and more importantly the sulfur tolerance of Ni-based anodes can be drastically improved (Chapter 4).

\subsection{SOFC Stack and System}

Typical cell voltage for a solid oxide fuel cell during operation is approximately 0.7 $\mathrm{V}$; hence it is necessary to connect a number of cells in series in order to produce larger voltages. The assembly of sets of cells in series and in parallel is referred to as a fuel cell stack. The two basic geometries commonly used in SOFC stacks are shown in Figure 6. 
The planar geometry has been developed by Topsoe Fuel Cells and Delphi, among others. While the variants of the tubular geometry have been developed by Siemens, Kyocera and Rolls Royce, among others. ${ }^{17}$
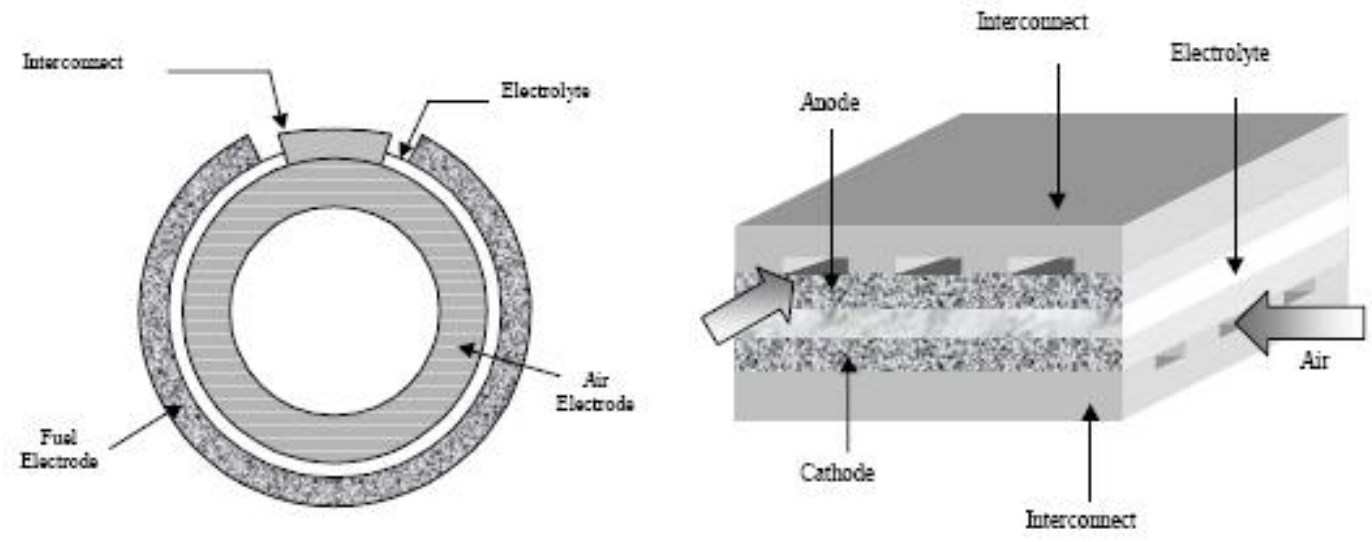

Figure 6. SOFC geometries, tubular and planar. ${ }^{18}$

While the SOFC stack is at the heart of the power generating system, the overall SOFC system is inherently complex due to the elevated operating temperatures, requiring numerous heat exchanging, gas flow and power system components. In Figure 7, we see flow diagram for a typical combined heat and power (CHP) SOFC. External cooling sources such as water are often needed to maintain temperature within an SOFC stack and hence it is often advantageous to utilize this heat in CHP systems. Even without CHP capabilities, it is evident that an SOFC system is inherently complex. It is estimated that the cost of cells themselves will only account for $\sim 50 \%$ of the overall system cost ${ }^{19}$. 


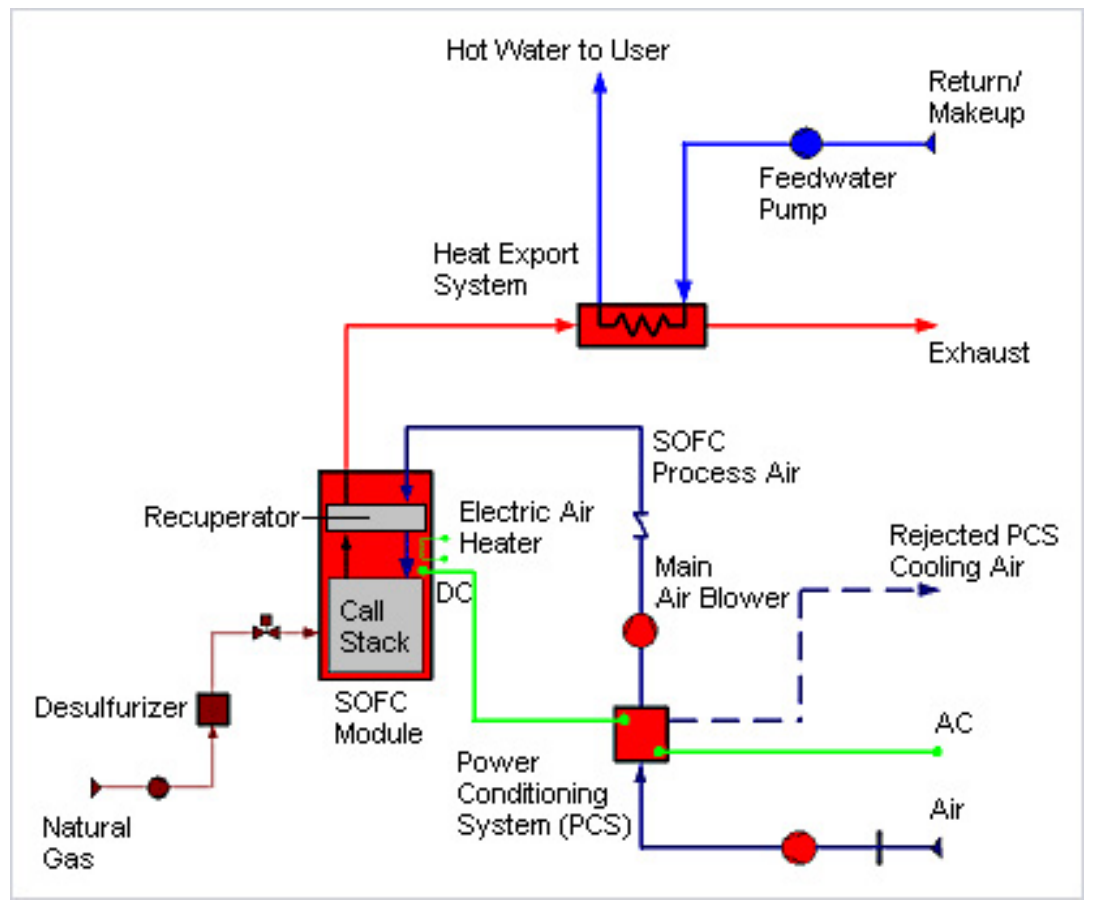

Figure 7. Flow diagram of a typical CHP SOFC system. ${ }^{20}$

\subsection{Metal Supported Solid Oxide Fuel Cell (mSOFC)}

Decreasing in operating temperatures has allowed for the use of ferretic steel as interconnect plates and within the stack itself, decreasing the dependence on more costly ceramic components. The classical cell designs used for manufacturing and presented in Appendix 1, are base on a ceramic supported structure. By switching to a metal supported structure dramatic cost benefits can be realized. It is estimated as of November 2007 that by switching from a ceramic, or ceramic-Ni based support, to a SS support the cell materials cost can be decreased by at least one order of magnitude. ${ }^{21-22}$ Additionally, there are a number of other benefits to using a metal support solid oxide fuel cell (mSOFC): cells are more robust; metal helps minimize thermal gradients minimizing balance of balance concerns. In 2007 scientists at LBNL developed metal supported cell 
capable of producing power densities of approximately $1 \mathrm{~W} / \mathrm{cm}^{2}$ at $700{ }^{\circ} \mathrm{C}$ providing a proof of concept for efficient mSOFCs. ${ }^{23}$

\subsection{Summary and Scope}

The focus of this dissertation is nanostructured SOFC electrodes. In Chapter 2 I will discuss infiltrated porous YSZ electrodes, which depend on the connected nanoparticles for both electronic conduction and catalysis. In Chapters 3 and 4, the focus shifts to the enhancement of conventional composite SOFC electrodes. As stated in this Section 1.4(?) cathode losses dominate in conventional SOFC, and the use of infiltration to significantly minimize this limitation will be discussed in Chapter 3. In Chapter 4 anode enhancement becomes the focus, and the problem of fuel contaminant tolerance is also addressed by nanostructuring. Finally, in Chapter 5, some conclusions will be presented.

Additional appendix sections are presented at the end of the dissertation, focusing on ASC Manufacturing (Appendix 1), and Infiltration (Appendix 2). 


\section{References}

1. http://www.whitehouse.gov/news/releases/2003/06/20030625-6.html

2. http://www.reuters.com/article/environmentNews/idUSN3146318320070831?

3. http://global.kyocera.com/news/2007/0201.html

4. $\quad$ http://www.netl.doe.gov/technologies/coalpower/fuelcells/hybrids.html

5. $\quad$ http://www.esc.ethz.ch/research/efficientconversion/fuelcells

6. N. Christiansen, J. Hansen, H. Holm-Larsen, S. Linderoth, P. Larsen, P. Hendrikson and M. Mogensen, Fuel Cell Seminar, HI, Honolulu (2006).

7. S.J. Visco, C.P. Jacobson and L.C. DeJonghe, Int. Symposium on Fuel Cells for Vehicles Nagoya, Japan (2000).

8. $\quad$ F.A. Kröger and H.J. Vink, 1958. In Solid State Physics - Advances in Research and Applications, ed. F. Seitz, T. Turnbull, 3:307. New York: Academic.

9. W. Weppner, J. Solid. State Chem., 20, 305 (1997).

10. Ralph, J.M, Schoeler, A.C., M. Krumpelt. Journal of Materials Science, 36, 5, 1161-1172 (2001).

11. A. Leming, "Cobalt post-Doping of Solid Oxide Fuel Cell Cathodes," P.h.D. Dissertation (UC Berkeley) 2004.

12. L. Kindermann, D. Das, H. Nickel, K. Hilpert, C. C. Appel, and F. W. Poulson, J. Electrochem. Soc., 144, 717-20 (1997).

13. K. Yamahara, T. Sholklapper, C.P. Jacobson S.J. Visco, L.C. De Jonghe, Solid State Ionics, 176, 1359 (2005).

14. Euro. Pat P.V. 1,513,796, (1968).

15. A.O. Isenberg, Solid State Ionics, 3/4, 431 (1981).

16. Y. Matsuzaki and I. Yasuda, Solid State Ionics, 132, 261 (2000). 
17. S. C. Singhal, at $31^{\text {st }}$ International Conference \& Exposition on Advanced Ceramics and Composites, January 2007, Daytona Beach, FL, USA.

18. N.Q. Minh and T. Takahashi, Science and Technology of Fuel Cells, Elsvier Science (1995).

19. http://www.netl.doe.gov/publications/proceedings/06/seca/pdf/Thijssen.pdf

20. http://www.powergeneration.siemens.com/products-solutions-services/productspackages/fuel-cells/principle-behind-technology/operation-principle/

21. http://www.metalprices.com/

22. http://www.netl.doe.gov/publications/proceedings/06/seca/pdf/Thijssen.pdf

23. M.C. tucker, G.Y. Lau, C.P. Jacobson, L.C. De Jonghe, S.J. Visco, Journal of Power Sources, 171, 2 (2007). 


\section{Chapter 2: Infiltrated Electrolyte Backbone}

\subsection{Introduction}

Nanoscale materials $(<100 \mathrm{~nm})$ are receiving increased interest for application in devices where their unusual properties may possibly be exploited. ${ }^{1,2}$ In solid oxide fuel cells (SOFCs) they can be added as catalysts, where it has been theorized that the advantageous catalytic properties of nanosized oxides relate to an enhanced surface vacancy concentration and increased ionic and electronic conductivities. ${ }^{3-6}$ However, due to the elevated operating temperatures found in modern SOFCs, $500-750{ }^{\circ} \mathrm{C}$, the use of entirely nanostructured components would undoubtedly lead to structural instability. Hence, nanoparticles have been incorporated in conjunction with more stable micrometer-sized supporting functional architectures.

The use of metal components in SOFC design has shifted system operating temperatures to $500-750{ }^{\circ} \mathrm{C}^{7}$ away from the $\sim 1000{ }^{\circ} \mathrm{C}$ systems initially adopted by Westinghouse and others. ${ }^{8}$ The penalty is that SOFC performance decreases significantly at these lower operating temperatures. Particularly, it is the oxygen reduction reaction in the conventional SOFC cathode, a composite of LSM and YSZ, which is limiting at these intermediate temperatures. ${ }^{9}$

Various models have been proposed to develop a relationship between cathode performance, e.g., characterized by an effective charge-transfer resistance, and its structure and catalytic properties. After some structural assumptions and simplifications, 
an effective charge-transfer resistance, $R_{c t}^{e f f}$, was derived by Virkar et al. ${ }^{10}$ and is expressed as $R_{c t}^{e f f}=\sqrt{R_{c t} L / \sigma_{O^{2}}(1-P)}$, in which $R_{c t}$ is the intrinsic averaged chargetransfer resistance; $L$ is the periodicity of the structural model, and could be taken to be the electrode pore spacing; $P$ is the electrode porosity; and $\mathrm{O}^{2-}$ is the ionic conductivity of electrolyte phase. In this model, the catalyst was assumed to form a thin, uniform layer on the pore walls of the electrode's YSZ network, which does not quite correspond to the usual structure of an YSZ-LSM composite cathode. Further, the oxygen ion conductivity, $\mathrm{O}^{2-}$, of the YSZ in composite electrodes is affected by other structural factors, such as the network connectivity that is in turn affected in the co-firing process by the presence of the LSM. ${ }^{11}$ An advantageous approach would therefore be first to form a well-connected oxygen ion-conducting network that can later be infiltrated with electrocatalysts, well below the usual co-firing temperatures. This concept was first reported in the patent literature in $1966,{ }^{12}$ and was also exploited by Isenberg. ${ }^{13}$ An interesting aspect is that the resulting structures conform more closely to the model assumptions of Virkar et al. ${ }^{10}$

Materials such as LSM provide not only catalytic sites for the oxygen reduction reaction, but also have high electronic conductivity. The latter requires a continuous LSM structure. Unfortunately, the particle distribution produced by typical infiltration methods necessitates a large number of repetitions to produce a connected network of nanoparticulates, causing pore filling besides the intended coating of pore walls. Progressive filling of the pores has the drawback of causing gas diffusion limitations within the electrodes, which in turn limit performance at higher current densities. It would therefore be advantageous to engineer a uniform networked nanoparticulate layer within the electrodes, involving a minimal number of processing steps. 
By using the infiltration method described in Appendix 2, we are able to nanostructure the electrodes in a single processing step. A proof of concept for these unique nanostructured electrodes is given in Section 2.2.1, using the traditional LSMYSZ material set, with LSM infiltrated into a pre-sintered porous YSZ backbone.

Furthermore, the method expands the set of viable electrode materials combinations; because of the elimination of thermal expansion mismatch and the suppression of possible deleterious reactions among the electrode materials when sintered at the high temperature required for co-firing. Therefore, a reactive ${ }^{14}$ but otherwise effective electrocatalyst ${ }^{15}$ such as LSF can be employed. Additionally, electrocatalysts, like Ag, which are volatile at high temperatures (e.g. 1.3x10-5 kPa @ $\left.800{ }^{\circ} \mathrm{C}\right),{ }^{16}$ can also be utilized. In Section 2.2.2 alternative electrocatalysts such as LSF and Ag will be discussed.

The method additionally allows for the infiltration of nanocomposite electrocatalysts, thus taking advantage of each of the individual catalyst components. In Section 2.3 an Ag-LSM nanocomposite is introduced, providing the advantages of both of the individual nanoscale components in addition to increasing the stability of the Ag morphology within the electrode.

In these electrode designs, the nanoparticulates not only serve as reaction sites, but also provide an electron pathway from the current collector to the individual reaction sites. Hence, persistent connectivity of the nanoparticulate networks and limited coarsening are essential to stable electrode function. Although a number of papers have been published on nanoparticle-infiltrated electrodes, ${ }^{26-27,} 29-31$ little mention has been made of the extended stability of such structures. The difficulty is that SOFC electrodes 
operate under demanding operating conditions: elevated temperatures $\left(600^{\circ} \mathrm{C}-1000^{\circ} \mathrm{C}\right)$, thermal cycling, high local current densities, and high local potential gradients. These conditions can be antagonistic to the stability of nanoparticulate networks.

Stability issues within single and nano component electrodes will be addressed in Section 2.4, demonstrating the potential viability of nanoparticulate-infiltrated electrodes for commercial SOFCs, and illustrating the functional stability of nanoparticulate catalysts in the demanding environment of SOFC electrodes.

\subsection{Single Component}

\subsubsection{LSM Electrodes}

Infiltrated LSM-YSZ cathode performance was measured and is shown in Figure 1 (IV curves). Figure 2 shows the impedance spectra of a non-infiltrated cell at near-open circuit voltage (OCV). At $923 \mathrm{~K}$ the cell $\mathrm{OCV}$ is $\sim 1.1 \mathrm{~V}$, and maximum power density is $\sim 0.27 \mathrm{~W} / \mathrm{cm}^{2}$. The cell ohmic resistance $\left(\mathrm{R}_{\mathrm{r}}\right)$, determined from the high-frequency intercept on the real axis, combines the ohmic loss from the cell anode, electrolyte, and

cathode. The infiltrated cell has an $\mathrm{R}_{\mathrm{r}}$ of $\sim 0.3 \Omega / \mathrm{cm}^{2}$, while the $\mathrm{R}_{\mathrm{r}}$ for the noninfiltrated cell is $~ 3.4 \Omega / \mathrm{cm}^{2}$. Because both cells have similar anodes, electrolytes and porous YSZ networks, this significant difference in the $\mathrm{R}_{\mathrm{r}}$ implies that the infiltrated LSM particles in the porous YSZ network impart sufficient electronic conductivity to the resulting LSMYSZ cathode. In addition, the polarization resistance for the infiltrated cell is $\sim 2.9$ $\Omega / \mathrm{cm}^{2}$, strikingly smaller than the $\sim 110 \Omega / \mathrm{cm}^{2}$ for the non-infiltrated cell. Therefore, it is 
the infiltrated LSM, not the Pt electrode paste that provides sufficient active reaction sites for electrochemical reduction of oxygen.

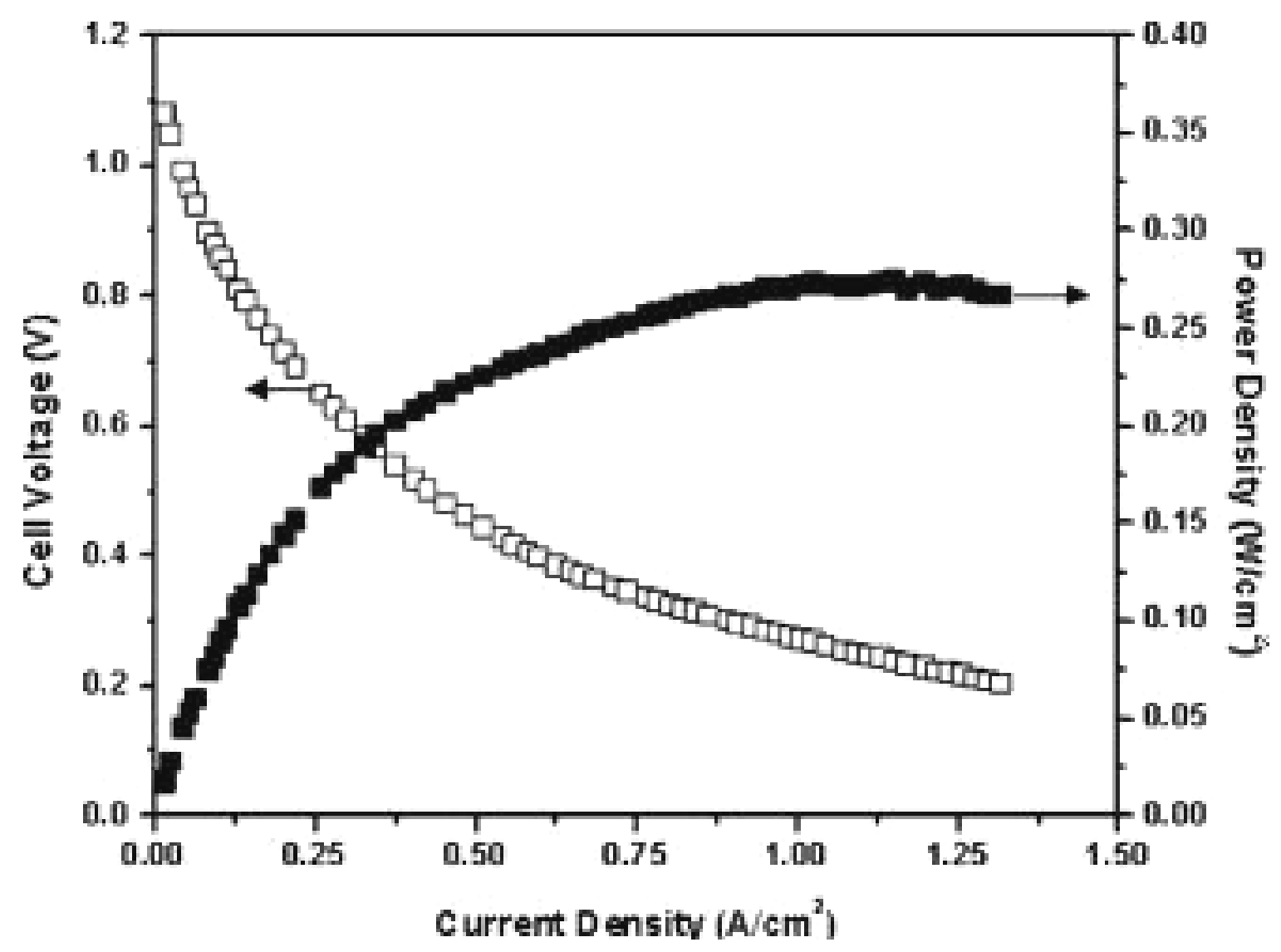

Figure 1. Voltage and power density vs current density at $650{ }^{\circ} \mathrm{C}$ for the cell with infiltrated LSM-YSZ cathode. 


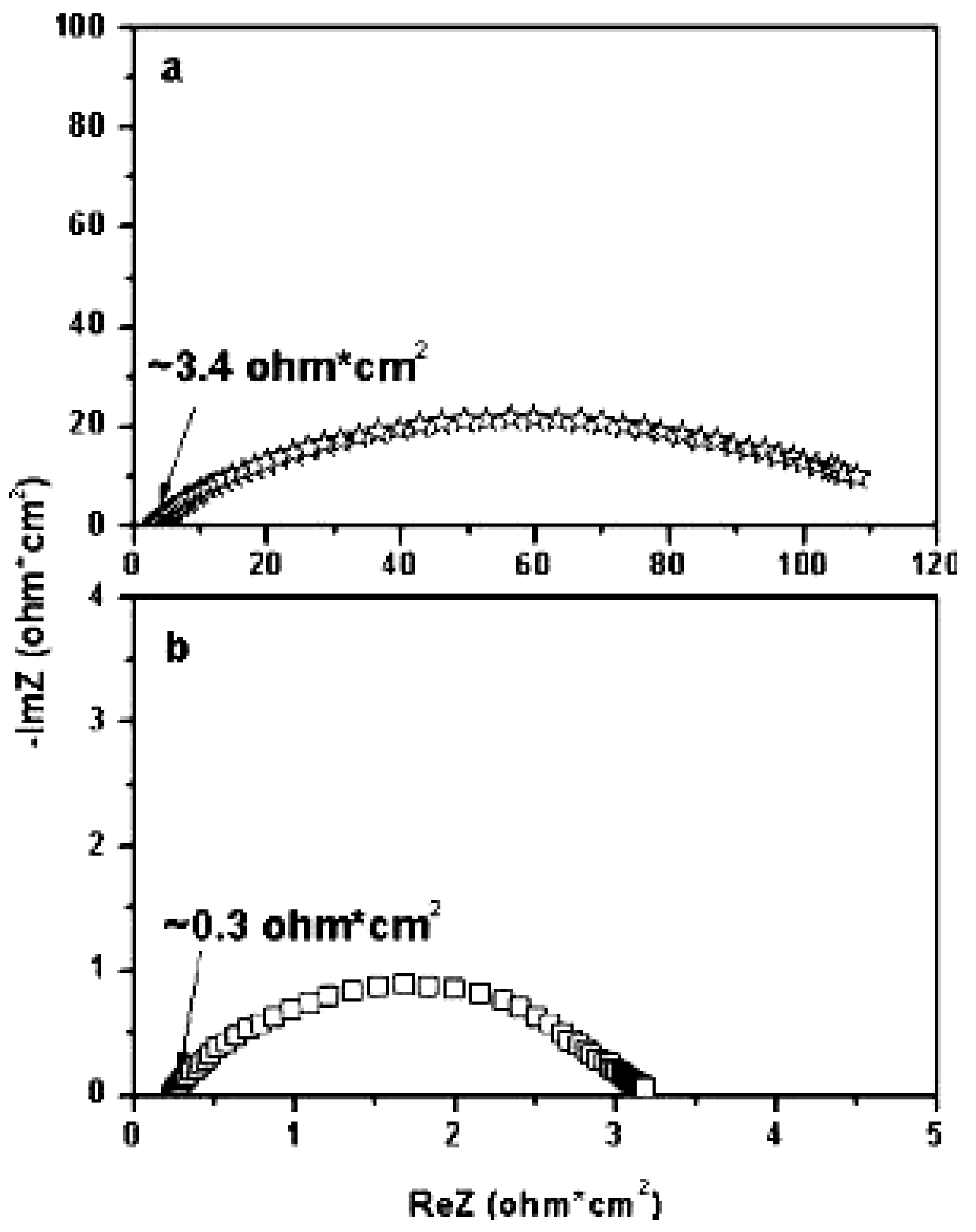

Figure 2. Impedance spectra at $650{ }^{\circ} \mathrm{C}$ for the cell (a) with a non-infiltrated cathode and (b) with the infiltrated LSM-YSZ cathode. 


\subsubsection{Alternative Electrodes}

The main advantage of the infiltrating the electrocatalyts subsequent to electrolyte sintering is the ability to infiltrate superior electrocatalysts. As is shown in Figure 3, an LSM-infiltrated electrocatalyst is compared to a superior LSF infiltrated electrocatalyst. LSM has been the material of choice in composite air electrodes because of its minimal interactions with YSZ at the elevated processing temperatures; however, it is a relatively poor electrocatalyst at intermediate operating temperatures. Therefore, since the infiltration procedure only requires low-temperature sintering, 600 to $1000{ }^{\circ} \mathrm{C}$, a reactive ${ }^{17}$ but otherwise effective electrocatalyst ${ }^{18}$ such as LSF can be used. In the I-V curve in Figure 3, the enhanced electrocatalytic activity is illustrated by both the decreased overvoltage and the lower slope of the porous YSZ electrode infiltrated with LSF.

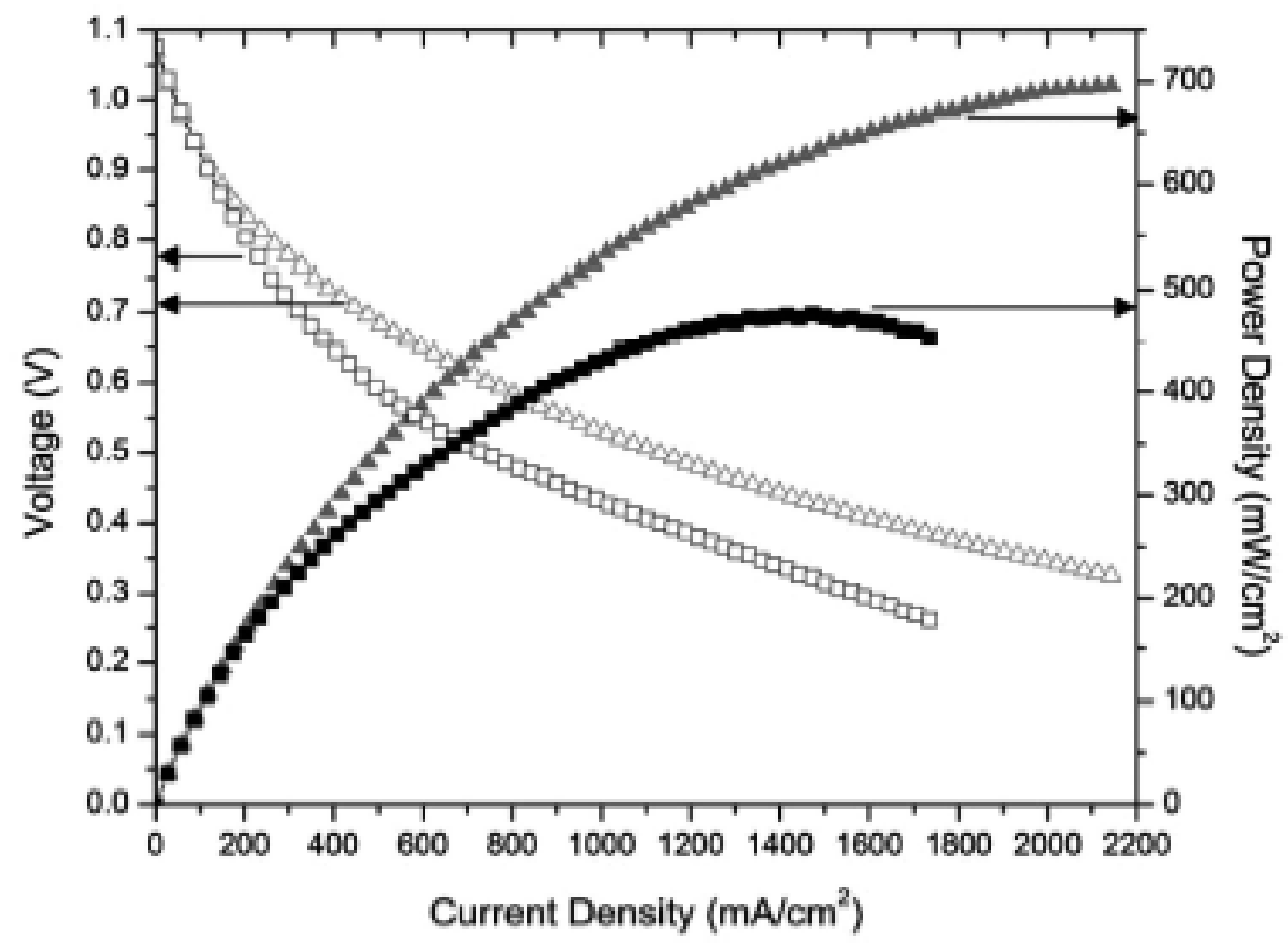


Figure 3. $\quad 700^{\circ} \mathrm{C}$ performance for cells infiltrated with $\operatorname{LSM}(v)$ or $\operatorname{LSF}(\sigma)$. The power density at $0.7 \mathrm{~V}$ is about $15 \%$ higher for the LSF compared to the LSM infiltrated YSZ backbones.

In addition, Ag has been studied as a candidate electrode material in this temperature range because of its high catalytic activity and substantial oxygen solubility and mobility. ${ }^{16,19}$ Initially, Ag was not pursued for SOFC's due to its volatility at high temperature $\left(\right.$ e.g. $\left.~ 1.3 \times 10^{-5} \mathrm{kPa} @ 800^{\circ} \mathrm{C}\right) .{ }^{16}$ However, in the early 1990 's interest in $\mathrm{Ag}$ electrodes again increased when Barnett et. al. suggested and later demonstrated that capping layers could largely suppress the evaporation of $\mathrm{Ag}^{20-23}$

To take advantage of the triple phase boundary extension seen in composite electrodes, Ag-YSZ cermets were presented. ${ }^{24,25}$ It has been found within these cermets, that the length of the oxygen diffusion paths through the Ag was the limiting factor in electrodes with high Ag content. High cathode reactivity was achieved by maintaining short oxygen diffusion paths, preferably sub-micron. However, an essential problem with the Ag-YSZ cermets is Ag's low melting point $\left(961^{\circ} \mathrm{C}\right)$, which does not allow for the elevated processing temperatures needed to bond the YSZ in a YSZ/Ag composite electrode to the YSZ electrolyte, thereby increasing the electrolyte/electrode impedance. To avoid the problems associated with the low melting point of $\mathrm{Ag}$, the electrode design presented by Virkar et al. ${ }^{10}$ and facilitated by the infiltration method described in appendix 2 was used. First, a porous scandia stabilized zirconia (SSZ) electrode was sintered to the SSZ electrolyte at a sufficient temperature $\left(1250^{\circ} \mathrm{C}\right)$, and then the $\mathrm{Ag}$ was infiltrated into this porous SSZ cathode backbone. After a conditioning step, a high 
surface area, thin $(<100 \mathrm{~nm})$ Ag layer formed over much of the well-sintered SSZ electrode backbone pore walls.

In typical composite SOFC electrodes the reaction takes place at the triple phase boundary (TPB) between the oxidant, electro-catalyst and electrolyte, but since Ag has significant oxygen $(\mathrm{O})$ conductivity, $\mathrm{O}$ will diffuse through the $\mathrm{Ag}$ to the boundary between it and the electrolyte where the oxygen reduction reaction will then occur. Therefore, as long as the $\mathrm{O}$ diffusion length is short enough, the Ag-SSZ composite electrodes should be completely active. This goal is achieved by infiltrating Ag into a preformed SSZ backbone. Figure 4 is a schematic image of a cross-section of an SSZ backbone, which is afterward, infiltrated with an idealized Ag layer. Since the SSZ backbone has been pre-sintered at sufficiently high temperatures to the electrolyte it can now provide ionic conductivity throughout the electrode. Therefore, when the electrolyte backbone is infiltrated with $\mathrm{Ag}$ a completely active electrode is formed. 


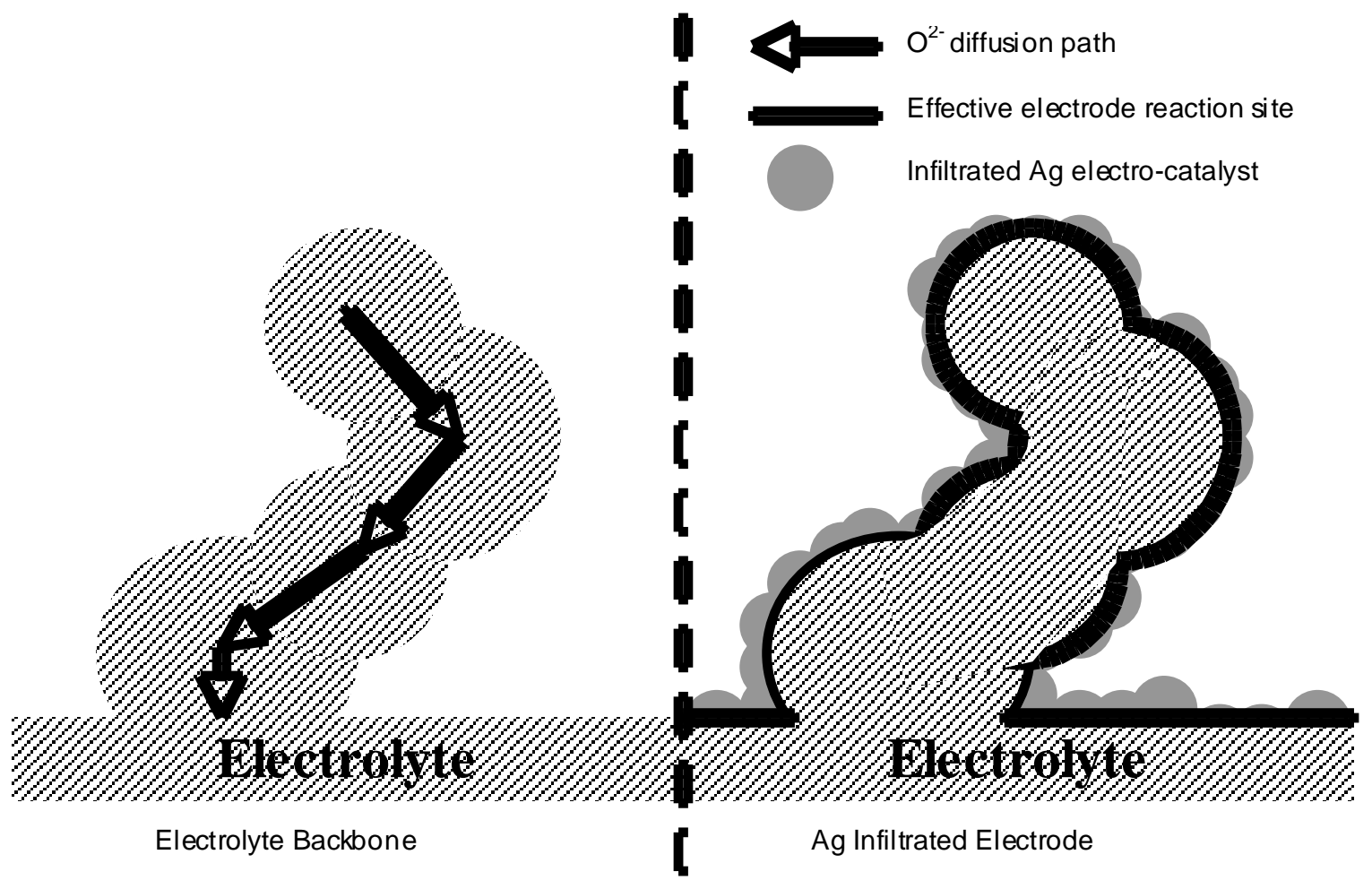

Figure 4. Cross-sectional illustration of Ag infiltrated porous electrolyte backbone.

To produce the desired Ag coating as in Figure 4, the infiltrated electrode is first conditioned by the an applied current. FIB cross-section micrographs of the as infiltrated and conditioned electrode are shown in Figure 5. As seen in Figure 5a, the as infiltrated electrode, which has been fired to $800{ }^{\circ} \mathrm{C}$ in air, the $\mathrm{Ag}$ is present in highly agglomerated form with a particle size on the order of $1 \mu \mathrm{m}$ and does not provide a continuous electronic pathway through the electrode. An interesting, and highly beneficial effect occurs as a result of current conditioning. After nominal operation, the Ag has spread over the ionic conducting backbone providing the electronic path through the electrode. The origin of this effect, which appears actively to oppose coarsening, is not entirely understood at present, but may relate to electrochemical migration. This point is under 
investigation at present, in a more clearly defined geometry. It is interesting to note that measuring an IV curve was sufficient to condition the cell, as was verified by a drastic drop in cell ohmic resistance when an electronic pathway was produced through the electrode. In Figure 5b, a conditioned electrode is shown after 100 hours of operation. While a large fraction of the pore walls appear to be covered by Ag nanolayers $(\leq 100$ $\mathrm{nm}$ ), some pockets of micron-sized Ag remain, indicating that further microstructural improvement may be made in the electrode.

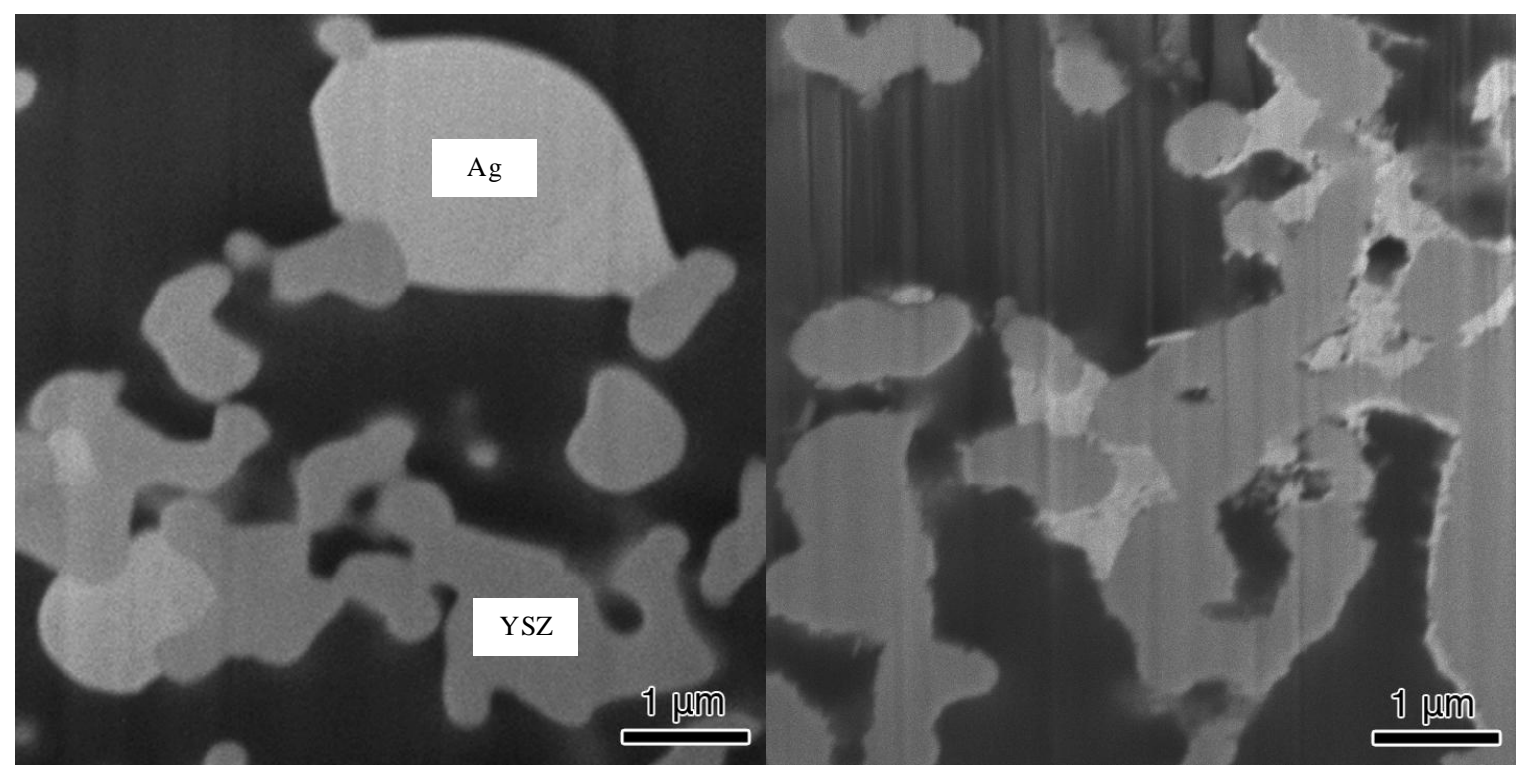

Figure 5. SEM images of FIB cross-sectioned Ag infiltrated electrode as infiltrated

(a) and after conditioning (b).

Performance curves and $\mathrm{AC}$ impedance spectra at $650{ }^{\circ} \mathrm{C}$ and $750{ }^{\circ} \mathrm{C}$ are presented in Figure 6 and Figure 7, respectively. The performance curve at $650{ }^{\circ} \mathrm{C}$ shows 2 distinct linear activation regimes, the first between $\sim 0.9$ and $0.5 \mathrm{~V}$, and the second below about $0.4 \mathrm{~V}$ implying that there are two processes that are inactive at $\mathrm{OCV}$ within this temperature range. This is also reflected in the AC impedance characteristics, where there 
is a large mid-frequency impedance peak found at $650{ }^{\circ} \mathrm{C}$. The large peak at $650{ }^{\circ} \mathrm{C}$ was not previously seen in the LSM infiltrated electrodes tested in section 2.2.1. By $750{ }^{\circ} \mathrm{C}$ the mid-frequency arc is on par with the high-frequency arc and there is only one linear activation regime, implying that the mid-frequency process was activated by $750{ }^{\circ} \mathrm{C}$.
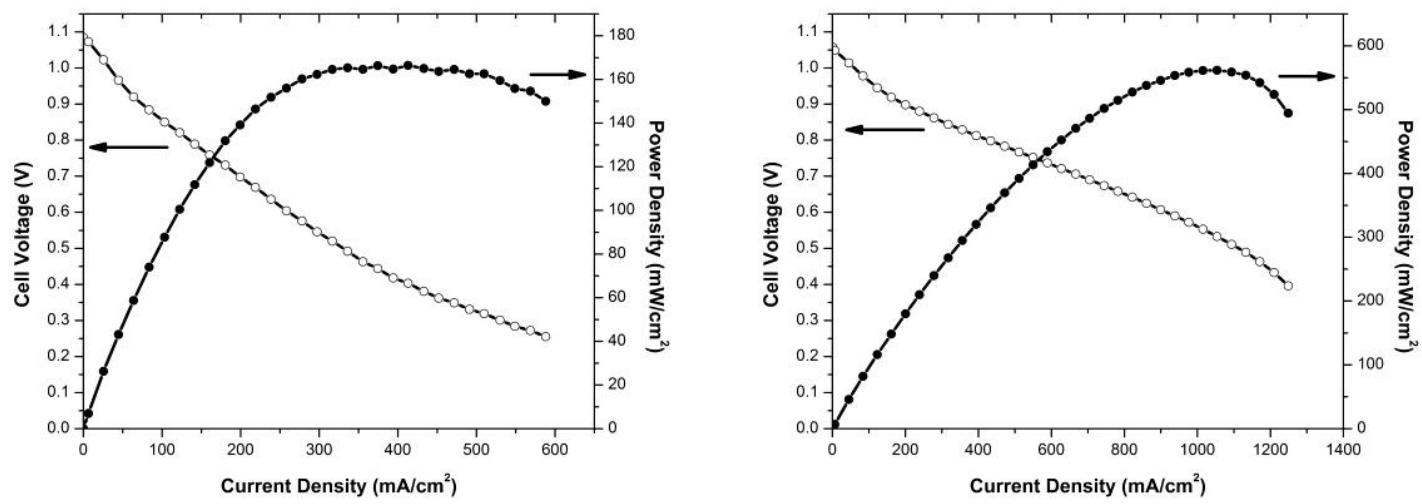

Figure 6. Potential and power density vs. current density for an Ag infiltrated electrode at $650^{\circ} \mathrm{C}$ (a) and $750{ }^{\circ} \mathrm{C}(\mathrm{b})$.
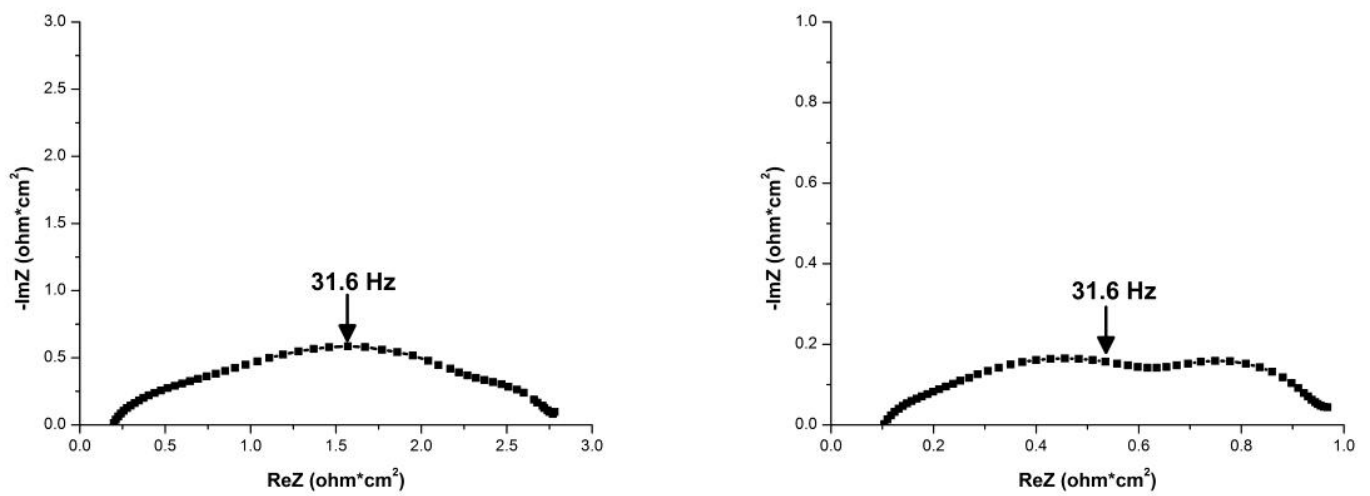

Figure 7. Impedance spectra for an $\mathrm{Ag}$ infiltrated electrode at $650^{\circ} \mathrm{C}$ (a) and $750^{\circ}$ $\mathrm{C}(\mathrm{b})$. 


\subsection{Nanocomposite Electrodes}

It is evident that LSM and Ag infiltrated electrodes "activate" differently (Figure 8a) with Ag activating earlier but LSM having smaller losses after activation. The Ag electrode is activated almost right away, while the LSM electrode is only fully active by $\sim 0.4 \mathrm{~V}$. This is more clearly seen in a differential plot of $\frac{d \eta}{d I}$ versus $-\eta$, where the cell losses (resistance) are shown versus cell potential (Figure $8 b$ ). By $\sim 0.6 \mathrm{~V}$, the LSM electrode has smaller losses as compared to the Ag electrode. The large post-activation losses in the Ag electrode may be due to the IR losses associated with the $\mathrm{O}$ transport within the silver, adding in essence an extra non-polarization activated term to the overall cell losses. It is interesting to note that the Ag-LSM nanocomposite electrode has lesser cell impedance than either of its component electrocatalysts (Figure 9). The minimum impedance could be associated with the unique microstructure of the nanoscale electrode (Figure 10). The nanoscale LSM grains separate nanoscale pockets of Ag (both 20 - 120 $\mathrm{nm}$ ), minimizing the $\mathrm{O}$ diffusion length within the $\mathrm{Ag}$ and hence maximizing its effectiveness.
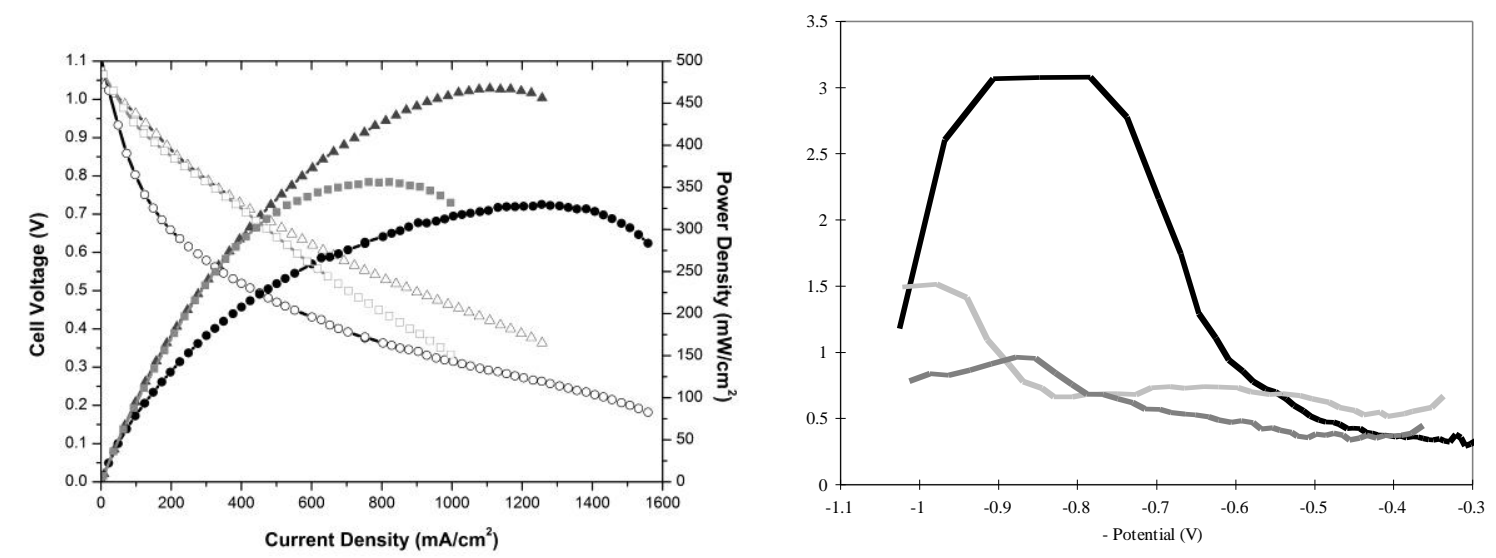
Figure 8. Potential and power density vs current density (a) and $\frac{d \eta}{d I}$ versus potential (b) for $\operatorname{Ag}(\square), \operatorname{LSM}(\bullet)$ and $\operatorname{Ag}-\operatorname{LSM}(\Delta)$ infiltrated electrodes at $700^{\circ} \mathrm{C}$.

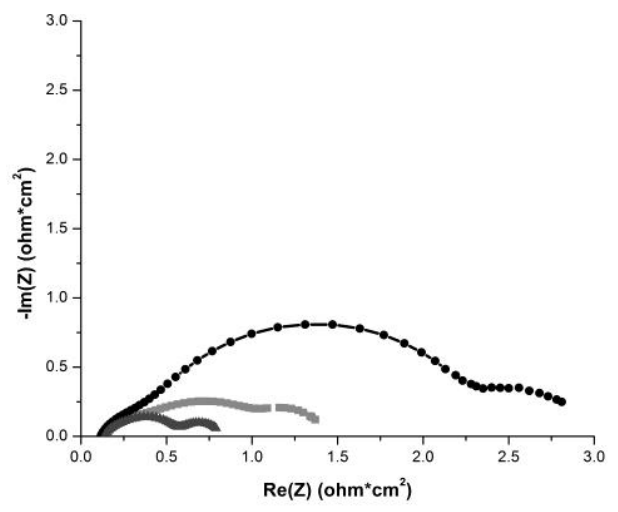

Figure 9. Impedance spectrum for $\operatorname{Ag}(\square), \operatorname{LSM}(\bullet)$ and $\operatorname{Ag}-\operatorname{LSM}(\Delta)$ infiltrated electrodes at $700^{\circ} \mathrm{C}$. 


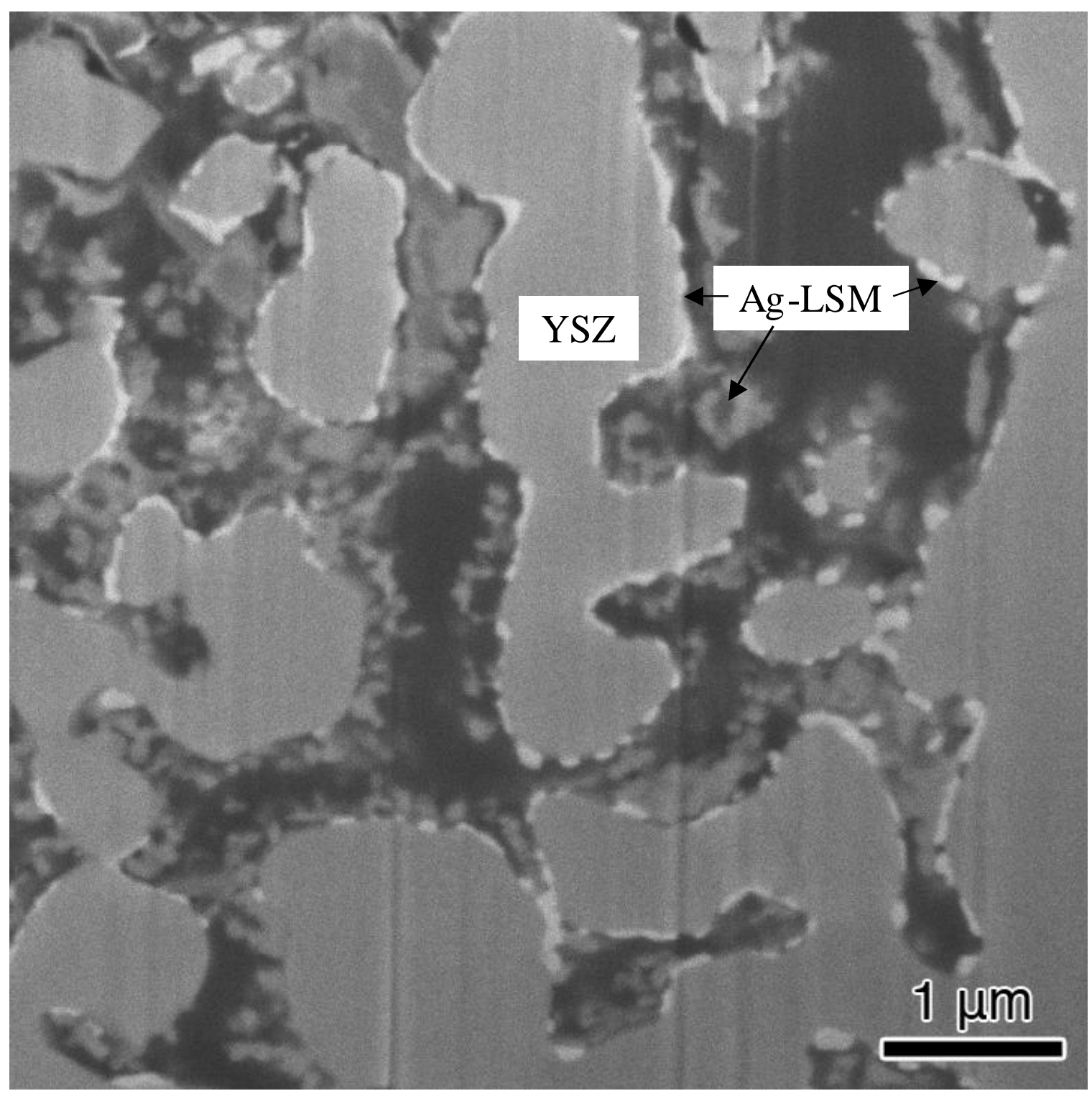

Figure 10. SEM image of FIB cross-sectioned LSM-Ag infiltrated electrode.

\subsection{Stability}

The microstructure that the infiltration method (Appendix 2) produces, and its relation to the stability of the cathode is first characterized by scanning electron microscopy. From the FIB cross-sectional SEM image, Figure 11, it is evident that the 
infiltration method produces a well-connected network and rafts of nanoparticulate LSM, confined nearly exclusively to the pore walls of the SSZ cathode backbone, providing a sufficient percolation path for electrons to the majority of the oxygen reduction reaction (ORR) sites.

These reaction sites are either near the SSZ/LSM pore triple junctions (TPBs) or on the surface of the dense LSM rafts. Since the LSM rafts produced by our method are generally just one nanoparticle thick, i.e. 50-150 nm (see inset in Figure 11), oxygen ion conduction directly through the dense raft can contribute significantly to the overall reaction rates by enabling the ORR on the entire LSM surface. ${ }^{26}$ In fact, it is the tendency to form particle rafts that can greatly assist in providing stability to the infiltrated cathode performance, so long as the rafts remain in electrical contact. This requirement is much less demanding than maintaining electrical connectivity in spare, single particle networks. Additionally, since the one-step infiltration methods leads mostly to single nanoparticle layers on the pore surfaces, effective electrodes can be obtained at much lower volume fractions than used by other workers. ${ }^{27-31}$ 


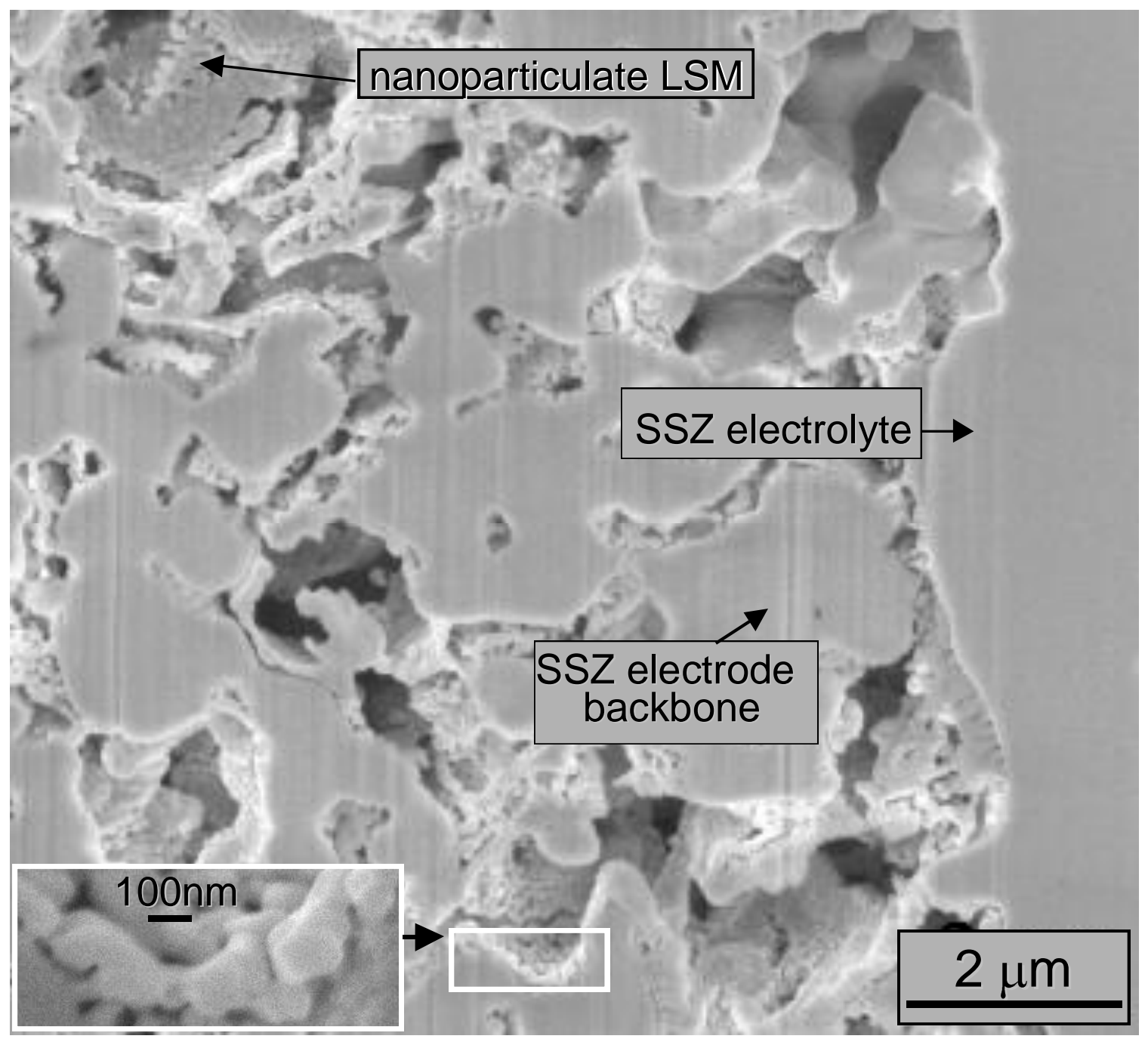

Figure 11. SEM image of FIB corss-sectioned nanoparticulate LSM-infiltrated cathode. The streaking in the image is unavoidable consequence of the presence of pores. The insert shows the size of some of the LSM nanoparticles.

Figure 12 reveals a tendency for some orientation alignment of the nanoparticulate LSM particles with the SSZ. The significance of the orientation is so far unknown; but may affect the ORR, particularly at lower temperatures, depending on which surface orientations of the nanoparticulate LSM are presented to the gas phase. 

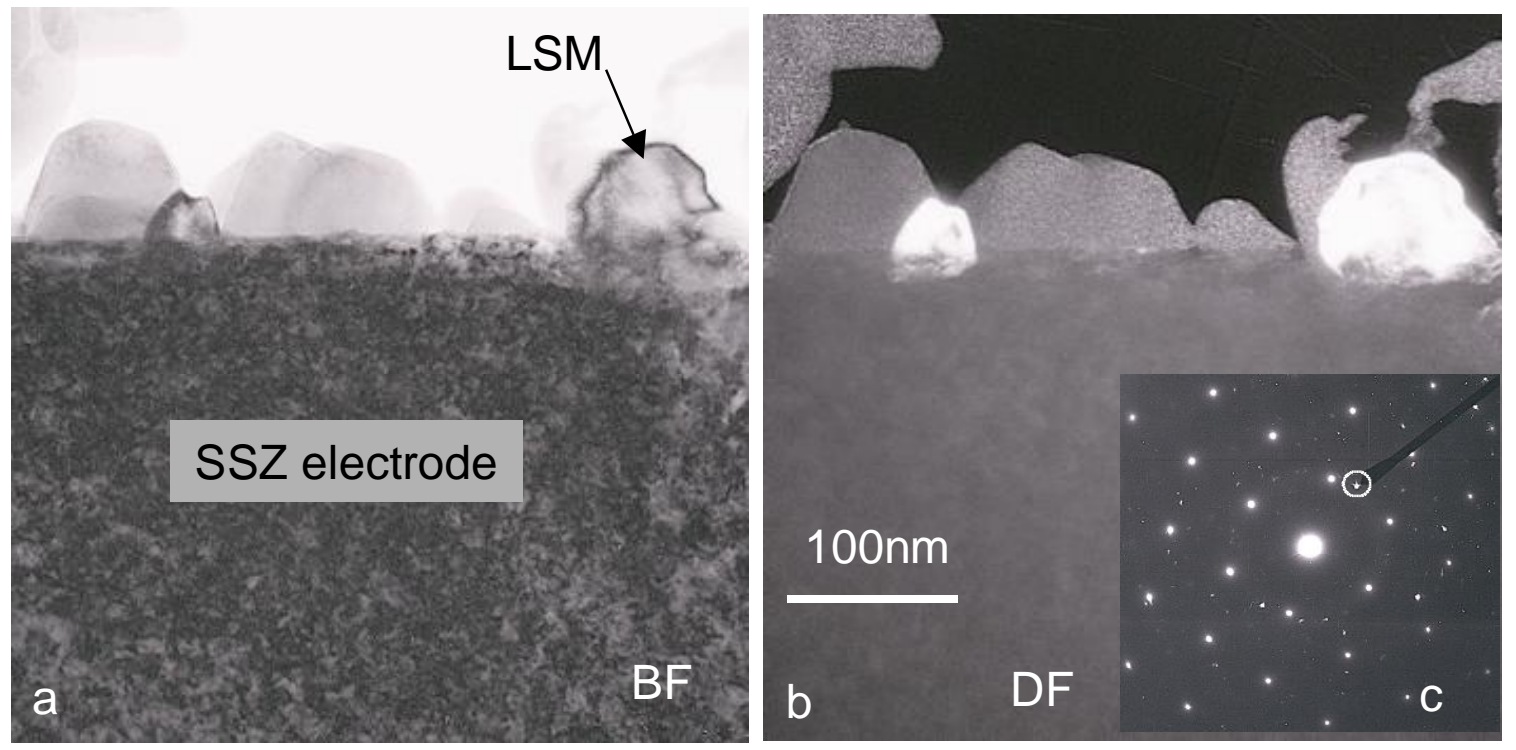

Figure 12. TEM a) Bright Field, b) Dark Field Patterns and c) corresponding Diffraction Pattern taken on [110] zone axis of SSZ with circle around nanoparticulate LSM reflection used for dark field imaging, showing nanoparticulate LSM grains on the SSZ porous electrode backbone.

Figure 13 shows that the contact angles of some individual LSM nanoparticles with the surface of the SSZ before and after $502 \mathrm{hrs}$ at temperature have not meaningfully changed. However, in the as-formed stage contact between the LSM particles and the SSZ pore walls shows a tendency to be more sporadic than after some time at operating temperatures, Figures 14a and 14b. 

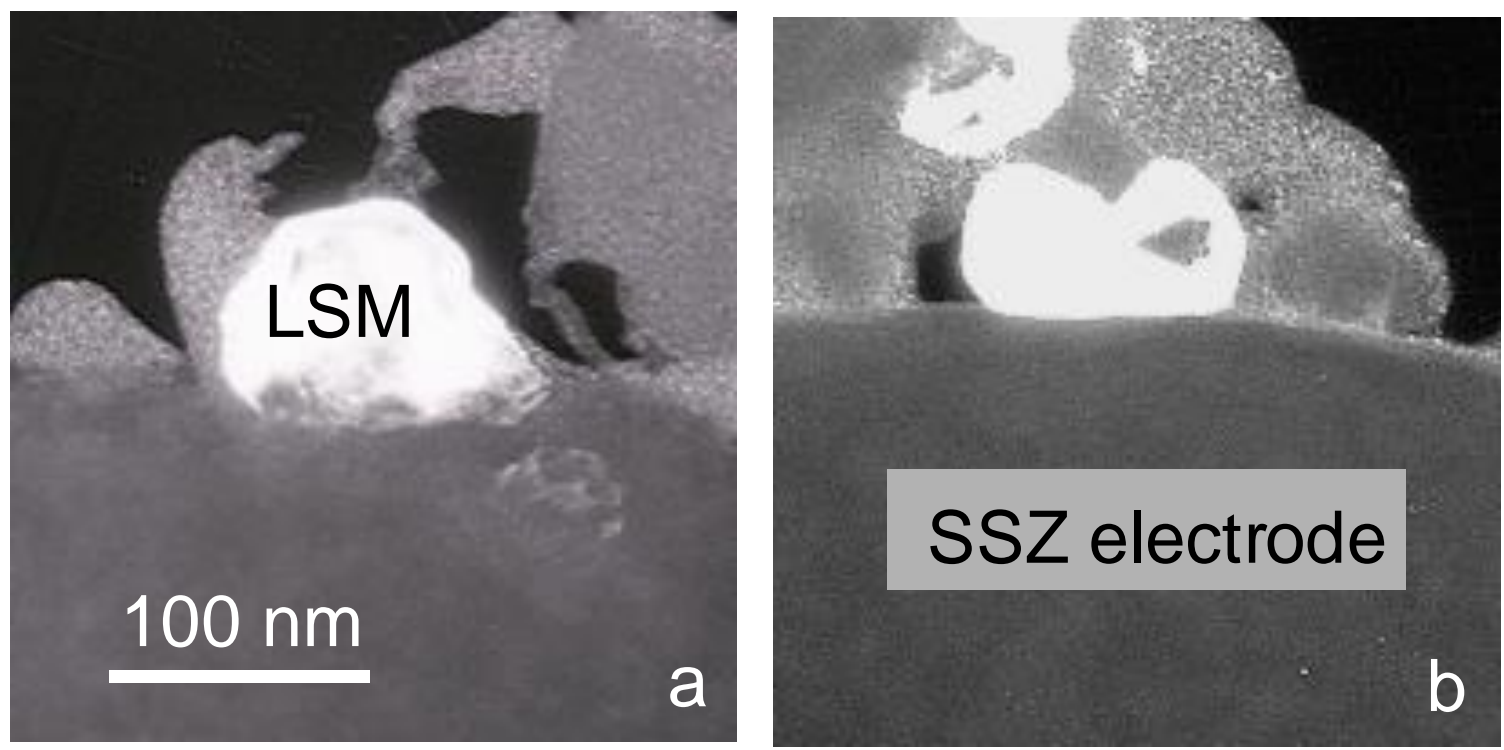

Figure 13. TEM Dark Field Images of LSM catalyst particles a) before and b) after 502 hours operation at $650{ }^{\circ} \mathrm{C}$ under $\sim 150 \mathrm{~mA} / \mathrm{cm}^{2}$ applied current. Contact angle changes are not evident.

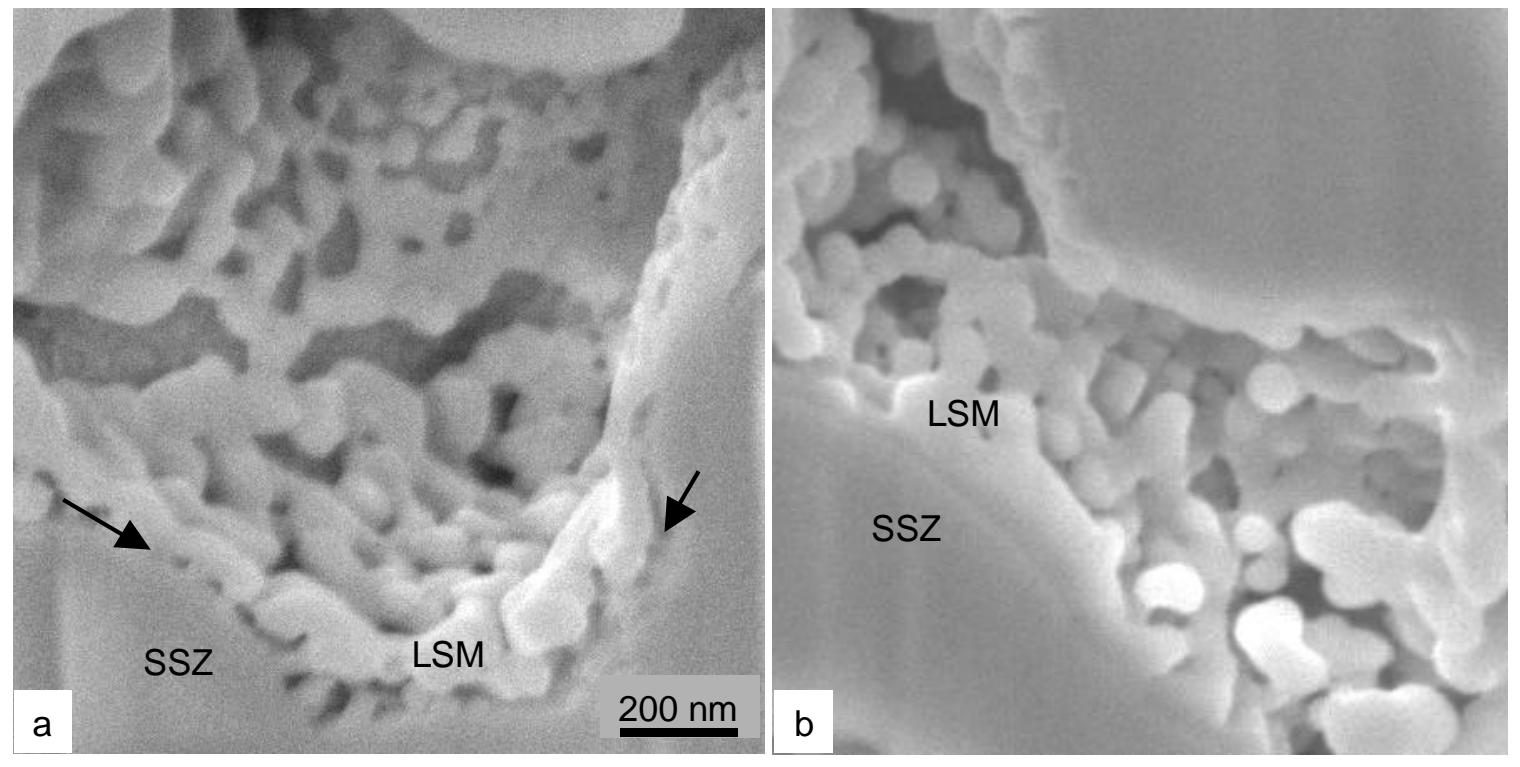


Figure 14. SEM images of FIB cross-sectioned nanoparticulate LSM infiltrated cathodes a) before and b) after 502 hours operation at $650{ }^{\circ} \mathrm{C}$ under $\sim 150 \mathrm{~mA} / \mathrm{cm}^{2}$ applied current.

The cell voltage of an anode supported SOFC with an LSM infiltrated porous SSZ cathode was recorded at a nearly constant applied current density of $\sim 150 \mathrm{~mA} / \mathrm{cm}^{2}$ for 502 hours at $650{ }^{\circ} \mathrm{C}$, Figure 15. The cell fabricated with a porous SSZ electrode backbone showed no voltage degradation at constant current, and even shows improvement over time. Note that the applied current density was initially set at $150 \mathrm{~mA} / \mathrm{cm}^{2}$, but declined somewhat after 366 hours to a low of $\sim 141 \mathrm{~mA} / \mathrm{cm}^{2}$, due to a slight experimental instability; upon readjustment to $150 \mathrm{~mA} / \mathrm{cm}^{2}$ at 457 hours, the cell performance once again returned to the original voltage. These results may be contrasted to those reported by Huang et $a l,{ }^{31}$ which appear to show a significant performance decline after 100 hours at $700^{\circ} \mathrm{C}$. 


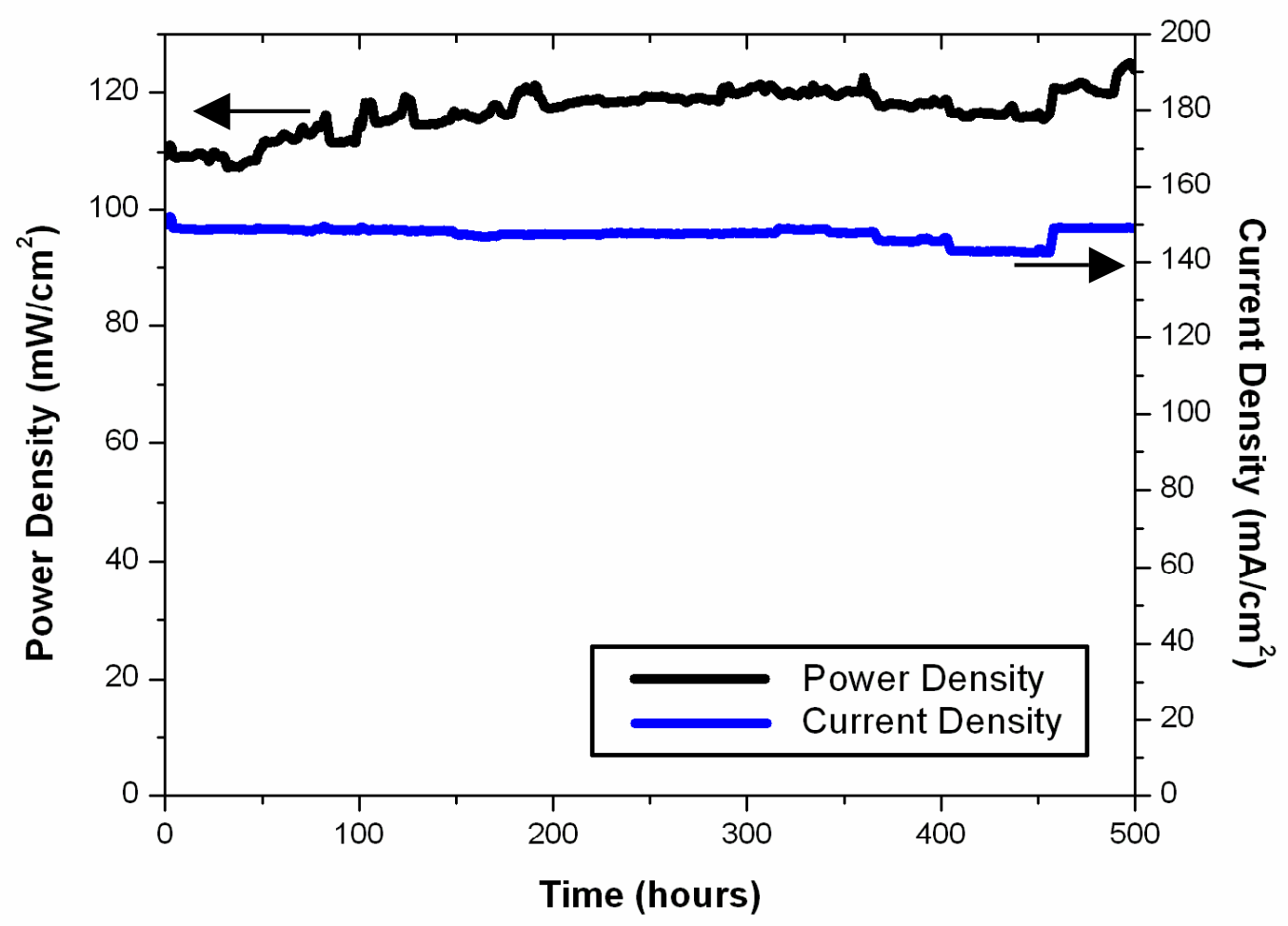

Figure 15. Performance of anode supported SOFC with nanoparticulate LSM infiltrated cathode over 502 hours operation at $650^{\circ} \mathrm{C}$ under near constant applied current of $\sim 150 \mathrm{~mA} / \mathrm{cm}^{2}$.

The improvement of the cell performance is detailed by data shown in Figure 16, which presents the I-V and power curves both before and after the long-term test. The most significant improvement is seen at current densities below $300 \mathrm{~mA} / \mathrm{cm}^{2}$. This region is typically associated with ill-defined activation or reaction losses when using an LSM electrocatalyst. However, the activation is typically complete within a couple of hours in conventional composite LSM-SSZ electrodes, making it unlikely that it is of a similar origin as for the continued increase in performance of the nanoparticulate electrodes over 
the 502 hour test. Instead, the increase in LSM/SSZ contact, shown in Figure 14 is viewed as the most likely cause for the gradual improvement.

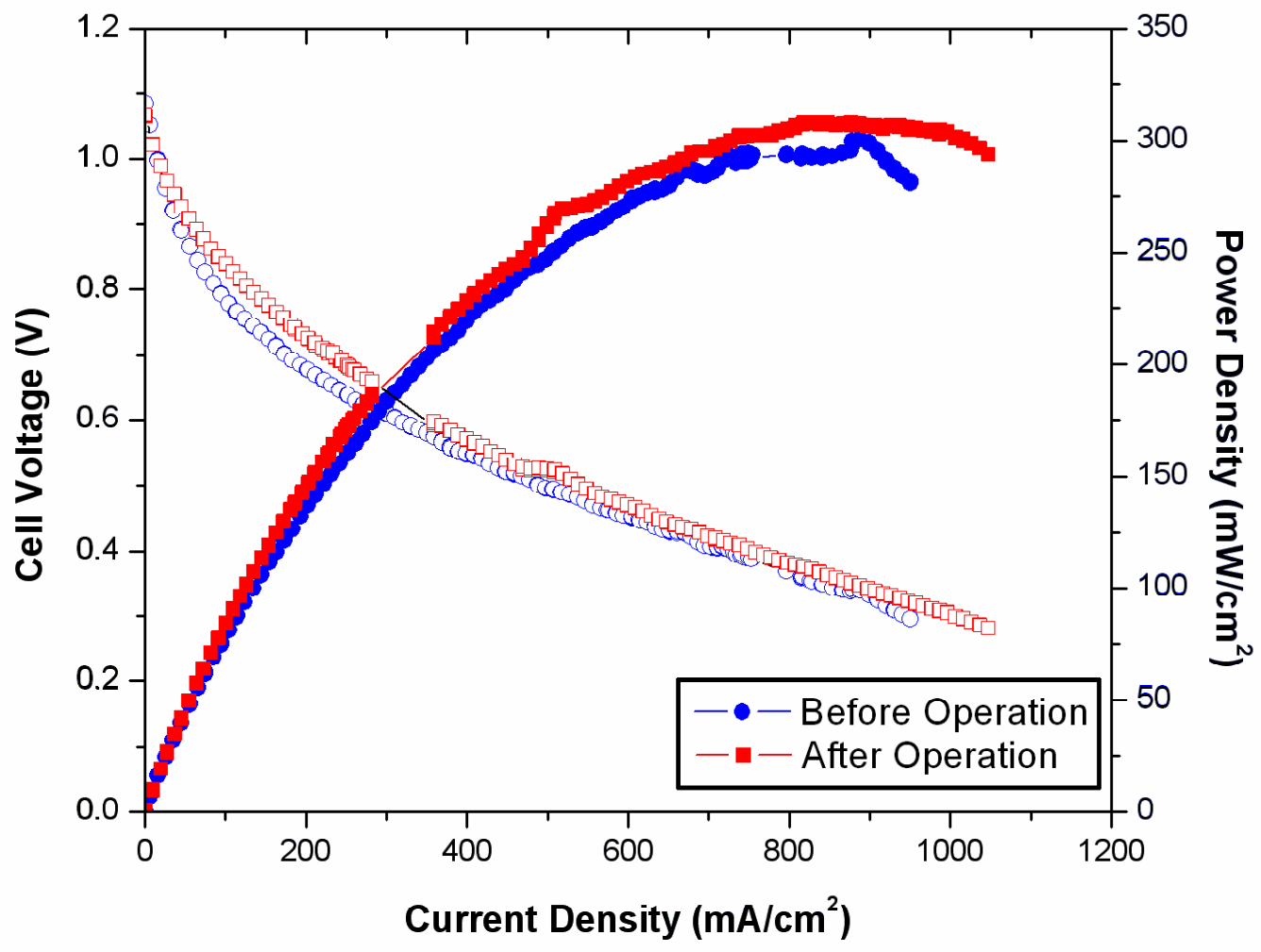

Figure 16. I-V curve before and after 502 hours operation at $650{ }^{\circ} \mathrm{C}$ under $\sim 150$ $\mathrm{mA} / \mathrm{cm}^{2}$ applied current.

Furthermore, the stability of the nanoscale LSM and the unique microstructure of the Ag-LSM composites can be utilized to increase the stability of Ag infiltrated electrodes. In Figure 17 long-term tests of Ag, LSM and the Ag-LSM nanocomposite electrode are given. The Ag cathode at $400 \mathrm{~mA} / \mathrm{cm}^{2}$ shows an unsteady I-V signature, followed by 
progressive degradation. This non-monotonic behavior could be due to the connecting/disconnecting of the Ag network within the electrode, which would significantly affect the amount of active cell area. In contrast, the LSM electrodes are relatively stable over 500 hours. In the case of this test, the cell temperature dropped after 200, decreasing the cell performance, but the LSM cell is relatively stable otherwise, as expected. The Ag-LSM nanocomposite cell, operating at $500 \mathrm{~mA} / \mathrm{cm}^{2}$ showed significantly enhanced performance. It is expected that by further microstructural optimization, and perhaps the addition of a capping layer, the nanocoposite Ag-LSM can be made fully stable.

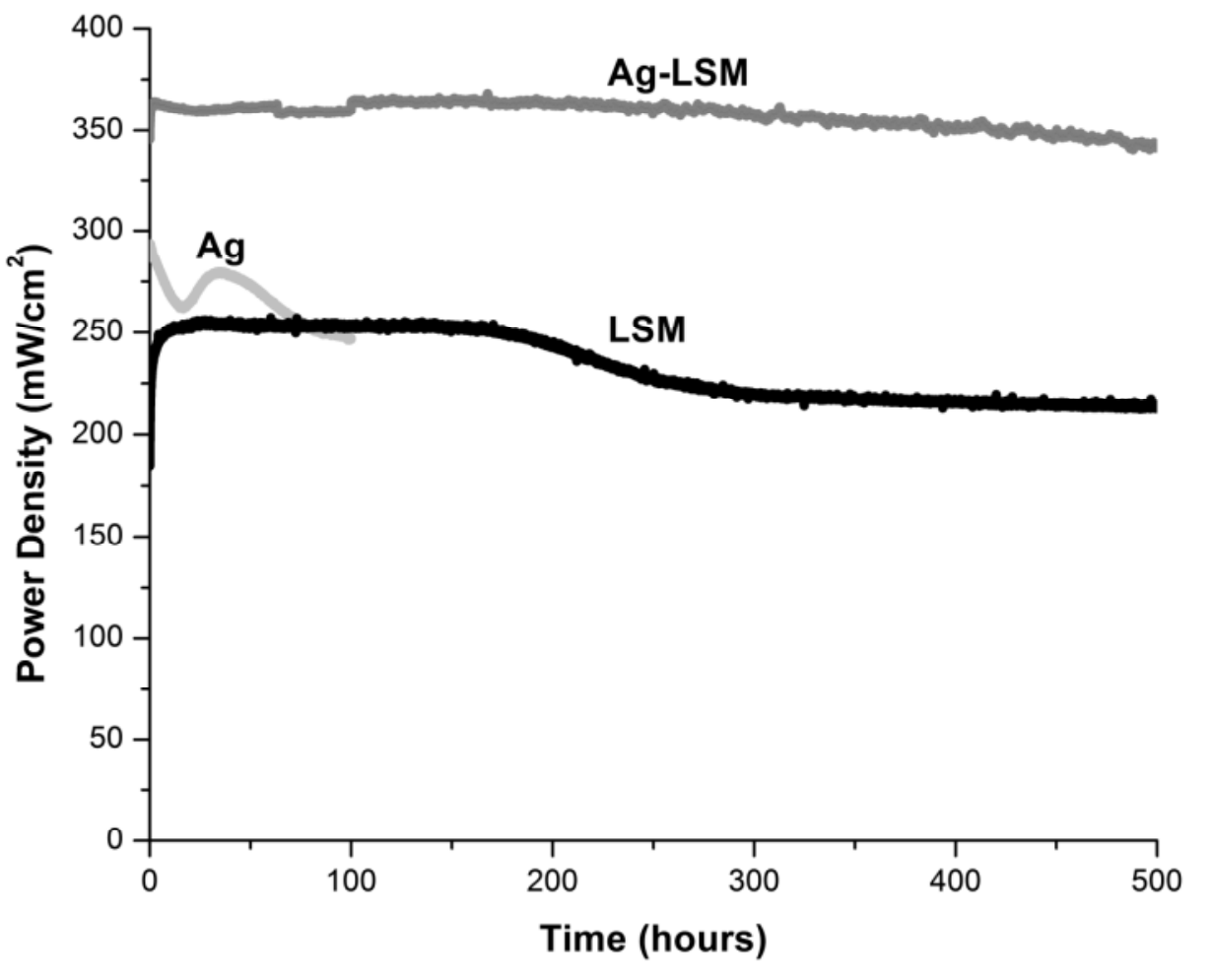


Figure 17. Constant current operation for $\mathrm{Ag}\left(400 \mathrm{~mA} / \mathrm{cm}^{2}\right), \mathrm{LSM}\left(300 \mathrm{~mA} / \mathrm{cm}^{2}\right)$ and $\operatorname{Ag}-\operatorname{LSM}\left(500 \mathrm{~mA} / \mathrm{cm}^{2}\right)$ infiltrated electrodes at $700^{\circ} \mathrm{C}$.

\subsection{Summary}

SOFC electrodes were created by infiltrating connected nanoparticulate networks of electrocalysts within pre-formed electrolyte backbones. First, LSM infiltration was demonstrated as a proof of concept, and later advanced electrocatalysts LSF and noble metal (e.g. Ag) were also tested. Furthermore, a nanocomposite Ag-LSM cathode electrocatalyst demonstrated the possibility of a synergistic combination of the characteristics of each of its nano-components. It is believed that LSM in the Ag-LSM composite may serve as a barrier to large-scale Ag agglomeration, thereby maintaining its effectiveness.

The nanoparticualte LSM infiltrated electrode was stable for over 500 hours of operation at $650^{\circ} \mathrm{C}$ under a near-constant applied current density of $\sim 150 \mathrm{~mA} / \mathrm{cm}^{2}$. Furthermore, the cell showed some improvement over this period. The stability is attributed in large part to the specific nanoparticle distribution produced by our singlestep infiltration method, leading to connected networks and monolayer rafts of nanoparticles that are confined to the pore walls. Furthermore, the stability of the nanoscale LSM and the unique microstructure of the Ag-LSM composites were utilized to increase the stability of Ag infiltrated electrodes. It is believed that LSM in the AgLSM composite may serve as a barrier to large- scale Ag agglomeration, thereby maintaining its effectiveness. 


\section{References}

1. Sata, N.; Eberman, K.; Eberl, K.; Maier, J. Nature, 408 (6815), 946-949, (2000).

2. Gu, Q.; Falk, A.; Wu, J.; Ouyang, L.; Park, H., Nano Lett., 7 (2), 363-366, (2007).

3. Tschope, A.; Birringer, R., J. Electroceram., 7 (3), 169, (2001).

4. Van Herle, J.; Horita, T.; Kawada, T.; Sakai, N.; Yokokawa, H.; Dokiya, M., J. Eur. Ceram. Soc., 16 (9), 961-973 (1996).

5. Tschope, A.; Kilassonia, S.; Zapp, B.; Birringer, R., Solid State Ionics, 149 (3-4), 261 (2002).

6. $\quad$ Laosiripojana, N.; Assabumrungrat, S., Chem. Eng. Sci., 61 (8), 2540-2549 (2006).

7. Steele, B. C. H.; Heinzel, A., Nature, 414 (6861), 345-352, (2001).

8. $\quad$ Feduska, W.; Isenberg, A. O., J. Power Sources, 10 (1), 89-102 (1983).

9. $\quad$ Murray, E. P.; Tsai, T.; Barnett, S. A., Nature,400 (6745), 649-651 (1999).

10. C. Tanner, K. Fung, and A. Virkar, J. Electrochem. Soc., 144, 21 (1997).

11. K. Yamahara, T. Sholklapper, C. P. Jacobson, S. J. Visco, and L. C. De Jonghe, Solid State Ionics, 176, 1359 (2005).

12. Euro. Pat. P.V. 1,513,796, (1968).

13. A. O. Isenberg, Solid State Ionics, 3/4, 431 (1981).

14. Anderson, M. D.; Stevenson, J. W.; Simner, S. P. J. Power Sources 2004, 129 (2), 188-192.

15. Simner, S. P.; Bonnett, J. F.; Canfield, N. L.; Meinhardt, K. D.; Shelton, J. P.; Sprenkle, V. L.; Stevenson, J. W. J. Power Sources 2003, 113 (1), 1-10.

16. Tedmon Jr, C. S.; Spacil, H. S.; Mitoff, S. P. 1969, 116, (9), 1170-5. 
17. Anderson, M. D.; Stevenson, J. W.; Simner, S. P. Journal of Power Sources 2004, 129, (2), 188-192.

18. Simner, S. P.; Bonnett, J. F.; Canfield, N. L.; Meinhardt, K. D.; Shelton, J. P.; Sprenkle, V. L.; Stevenson, J. W. Journal of Power Sources 2003, 113, (1), 1-10.

19. Markin, T. L., Power Souces 4. Oriel: New York, 1973; p 583.

20. Barnett, S. A. Energy (Oxford) 1990, 15, (1), 1.

21. Wang, L. S.; Thiele, E. S.; Barnett, S. A. Solid State Ionics 1992, 52, (1-3), 261.

22. Wang, L. S.; Barnett, S. A. Solid State Ionics 1993, 61, (4), 273.

23. Wang, L. S.; Barnett, S. A. Solid State Ionics 1995, 76, (1-2), 103.

24. Sasaki, K.; Hosoda, K.; Lan, T. N.; Yasumoto, K.; Wang, S.; Dokiya, M. Solid State Ionics 2004, 174, (1-4), 97.

25. Sasaki, K.; Tamura, J.; Dokiya, M. Solid State Ionics 2001, 144, (3-4), 233.

26. Y. Huang, J. M. Vohs and R. J. Gorte, Journal of the Electrochemical Society, 151 (4), 646-651 (2004).

27. S. P. Jiang, Materials Science and Engineering, A 418 (1-2), 199-210 (2006).

28. T. Z. Sholklapper, C. Lu, C. P. Jacobson, S. J. Visco and L. C. De Jonghe, Electrochemical and Solid-State Letters, 9 (8), 376-378 (2006).

29. S. Park, J. M. Vohs and R. J. Gorte, Nature, 404 (6775), 265-267 (2000).

30. Y. Huang, J. M. Vohs and R. J. Gorte, Electrochemical and Solid-State Letters, 9 (5), 237-240 (2006).

31. Y. Huang, J. M. Vohs and R. J. Gorte, Journal of the Electrochemical Society, 152 (7), 1347-1353 (2005). 


\section{Chapter 3: Enhancing Composite LSM-YSZ Cathodes}

\subsection{Introduction}

In order to decrease system cost, there has been a transition to lower operating temperatures; however, this has led to significant cathode polarization losses. In Chapter 2 an alternative cathode design was presented that utilizes well-formed electrolyte backbones that are then infiltrated with electrocatalyts. Additionally, the traditional LSMYSZ cathode can be enhanced by nanostructing with secondary electrocatalysts.

Incorporation of nanoparticulate networks into traditional electrodes serves two purposes: it acts as an added electrocatalyst, but more importantly it eliminates the strict triple phase boundary reaction area seen in typical composite electrodes. In Figure 1, an illustration of the enhanced electrode microstructure is given in the cross-sectional image of neighboring electrode and electrolyte grains. The electrode and electrolyte grains in the composite electrode structure - each on the order of $1 \mu \mathrm{m}$-provide percolation networks for both electronic and ionic conductivity, respectively, within the electrode. The typical reaction area for conventional electrodes is limited to near the three phase boundary at the intersection of the fuel or oxidant $\left(\mathrm{H}_{2}\right.$ or $\left.\mathrm{O}_{2}\right)$, electrons $\left(\mathrm{e}^{-}\right.$, conducted by electrode grain network), and oxygen ions $\left(\mathrm{O}^{2-}\right.$, conducted by electrolyte grain network). The nanoparticulate chosen for infiltration was doped ceria (DC) due to its mixed conducting properties in the nanoparticulate form. ${ }^{1-3}$ This allows for both ionic and electronic extension within the electrodes. The nanoparticulate DC serves to extend 
conductivity ionically from electrolyte grains onto electrode grains and, conversely, electronically from electrode grains onto electrolyte grains, creating a further utilized electrode. Additionally, the electrocatalytic properties of the DC serve to enhance and extend the reaction area of the electrode, as seen in studies of isolated electrocatalysts. ${ }^{4}$ Since composite electrodes already possess built in electronic and ionic percolation networks through the electrode, the networked nanoparticulate DC layer requires only a short-range extension on the grain level. This significantly decreases the dependence of the cell on the stability of the nanonparticulate networks since a stable backbone is already present. Furthermore, in Chapter 2 it was demonstrated that doped $\mathrm{ZrO}_{2}$ with infiltrated LSM, which much be stable through out the electrode ( $>10 \mu \mathrm{m}$ ) in order to provide electronic conductivity to the reaction sites, is stable for over 500 hours, suggesting that nanoparticulate networks can be stable under SOFC operating conditions. 


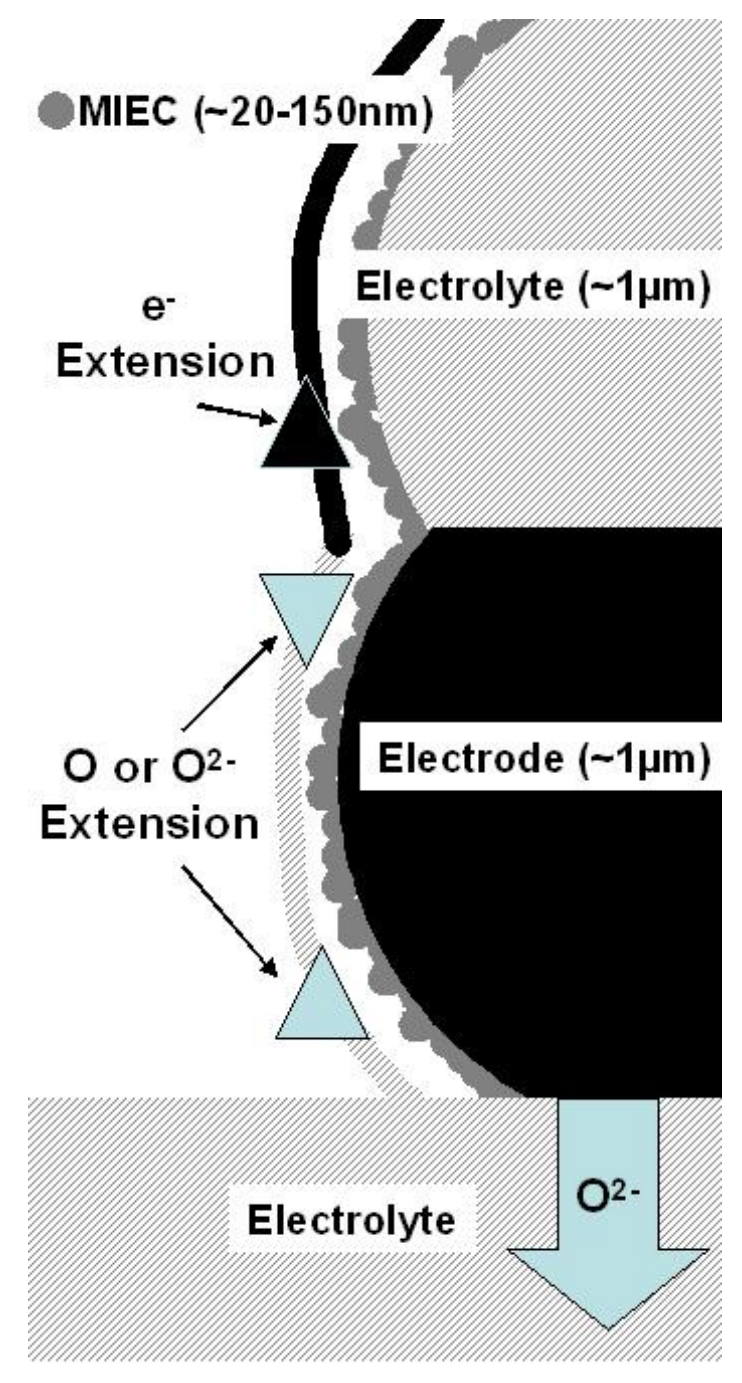

Figure 1. Cross-sectional illustration of networked nanoparticulate infiltration into composite electrodes.

When used to nanostructure the traditional LSM-YSZ cathode, the intrinsic properties of DC have translated to large increases in cell performance, Section 3.2. In order to gain a better understanding of the mechanism of enhancement by ceria, the enhancement of each component of the LSM-YSZ composite cathode is studied separately. In Section 3.3, the analysis of YSZ and LSM electrodes infiltrated with ceria is used to formulate a 
reaction level analysis of the enhancement within the LSM-YSZ composite cathode. Finally, in Section 3.4, initial stability studies are presented for DC infiltrated LSM-YSZ.

\subsection{Performance}

Dramatic improvements in cathode performance due to the improved microstructure created by infiltration are directly evident in cell AC impedance characteristics, seen in Figure 2. After cathode infiltration with YDC (yttria doped ceria) the Nyquist plot, Figure 2a, reduced in size to less than $50 \%$ of the conventional LSM-YSZ cell. The reduction in overall cell impedance is more readily seen in the bode plots which explicitly show frequency information, presented in Figure $2 \mathrm{~b}$. While there is an overall decrease in the phase (theta) of the impedance characteristics of the cell after infiltration with both the intermediate $\sim 10 \mathrm{~Hz}$ and high $\sim 10000 \mathrm{~Hz}$ frequency peaks being diminished, it is the peak at $\sim 10 \mathrm{~Hz}$, which is most drastically reduced. This intermediate frequency peak is typically associated with the dissociation of oxygen molecules and adsorbtion of oxygen atoms into LSM-YSZ composite electrodes. ${ }^{5}$ The dramatic decrease in the phase and overall impedance at this frequency with infiltration suggests that the enhanced microstructure removes this previously rate limiting step in the reduction reaction within LSM-YSZ electrodes. 

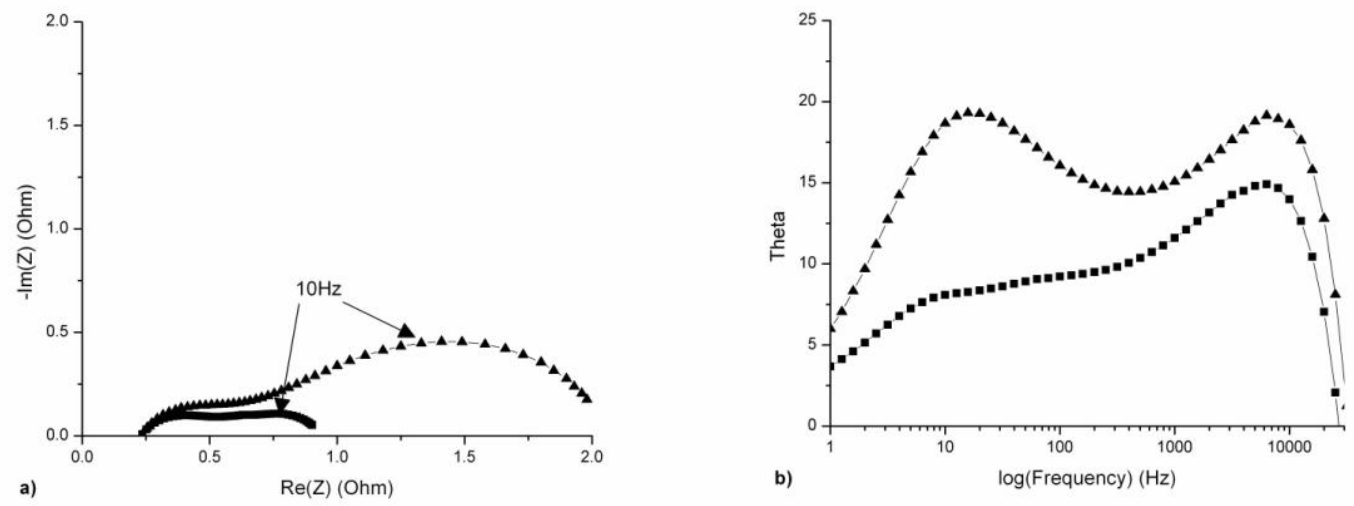

Figure 2. AC impedance characteristics of LSM-YSZ cell, with a) Nyquist and b) Bode plots shown before $(\boldsymbol{\Delta})$ and after $(\boldsymbol{\square})$ infiltration of $\mathrm{YDC}$ at $700{ }^{\circ} \mathrm{C}$.

The final outcome of the infiltration is a dramatic increase in cell performance, which is shown in Figure 3. Though the peak power density increases from $208 \mathrm{~mW} / \mathrm{cm}^{2}$ to 519 $\mathrm{mW} / \mathrm{cm}^{2}$ after infiltration are impressive, the most significant result of the infiltration is a dramatic increase in the power densities at low over-potentials. As can be seen by the decreased slope in the I-V curve after infiltration, the cell shows a drastic decrease not only in overall activation losses but also in overall overpotential until activation, enhancing power density at $0.7 \mathrm{~V}$ from $\sim 135 \mathrm{~mW} / \mathrm{cm}^{2}$ to $\sim 370 \mathrm{~mW} / \mathrm{cm}^{2}$ before and after infiltration, respectively. This decrease in activation losses is markedly different and improved as compared to isolated nanoparticulate infiltrations . ${ }^{4,6}$ 


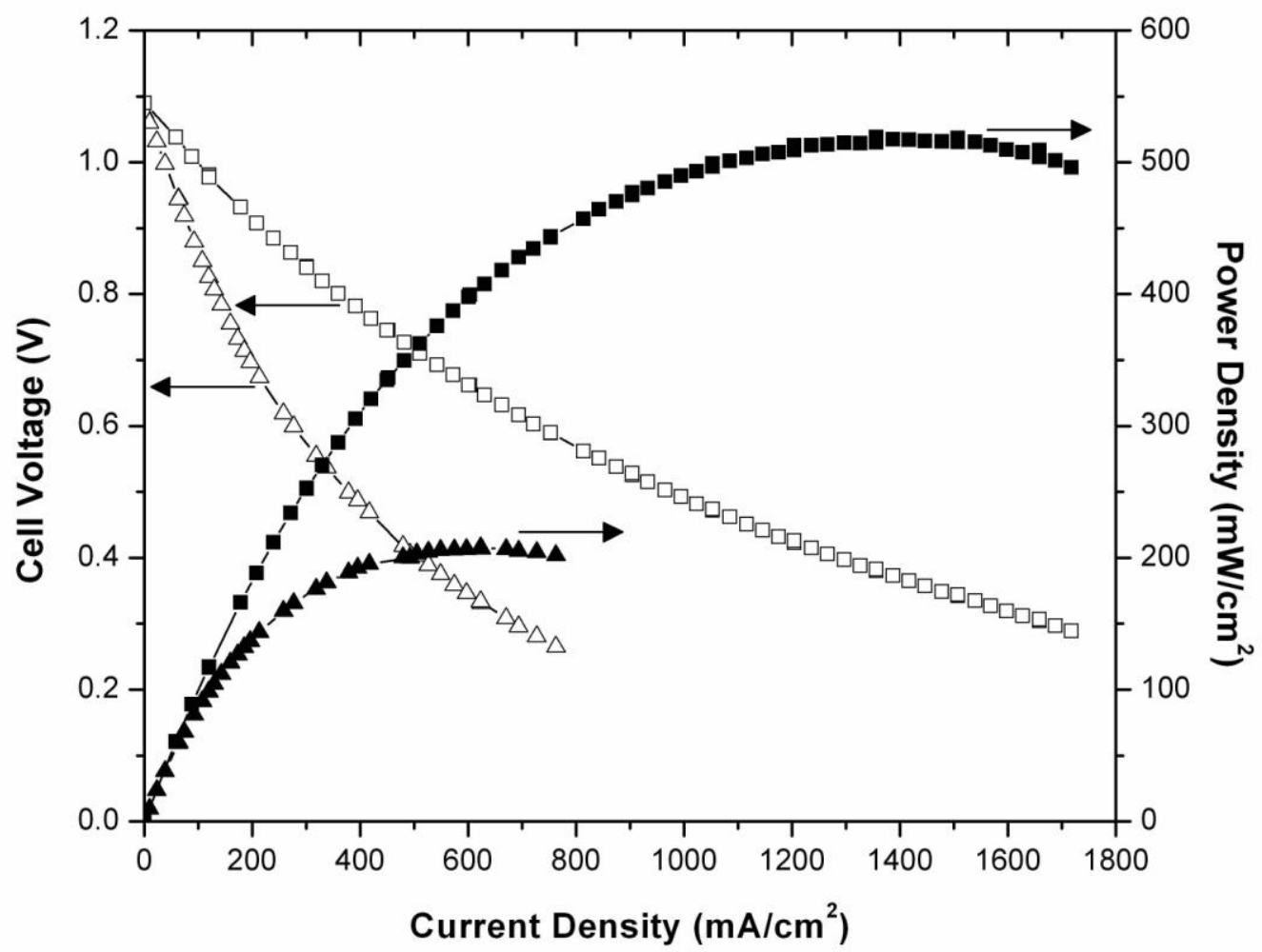

Figure 3. Enhancement of LSM-YSZ cell before ( $\boldsymbol{\Delta})$ and after $(\boldsymbol{\bullet})$ infiltration of YDC at $700{ }^{\circ} \mathrm{C}$.

\subsection{Enhancement Mechanism}

In order to gain a better understanding of the mechanism of enhancement by Ceria, the enhancement of each component of the LSM-YSZ composite cathode is studied separately. To simplify the study, the electrodes were infiltrated with un-doped Ceria. Ceria is an ideal infiltrant because, in the nanoscale, its ionic and electronic conductivities are of the same order. The increased disorder in the nanoscale Ceria induces higher electronic conductivity as demonstrated by Y.-M. Chiang et al. ${ }^{7}$ Additionally, the LSM and YSZ in the composite serve as an ideal backbone, since LSM 
is almost strictly electronically conductive and YSZ is almost strictly ionically conductive.

The performance enhancement of the LSM-YSZ cell before and after infiltration with Ceria is shown in Table 1. While performance characteristics are the main measure of cell enhancement, a mechanistic level understanding of the enhancement is only gained by analyzing the AC impedance spectra. It is specifically the bode characteristic which allows us to gain a reaction level understanding of the enhancement. The change in peak phase and frequency (speed of reaction) provides a mechanistic level view of the enhancement.

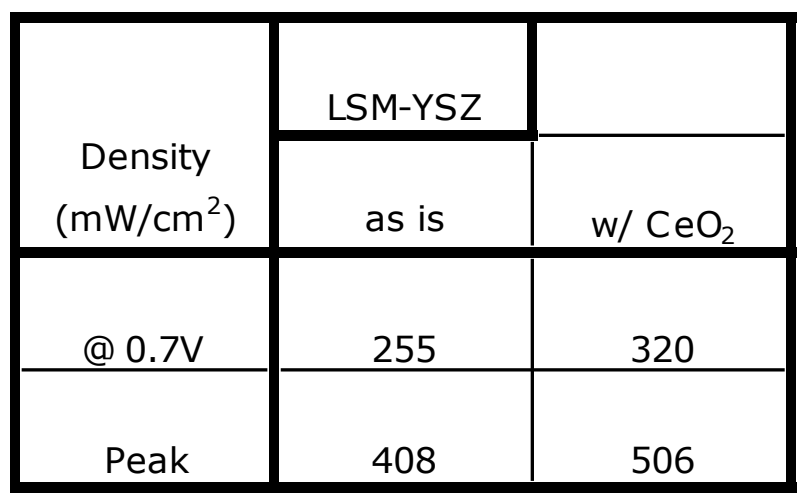

Table 1. Performance characteristics of LSM-YSZ cell before and after infiltration with $\mathrm{CeO}_{2}$.

The bode characteristics of the LSM-YSZ and single component LSM and YSZ cells show 2 dominant peaks, one at high frequencies $(10 \mathrm{kHz})$ and the other at intermediate frequencies $(\sim 10 \mathrm{~Hz})$. As mentioned previously, the intermediate frequency peak is associated generally with oxygen adsorption within the electrode. Additionally, the high 
frequency peak is associated with charge transfer; ${ }^{8}$ the change is both peaks is listed in Table 2.

\begin{tabular}{|c|c|c|c|c|c|c|}
\hline & LSM-YSZ & & LSM & & YSZ & \\
\hline $\begin{array}{l}\text { High Frequency } \\
\text { "Charge Transfer }\end{array}$ & as is & $\mathrm{w} / \mathrm{CeO}_{2}$ & as is & $\mathrm{w} / \mathrm{CeO}_{2}$ & as is & $\mathrm{w} / \mathrm{CeO}_{2}$ \\
\hline Phase $\left({ }^{\circ}\right)$ & 21.7 & 18.1 & 26.1 & 13.9 & 20 & 23 \\
\hline Frequency $(\mathrm{Hz})$ & 5,010 & 12,600 & 3160 & 63097 & 63,100 & 39,800 \\
\hline \multicolumn{7}{|l|}{$\begin{array}{c}\text { Inter. Frequency } \\
\text { "A ds orption" }\end{array}$} \\
\hline Phase $\left({ }^{\circ}\right)$ & 14.8 & 12.1 & 38.5 & 17 & 17.5 & $x$ \\
\hline Frequency $(\mathrm{Hz})$ & 7.94 & 50.1 & 126 & 19.953 & 31.6 & $x$ \\
\hline
\end{tabular}

Table 2. Change in phase and frequency of high and intermediate frequency bode peaks of cells before and after infiltration with $\mathrm{CeO}_{2} . \mathrm{X}$ symbolizes no measurable peak.

In general, infiltrating ceria decreases the phase and increases the frequency of all of the peaks, indicating an improvement in the processes. This is particularly the case for the intermediate frequency process in YSZ, which becomes too small to measure after ceria infiltration. The process is still present, but because the processes are coupled and the high frequency is so dominant, it is essentially hidden. The coupled nature of processes within a cell are also attributed to the decrease in frequency of the intermediate phase process in LSM. It seems that a slightly higher frequency adsorption process is normally dominant on un-infiltrated LSM. The large decrease in phase indicates that the adsorption process is greatly enhanced by nanostructuring with ceria. 
The high frequency process in YSZ is the only one that slows after infiltration. Before infiltration, the Pt current collector is the only electrocatalyst, so the reaction/ charge transfer process occurs on the YSZ/Pt current collector interface. After ceria nanostructuring YSZ, the reaction takes place in the electrode and ceria is required to perform the charge transfer process. But ceria's electronic conductivity is low in this range $\left(\sim 10^{-4} \mathrm{~S} / \mathrm{cm}\right)$ so that even though ceria nanostructured YSZ has improved adsorption properties, it still requires a good electronic conductor, such as LSM, to facilitate charge transfer.

\subsection{Stability}

Preliminary stability studies have been performed on Ceria infiltrated LSM-YSZ cathodes. An LSM-YSZ cell infiltrated with SDC has been stable for over 125 hours, Figure 4. The cell's performance actually continues to improve over the lifetime of the test. This preliminary study and longer studies (> 500 hours) on LSM infiltrated SSZ cells suggest that ceria nanostructured LSM-YSZ electrodes can be stable for long-term operation. 


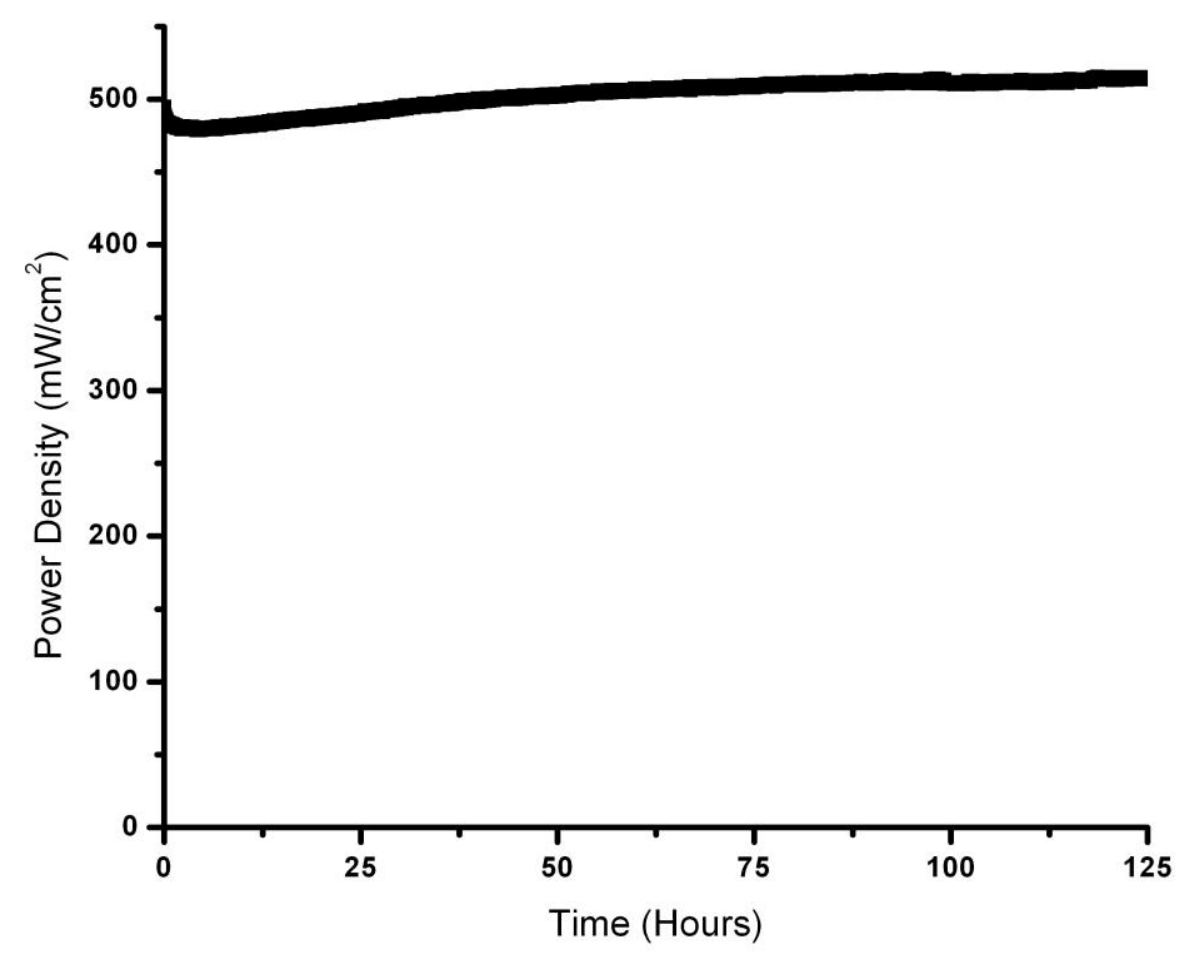

Figure 4. YDC infiltrated LSM-YSZ electrode under $700 \mathrm{~mA} / \mathrm{cm}^{2}$ constant current at $700{ }^{\circ} \mathrm{C}$.

\subsection{Summary}

In addition to facilitating porous electrolyte backbone electrodes, nanostructuring dramatically improves traditional composite cathode performance. An LSM-YSZ cell improved in power density at $0.7 \mathrm{~V}$, from $\sim 135 \mathrm{~mW} / \mathrm{cm}^{2}$ to $\sim 370 \mathrm{~mW} / \mathrm{cm}^{2}$ after nanostructuring with YDC. An investigation of the mechanism of this enhancement has shown that ceria enhances the oxygen reduction reaction on both LSM and YSZ, but that the charge transfer process requires a source of electrons. Hence, YSZ infiltrated with ceria still requires LSM in the composite in order to supply electrodes. Finally, initial 
stability tests indicate that nanostructured LSM-YSZ electrodes should be stable for longterm operation. 


\section{References}

1. J. Van Herle, T. Horita, T. Kawada, N. Sakai, H. Yokokawa, M. Dokiya, J. Europ. Ceram. Soc., 16961 (1996).

2. Y. Xiong, K. Yamaji, T. Horita, N. Sakai and H. Yokokawa, J. Electrochem. Soc., 149, 450 (2002).

3. A. Tschope, E. Sommer and R. Birringer, Solid State Ionics, 139, 225 (2001).

4. C. Lu, T. Z. Sholklapper, C. P. Jacobson, S. J. Visco and L. C. De Jonghe, J. Electrochem. Soc., 153, 1115 (2006).

5. X. J. Chen, K. A. Khor and S. H. Chan, J. Power Sour., 123, 17 (2003).

6. K. Yamahara, C. P. Jacobson, S. J. Visco, X.-F. Zhang and L. C. De Jonghe, Solid State Ionics, 176, 275 (2005).

7. Y.-M. Chiang, E.B. Lavik, I. Kosacki, H.L. Tuller, J.Y. Ying, J. Electroceramics, 1 (1997).

8. S. Primdahl and M. Mogensen, J. Electrochem. Soc., 144, 3409 (1997). 


\section{Chapter 4: Enhancing Composite Ni-YSZ Anodes}

\subsection{Introduction}

While cathode performance has traditionally been the main impediment to high performance at intermediate temperatures, the development of infiltrated cathodes ${ }^{1,2}$ and alternative cathode electrocatalysts ${ }^{3,4}$ has brought down cathode losses to the level of anode losses. As long as cathode losses were dominant, there was little point in improving anode performance. However, with the dramatic improvement of cathode performance, the problem of anode losses becomes relevant. In Section 4.2, infiltration of traditional Ni-YSZ anodes will be discussed for further improvement in overall cell performance. Additionally, since one of the major benefits of solid oxide fuel cells (SOFCs) is the ability to operate on hydrocarbon fuels without the need for complex reforming systems, the tolerance of the anode to contaminants in the fuel is a major issue that must be addressed.

Sulfur in hydrocarbon fuels, present primarily as hydrogen sulfide $\left(\mathrm{H}_{2} \mathrm{~S}\right)$, leads to rapid catalysis inhibition and has the strongest impact on intermediate temperature SOFC performance and lifetime. ${ }^{5}$ At intermediate temperatures of $600{ }^{\circ} \mathrm{C}-800{ }^{\circ} \mathrm{C}$, Ni-based anodes will tolerate only $\sim 0.1 \mathrm{ppm}$ of sulfur, ${ }^{6}$ necessitating aggressive sulfur removal

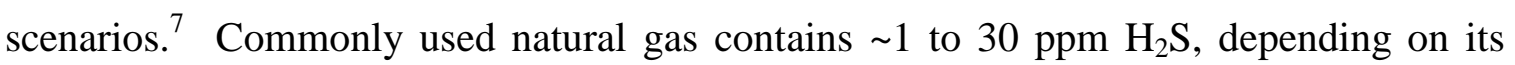
source and may additionally contain several ppm of sulfur-based odorants. ${ }^{8,9}$ A sulfur tolerance of $40 \mathrm{ppm} \mathrm{H}_{2} \mathrm{~S}$ at intermediate operating temperatures would be sufficient for 
the direct use of most natural gas in SOFCs. The use of an external sulfur removal device is an option, but adds undesirable complexity to the SOFC system.

The option of using $\mathrm{Ni}$ anodes for sulfur-containing commercial fuels at lower temperatures would mark significant progress in the development of practical SOFCs since it would not require significant processing modifications. The purpose of section 4.3 is to demonstrate the effectiveness of ceria nanosructuring Ni-YSZ anodes, significantly suppressing sulfur sensitivity at $700{ }^{\circ} \mathrm{C}$.

\subsection{Performance}

Due to their dominant contribution to overall cell impedance at intermediate temperatures, cathodes stand to improve the most by improving electrode microstructure through infiltration; nonetheless, significant improvement in anode impedance characteristics are seen in Figure 4 through the infiltration of SDC (Samarium Doped Ceria) into a Ni-SSZ anode. Unlike cathodes, the high frequency peak at $\sim 20000 \mathrm{~Hz}$ most dramatically affects the overall cell impedance seen in the Nyquist plot Figure 1a. However, this decrease in phase (theta) at high frequencies is common to both cathodes, Figure 2b. (Chapter 3), and anodes, Figure 1b., suggesting a common origin. 

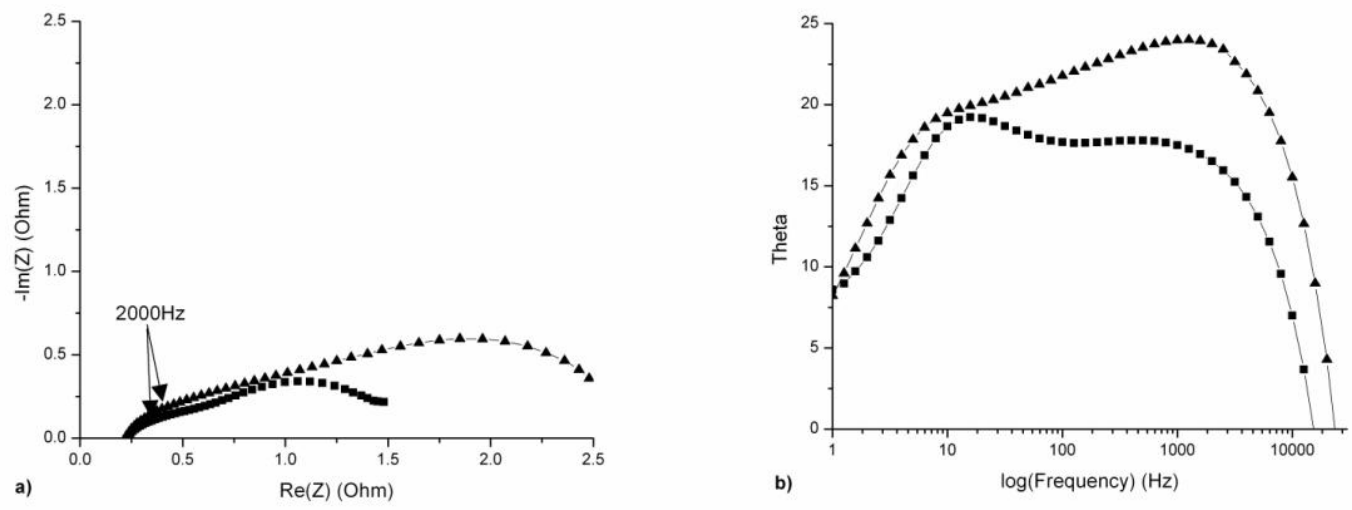

Figure 1. Impedance characteristics of anode supported cell with Ni-SSZ anode, with a) Nyquist and b) Bode plots shown before ( $\boldsymbol{\Delta})$ and after ( $\boldsymbol{\square})$ infiltration of SDC at $700{ }^{\circ} \mathrm{C}$.

Even though improvement was seen in cell impedance characteristics after anode infiltration, it does not appear to translate into significant improvement in cell performance at low overvoltages, Figure 2, since losses in this range are typically associated with cathode linked cell activation, which would not be improved by improvement in anode microstructure. However, the infiltrated microstructure produces a jump in peak power density from $\sim 348 \mathrm{~mW} / \mathrm{cm}^{2}$ to $\sim 403 \mathrm{~mW} / \mathrm{cm}^{2}$. The improved anode performance should translate to more significant gains in performance in cells with improved cathodes. 


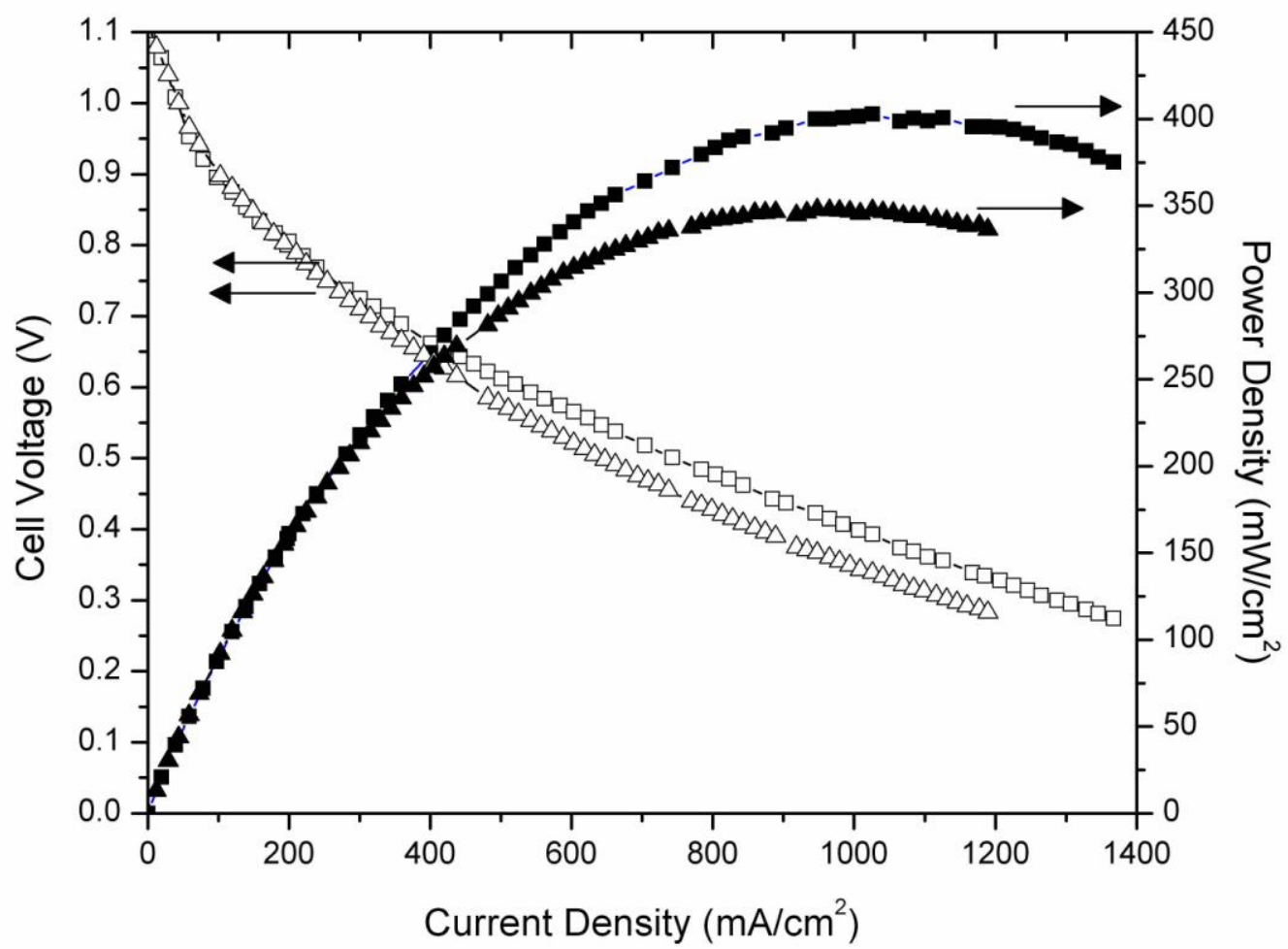

Figure 2. Enhancement of anode supported cell before ( $\mathbf{\Lambda})$ and after ( $\mathbf{\square})$ infiltration of anode with SDC at $700{ }^{\circ} \mathrm{C}$.

\subsection{Sulfur Tolerance and Stability}

To check the sulfur tolerance of the infiltrated and non-infiltrated cells, a constant current density of $0.4 \mathrm{Acm}^{-2}$ was applied at $973 \mathrm{~K}$ while the fuel atmosphere was changed from $\mathrm{H}_{2}$ to $40 \mathrm{ppm} \mathrm{H}_{2} \mathrm{~S} / \mathrm{H}_{2}$, and back, as shown in Figure 3. After the cells were exposed to $\mathrm{H}_{2}$ for about $\sim 14$ hours, the atmosphere was changed to contain $40 \mathrm{ppm} \mathrm{H}_{2} \mathrm{~S}$. The non-infiltrated cell with traditional Ni-YSZ anode deteriorated rapidly as its voltage quickly dropped from $0.45 \mathrm{~V}$ immediately after exposure, to $0 \mathrm{~V}$ in merely $\sim 13 \mathrm{~min}$. It may be noted that this cell showed a higher polarization in $\mathrm{H}_{2} / \mathrm{H}_{2} \mathrm{O}$ at $0.4 \mathrm{Acm}^{-2}$, which 
exemplifies the beneficial action of the ceria infiltration even in the absence of S. This will be discussed more extensively in a later report. In contrast, the ceria infiltrated cell performed for 500 hours after which the atmosphere was returned to $\mathrm{H}_{2}$. For the infiltrated cell, the cell voltage dropped rapidly (in about $20 \mathrm{~min}$ ) by $170 \mathrm{mV}$ to $0.60 \mathrm{~V}$, and then decreased gradually to $0.56 \mathrm{~V}$ after about 278 hours, after which the cell did not change significantly. It is tempting to associate this initial transient with a saturation time of the bubbler water since hydrogen sulfide has some solubility in water ${ }^{10}$. However, additional tests in which the $\mathrm{H}_{2} \mathrm{~S}$ was fed in after the water bubbler produced the same transients. The infiltrated cell maintained a power density of $220 \sim 240 \mathrm{mWcm}^{-2}$ for 500 hours under the applied current of $0.4 \mathrm{~A} / \mathrm{cm}^{2}$, at $973 \mathrm{~K}$, in $40 \mathrm{ppm} \mathrm{H}_{2} \mathrm{~S}$, lower by only $27 \%$ of the sulfur-free performance. After a 500 hour exposure to $40 \mathrm{ppm}_{2} \mathrm{~S}$, the atmosphere was switched back to $\mathrm{H}_{2}$, and the voltage returned remarkably quickly, in about $12 \mathrm{~min}$, to $0.75 \mathrm{~V}$, only $20 \mathrm{mV}$ lower than the initial operating voltage. 


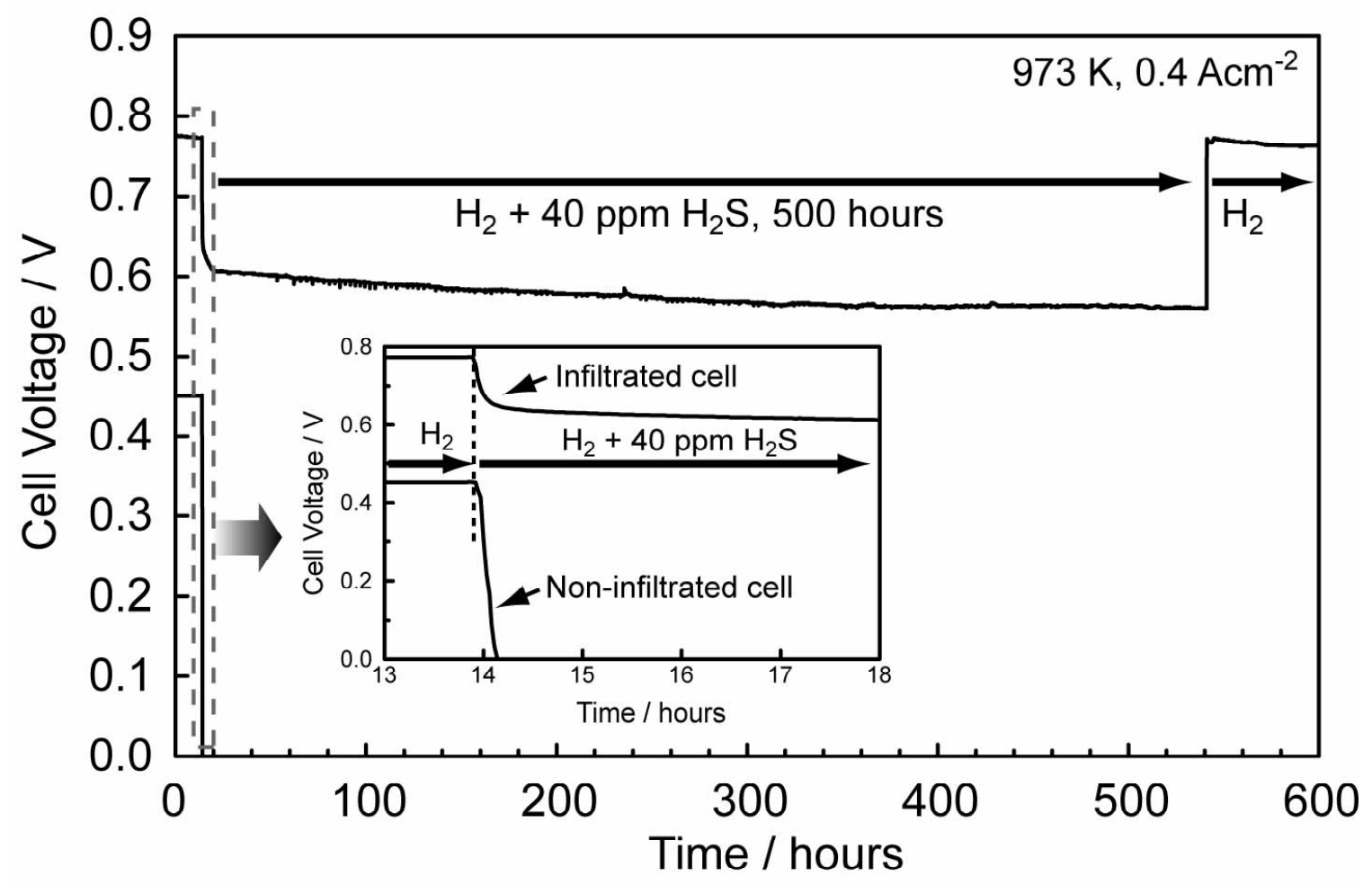

Figure 3. Cell voltage as a function of time for cells exposed to $40 \mathrm{ppm}_{2} \mathrm{~S}$ at 700 ${ }^{\circ} \mathrm{C}$.

Figure 4 shows current- voltage characteristics and power density of the cell with the Ceria nano-particle infiltrated Ni-YSZ anode before/after exposure to $40 \mathrm{ppm}_{2} \mathrm{~S}$ for 500 hours at $973 \mathrm{~K}$, with both characteristics determined in $\mathrm{H}_{2}$. The peak power density of the cell dropped slightly from 314 to $308 \mathrm{mWcm}^{-2}$ after the cell was exposed to 40 ppm $\mathrm{H}_{2} \mathrm{~S}$ for 500 hours at $973 \mathrm{~K}$. Degradation of the cell power density was only 2\%,

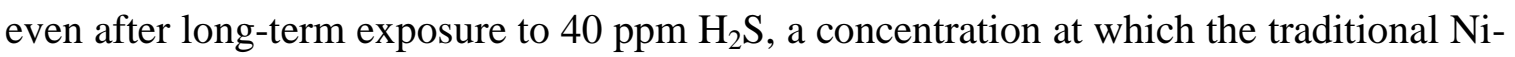
YSZ anodes deteriorated quickly. The mechanism of the $\mathrm{H}_{2} \mathrm{~S}$ poisoning of Ni-YSZ anodes possibly involves formation of $\mathrm{Ni}_{3} \mathrm{~S}_{2}$ on the surface of the $\mathrm{Ni}$, preventing the direct oxidation reaction within the anodes. ${ }^{11}$ The blocking of active Ni-YSZ triple phase boundaries by sulfur species and the formation of a thin layer of $\mathrm{Ni}_{3} \mathrm{~S}_{2}$ anode are likely to 
contribute to the anode deactivation. ${ }^{12}$ It is possible that the infiltration of the ceria nanoparticulate layer prevented the deleterious formation of $\mathrm{Ni}_{3} \mathrm{~S}_{2}$ at $973 \mathrm{~K}$, increasing sulfur tolerance of Ni-YSZ drastically.

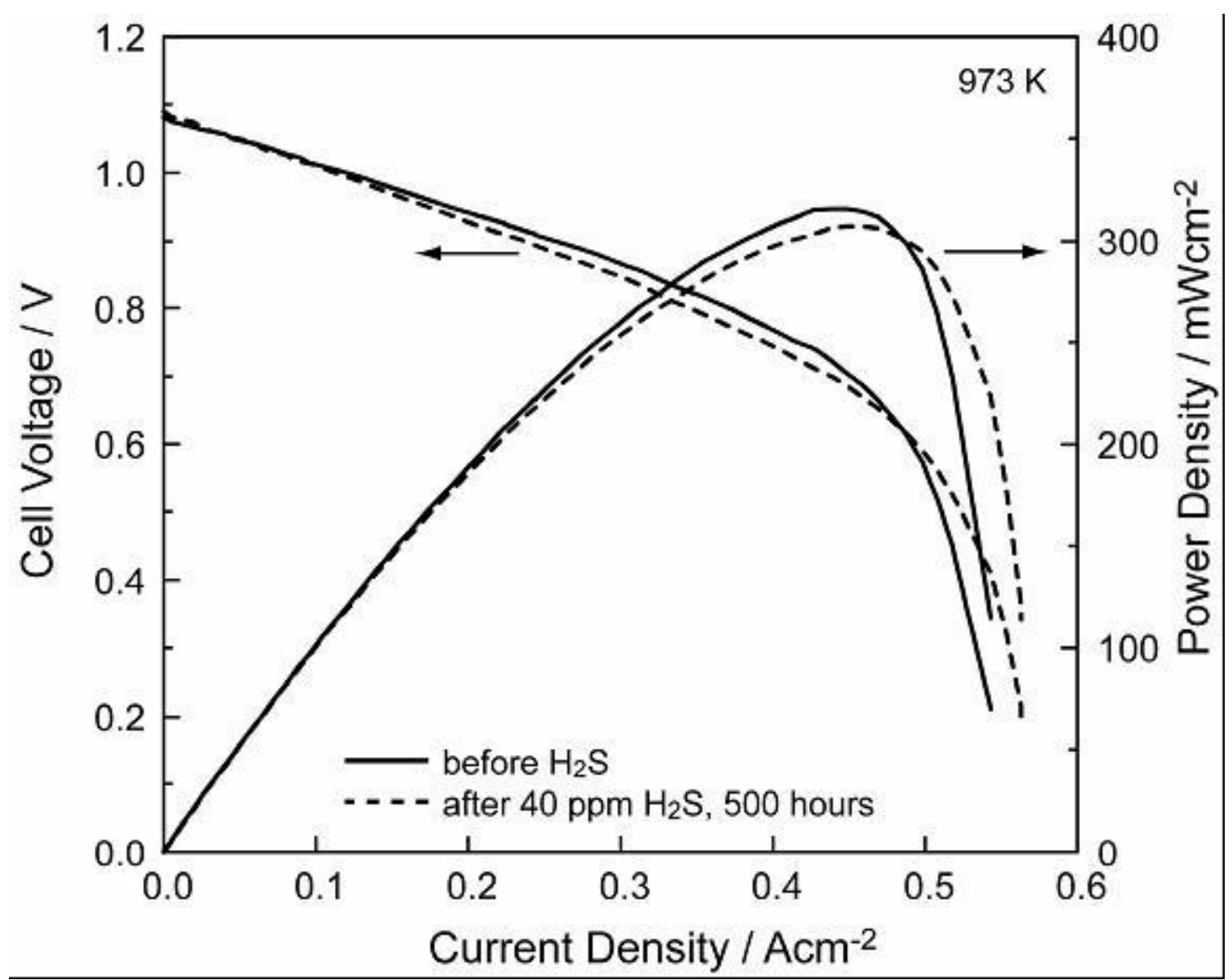

Figure 4. Cell voltage and power density as a function of current density for a cathode support cell with ceria nano-coated Ni-YSZ anode at $700{ }^{\circ} \mathrm{C}$.

Figure 5 shows the AC impedance spectra of the ceria-infiltrated cell between $923 \mathrm{~K}$ and $1023 \mathrm{~K}$ before/after exposure to $40 \mathrm{ppm} \mathrm{H}_{2} \mathrm{~S}$ for 500 hours. Three arcs are identifiable, with the peak frequencies of the high, intermediate and low frequency arcs at $1 \mathrm{kHz}, 25 \mathrm{~Hz}$ and $1 \mathrm{~Hz}$ respectively. Though the analysis of impedance spectra of multilayer fuel cells is complicated and often uncertain, some approximate analysis is possible 
based on previous studies. ${ }^{13-15}$ Kim et al. ${ }^{13}$ studied the impedance spectra of oxygen reduction on LSM-YSZ cathodes in air and concluded that high-frequency $\operatorname{arc}(\sim 10 \mathrm{kHz})$ was attributed to oxygen-ion transfer from the triple-phase boundary (TPB) to the electrolyte. Additionally, Primdahl and Mogensen ${ }^{14}$ reported that the arc at high frequency $(1 \sim 10 \mathrm{kHz})$ depends on the anode microstructure, and could be attributed to protonic charge transfer across the Ni/YSZ interface, with an additional contribution of an $\mathrm{O}^{2-}$ transport resistance through YSZ particles in the porous electrode. The lowfrequency arc $(\sim 1 \mathrm{~Hz})$ was attributed to a cathode gas phase diffusion resistance with low activation energy, ${ }^{13}$ as well as to gas conversion in the Ni-YSZ anode. ${ }^{14}$ The arc at $10 \sim 100 \mathrm{~Hz}(25 \mathrm{~Hz}$ peak here) is the one most sensitive to the atmosphere of the Ni-YSZ anode. $^{15}$ In the present study, the intermediate-frequency arc of the infiltrated cell was very sensitive to the levels of $\mathrm{H}_{2} \mathrm{~S}$, as well as to temperature, while the low-frequency arc was little affected by the fuel atmosphere and temperature. In a previous study with $\mathrm{Ni}$ free sulfur-tolerant oxide anodes, ${ }^{16}$ the size of secondary arc at $\sim 13 \mathrm{~Hz}$ increased with increasing levels of $\mathrm{H}_{2} \mathrm{~S}$ (from 10 to $40 \mathrm{ppm}$ ) in $\mathrm{H}_{2} / \mathrm{H}_{2} \mathrm{O}=97 / 3$ and was reversed after exposure to $\mathrm{H}_{2} / \mathrm{H}_{2} \mathrm{O}=97 / 3$. The arc at $\sim 25 \mathrm{~Hz}$ shown in Figure 4 is therefore associated with sulfur species catalyst inhibition of the ceria-coated Ni-YSZ anode. The mechanism by which this S-tolerance and fast recovery occurs is, however, at present speculative, and is currently under investigation. It is, for example, not clear if the catalysis occurs only on the ceria, as appears to be the case for $\mathrm{Cu}$-ceria cermet anodes, ${ }^{17}$ or if there is a residual catalysis role of the $\mathrm{Ni}$. 


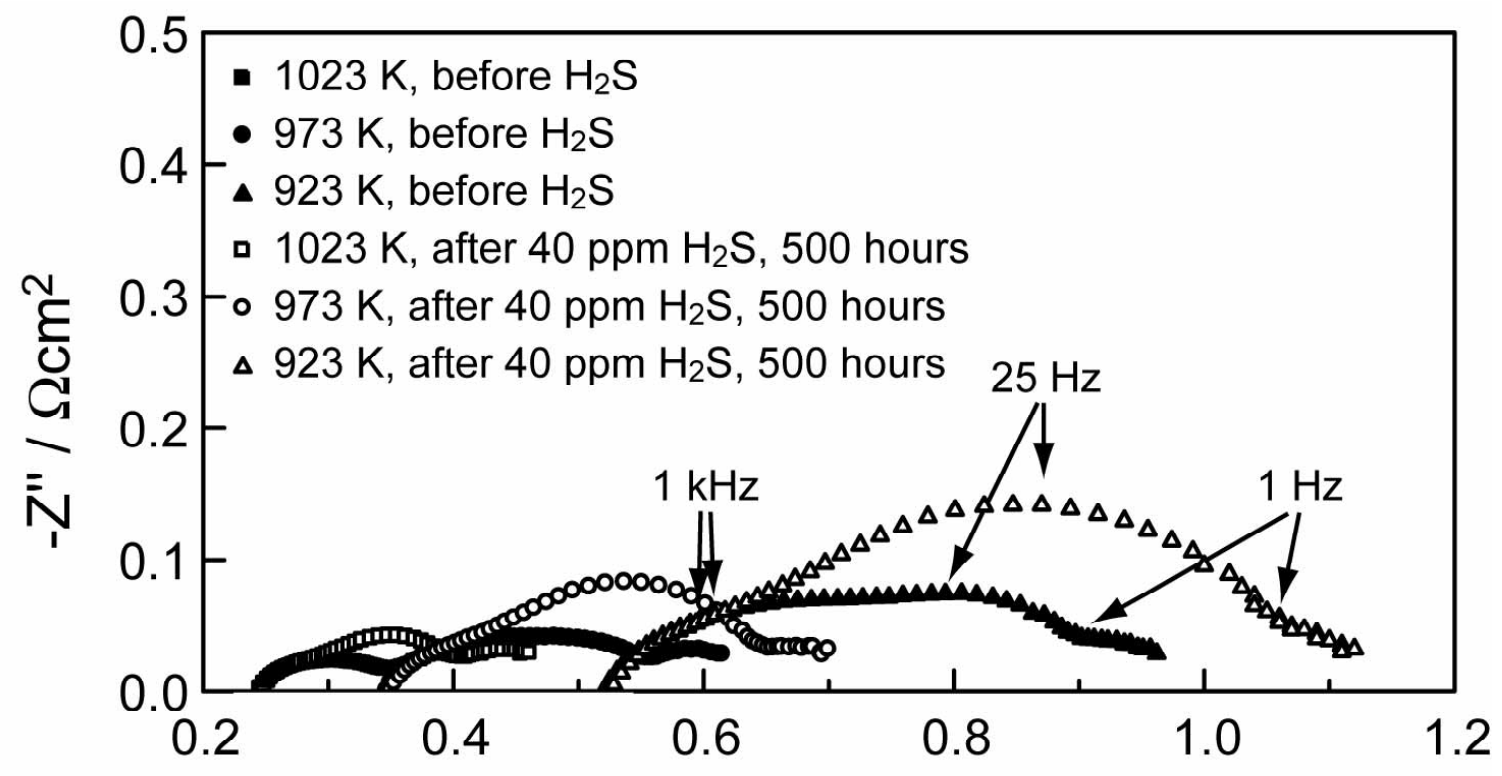

\section{$Z^{\prime} / \Omega \mathrm{cm}^{2}$}

Figure 5. Impedance spectra for Ceria infiltrated cell before/after exposure to 40 ppm $\mathrm{H}_{2} \mathrm{~S}$ for 500 hours.

The AC impedance spectra were fitted to an equivalent circuit, $L R_{\mathrm{S}}\left(R_{1} Q_{1}\right)\left(R_{2} Q_{2}\right)\left(R_{3} Q_{3}\right)$, as shown in Figure 6, to evaluate the effect of long-term exposure to ppm levels of $\mathrm{H} 2 \mathrm{~S}$. In the model, $L$ is an inductance, $R_{i}$ are resistances, and $Q_{i}$ are constant phase elements (CPE). The admittance $\mathrm{Y}$ of a $\mathrm{CPE}, Q$, is given as

$$
Y=Y_{0}(j \omega)^{n}
$$

where $Y_{0}$ is an admittance, $j$ is the imaginary unit, $\omega$ is the angular frequency, and $n$ is the frequency power. To compare the values of $R$ and $Q$, constant n-values for $Q_{1}, Q_{2}$, and $Q_{3}$ were set appropriately during fitting process, using all the cell AC impedance data.

The n-values were selected as: $n_{1}=0.75, n_{2}=0.75$, and $n_{3}=0.85$. The equivalent circuit with these fitted values was able to describe all AC impedance spectra with less than $3 \%$ 
relative error at all frequencies used for measurement. Table 1 shows the values of $R$ and obtained from the spectra shown in Fig 5. The equivalent circuit values indicate that all the resistances decrease with increasing temperature, with only resistor $R_{2}$, associated with the intermediate-frequency arc, strongly affected by $\mathrm{H}_{2} \mathrm{~S}$. The values of $R_{2}$ almost doubled after exposed to $40 \mathrm{ppm} \mathrm{H}_{2} \mathrm{~S}$ for 500 hours, between 923 and $1023 \mathrm{~K}$.

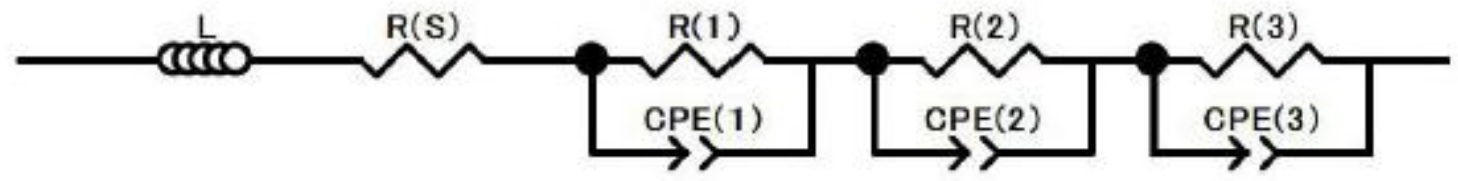

Figure 6. Equivalent circuit for fitting the measured impedance spectra.

\begin{tabular}{|l|c|c|c|c|}
\hline data & $R_{5}\left(\Omega \mathrm{cm}^{2}\right)$ & $R_{1}\left(\Omega \mathrm{cm}^{2}\right)$ & $R_{2}\left(\Omega \mathrm{cm}^{2}\right)$ & $R_{3}\left(\Omega \mathrm{cm}^{2}\right)$ \\
\hline $923 \mathrm{~K}$ & 0.52 & 0.16 & 0.21 & 0.08 \\
\hline $923 \mathrm{~K}$ after $\mathrm{H}_{2} \mathrm{~S}$ & 0.52 & 0.14 & 0.42 & 0.08 \\
\hline $973 \mathrm{~K}$ & 0.35 & 0.10 & 0.11 & 0.08 \\
\hline $973 \mathrm{~K}$ after $\mathrm{H}_{2} \mathrm{~S}$ & 0.35 & 0.08 & 0.23 & 0.07 \\
\hline $1023 \mathrm{~K}$ & 0.24 & 0.06 & 0.06 & 0.08 \\
\hline $1023 \mathrm{~K}$ after $\mathrm{H}_{2} \mathrm{~S}$ & 0.24 & 0.06 & 0.12 & 0.07 \\
\hline
\end{tabular}

Table 1. Equivalent circuit values derived by fitting the measured impedance spectra.

The microstructure of the ceria infiltrated Ni-YSZ anode after 500 hours $\mathrm{H}_{2} \mathrm{~S}$ exposure is shown in Figure 7. The thickness of the YSZ electrolyte and Ni-YSZ anode 
layer on cathode support layer were about $15 \mu \mathrm{m}$ and $10 \mu \mathrm{m}$, respectively. The surface of the Ni-YSZ was partially covered with a ceria layer of thickness $30 \sim 50 \mathrm{~nm}$. The NiYSZ and the thin ceria nanoparticle layer appear to be intimately connected. Infiltrated ceria settled well on the Ni-YSZ during pre-treatment, and retained its morphology during the experiment for 500 hours at $973 \mathrm{~K}$. The ceria nano-layer covered a significant fraction of the triple phase boundaries at Ni/YSZ junctions, yet the cell performanceprior to sulfur exposure- increased slightly after infiltration. This is likely due to nanosized nature of the coating layer and the mixed conduction and catalytic properties of ceria in reducing atmospheres. In addition to preventing sulfur poisoning, the ceria nanocoating has significant known benefits for Ni-YSZ anodes: preventing coking in hydrocarbons as well as enhancing the anode performance due to its mixed conduction and catalytic properties. ${ }^{18,19}$ The thin ceria coating layer may also help in reducing Ni coarsening.

It is noteworthy that the Ceria nano-layer coverage of the fuel electrode pore walls can be produced readily by cost-effective simple vacuum infiltration method and offers a promising solution to sulfur poisoning of conventional Ni-YSZ anodes. 


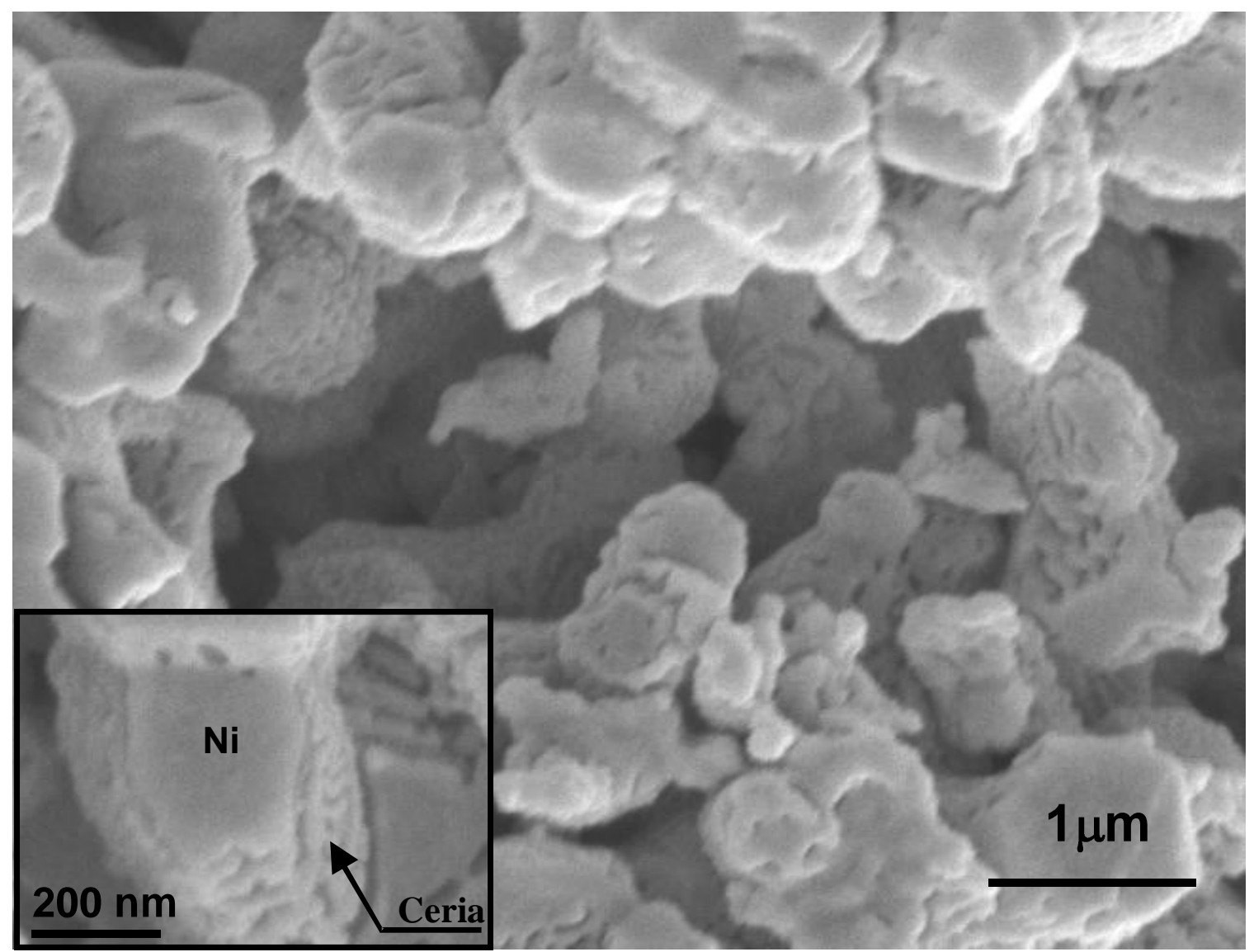

Figure 7. Scanning electron micrographs of ceria infiltrated cathode supported cell after exposure to $40 \mathrm{ppm} \mathrm{H}_{2} \mathrm{~S}$ for 500 hours.

\subsection{Summary}

With the recent advancement in previously limiting cathode performance, there is now room to improve anode performance as well. SDC infiltration into the traditional Ni-YSZ anode of an anode supported cells showed an increase in peak power density from $348 \mathrm{~mW} / \mathrm{cm}^{2}$ to $\sim 403 \mathrm{~mW} / \mathrm{cm}^{2}$.

More importantly a ceria nano-coating of a Ni-YSZ anode led to stable performance for greater than $500 \mathrm{hrs}$ with humidified hydrogen containing significant concentrations of sulfur. The cathode-supported cell with infiltrated Ni-YSZ anode delivered more than 
$220 \sim 240 \mathrm{mWcm}^{-2}$ at $0.6 \mathrm{~V}$, for 500 hours under an applied current of $0.4 \mathrm{~A} / \mathrm{cm}$ at $973 \mathrm{~K}$ in $40 \mathrm{ppm} \mathrm{H}_{2} \mathrm{~S}$, while the voltage of the non-infiltrated cell with traditional Ni-YSZ anode dropped to zero in $\sim 13 \mathrm{~min}$. The cell voltage and performance of the infiltrated cell recovered nearly fully in 20 min after $\mathrm{H}_{2} \mathrm{~S}$ exposure for 500 hours. Infiltrated ceria nano-coating increased the sulfur tolerance of traditional Ni-YSZ anode dramatically and made these anodes viable at intermediate operating temperatures for SOFCs. 


\section{References}

1. S. P. Jiang, Mater. Sci. and Eng. A, 418, 199-210 (2006).

2. T. Z. Sholklapper, H. Kurokawa, C. P. Jacobson, S. J. Visco, L. C. De Jonghe, Nano Letters, 7, 2136-241 (2007).

3. Z. Shao, S. Haille, Nature, 431, 170-173 (2004).

4. I. A. Raj, A. S. Nesaraj, M. Kumar, F. Tietz, H. P. Buchkremer, D. Stoever, J. New Mater. Electrochem. Sys., 7, 145-151, (2004).

5. N. Q. Minh and T. Takahashi, in Science and Technology of Ceramic Fuel Cells, p. 209, Elsevier, New York (1995).

6. Y. Matsuzaki and I. Yasuda, Solid State Ionics, 132, 261 (2000).

7. J. Larminie, Fuel Cell Systems Explained, John Wiley \& Sons Ltd., Chichester (2001).

8. Natural Gas 1998: Issue and Trend, U.S. Department of Energy, Washington, DC (1998).

9. R. H. Cunnigham, M. Fowles, R. M. Ormerod, and J. Staniforth, Sulfur Poisoning of the Active Materials Used in SOFCs, Rolls-Royce plc, London (2004).

10. R. Belcher, J. Buchanan, and W. I. Stephen, J. Royal Inst. Chem., 73, 101 (1949).

11. J. Dong, Z. Cheng, S. Zha, and M. Liu, J. Power Sources, 156, 461 (2006).

12. S. J. Xia and V. I. Birss, in Solid Oxide Fuel Cells (SOFC IX), S. C. Singhal and J. Mizusaki, Editors, PV 2005-07. p. 1275, The Electrochemical Society Proceedings Series, Pennington, NJ (2005).

13. J.-D. Kim, G.-D. Kim, J.-W. Moon, Y. I. Park, W.-H. Lee, K. Kobayashi, M. Nagai, and C.-E. Kim, Solid State Ionics, 143, 379 (2001).

14. S. Primdahl and M. Mogensen, J. Electrochem. Soc., 144, 3409 (1997).

15. S. Primdahl and M. Mogensen, J. Electrochem. Soc., 146, 2827 (1999). 
16. H. Kurokawa, L. Yang, C. P. Jacobson, L. C. De Jonghe, and S. J. Visco, J. Power Sources, 164, 510 (2007).

17. A. Atkinson, S. Barnett, R. J. Gorte, J. T. S. Irvine, A. J. Mcevoy, M. Mogensen, S. C. Singhal, and J. Vohs, Nat. Mater., 3, 17 (2004).

18. S. P. Jiang, Mater. Sci. Eng., A, 418, 199 (2006).

19. B. C. H. Steele, K. M. Hori, and S. Uchino, Solid State Ionics, 135, 445 (2000). 


\section{Chapter 5: Conclusion}

By nanostructing SOFC electrodes, electrode issues associated with the cost-driven decrease in temperature have been offset. The connected network of nanoparticles created by a new infiltration method allows for the incorporation of the nanoparticles after electrode backbone formation, allowing for previously incompatible advanced electrocatalysts to be infiltrated. This provides electronic conductivity and electrocatalysis within well-formed electrolyte backbones. Furthermore, the method was used to significantly enhance the conventional electrode design by adding secondary electrocatalysts. The performance enhancement and the added critical benefit of significantly increased anode-contamination-tolerance were demonstrated in each of the electrodes. Additionally, cell processing and the infiltration method developed in conjunction with this dissertation were reviewed.

In order to compete with entrenched technologies such as gasoline engines and steam turbines, fuel cells will need to be cost competitive. My future work will focus on metal supported SOFC's, which should be able to meet these criteria, as discussed in section 1.8. One of the major difficulties with the metal supported design has been the engineering of stable anodes because of the difficulty of infiltrating a connected network of $\mathrm{Ni}$, as discussed in section A2.3.4 of appendix 2. Once these issues are addressed I hope to help transfer the metal supported SOFC technology to market. 


\section{Appendix 1: Cell Processing and Testing Procedure}

\section{A1.1 Introduction}

Two cell configurations were used in this study, anode supported cells (ASC) in chapters 2-4 and cathode supported cells (CSC) in chapter 4. While ASCs are currently the cell design of choice for most commercial SOFC development, CSC as well as electrolyte supported cells (ESC) are also being considered for commercialization. A review of the specific processing methods used to produce the cells in this dissertation will be given in section A1.2. A more through review of infiltration can be found in appendix 2. Additionally the specific order in which layers are deposited for each of the 3 SOFC types is given in section A1.3. At the end of the section a table is given listing the composition of each of the cells tested in this dissertation.

Section A1.4 will then go over electrochemical testing procedure for the above cells. Additionally, in section A1.4, other testing procedure not associated with whole cells will be reviewed.

\section{A1.2 Processing}

The same basic processing methods are used for all layers (electrolyte or electrodes) in the 3 cell types. All powders that compose the different cell layers begin with a mixing/ de-agglomerating step. If added porosity is needed a pore former may be added to this powder mixture. The powders are then formed into the individual cell layers by 
compaction (uniaxially die-pressing), tape-casting or spraying, While the sprayed layers can be deposited directly after the mixing/ de-agglomerating step, the tape-cast solution must be partially dried, and the powder for compaction must be dried and sieved.

\section{A1.2.1 Supports: Compaction or Tape Cast}

Compacted supports are made by combining appropriate weights of support powder with 2.5 wt.\% of menhaden fish oil (MFO) (Sigma), poly (vinyl butyral-co-vinyl alcoholco-vinyl acetate) (PVB) (Aldrich) and dibutyl phthalate (Mallinckrodt). The mixture is then either attritor-milled between 500 to $550 \mathrm{rpm}$ for 3 hours or ball-milled for 24 hours using $3 \mathrm{~mm}$ YSZ balls (Union Process), in isopropanol alcohol (IPA). (It must be noted that attritor-milling is a more aggressive method of de-agglomerating as it breaks up whole grains as well as separating clusters). If added porosity is required, the suspension is then put in a beaker and appropriate amounts of pore former, typically KS4 or KS6 graphite (Timrex), is added with 2.5 wt.\% of MFO, PVB and dibutyl phthalate. The solution is then stirred and dried under a heating lamp. The resulting agglomerated powder is ground with mortar and pestle, and passed through a $150 \mathrm{~mm}$ mesh sieve. The sieved powder is uniaxially die-pressed into disks at $15 \mathrm{kpsi}$ using a stainless steel die, then pre-fired at an appropriate temperature in air, typically, $900{ }^{\circ} \mathrm{C}-1150{ }^{\circ} \mathrm{C}$ for 1 hour for electrode supported cells and $1300{ }^{\circ} \mathrm{C}$ to $1400{ }^{\circ} \mathrm{C}$ for 4 hours for electrolyte supports.

Supports can also be fabricated by tape casting. ${ }^{1}$ Appropriate weights of support powder are thoroughly mixed in water with Duramax D3005 as the dispersant. Duramax B1000 and HA-12 binders are then added to form the NiO-YSZ slurry. After evaporation of excessive water, the slurry is tape-cast onto a Mylar film, and dried at ambient 
temperature. The green tape is then cut into circular disks with a diameter of about $4 \mathrm{~cm}$. The supports are then pre-fired at an appropriate temperature in air, typically, $700{ }^{\circ} \mathrm{C}$ $1150{ }^{\circ} \mathrm{C}$ for 1 or 2 hours for electrode supported cells and $1300^{\circ} \mathrm{C}$ to $1400^{\circ} \mathrm{C}$ for 4 hours for electrolyte supports.

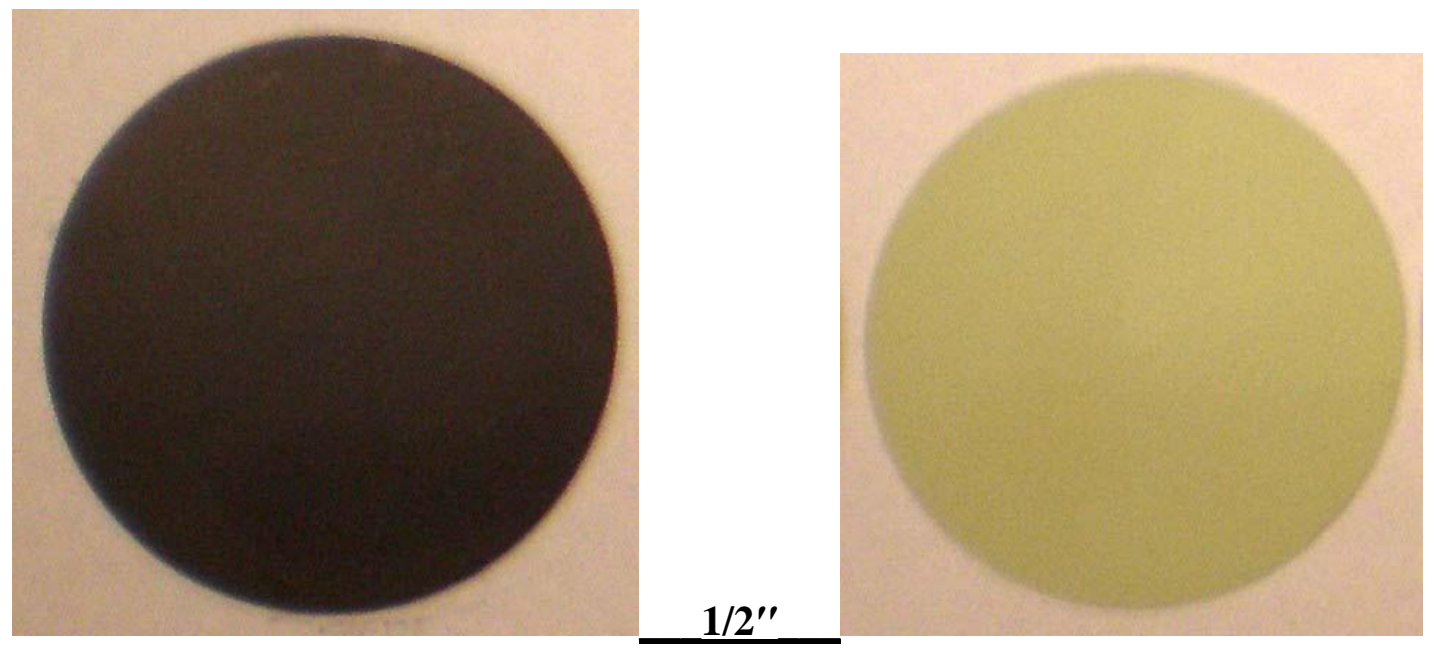

Figure A1. Picture of green and pre-fired NiO-YSZ anode supports.

\section{A1.2.2 Thin Film Electrodes and Electrolytes}

Thin film electrodes and electrolytes are formed on supports by colloidal deposition. ${ }^{2}$ Suspension for colloidal deposition are prepared by combing $2 \mathrm{~g}$ of the appropriate powder with $0.1 \mathrm{~g}$ of MFO and 1 drop $(\sim 0.02 \mathrm{~g})$ of dibuty phthalate, in $50 \mathrm{~mL}$ of IPA, and attritor milling using $3 \mathrm{~mm}$ YSZ balls for 1 hour, at $500 \mathrm{rpm}$. If additional porosity is needed for the electrodes, pore former, typically KS4 or KS6 graphite (Timrex), can then be ultra sonically dispersed into the solution before deposition. Thin film electrolytes are deposited over the entire support, while electrodes are typically deposited over $1 \mathrm{~cm}^{2}$ area on the electrolyte. The resulting layers are then sintered at appropriate temperatures in 
air, typically, $1100{ }^{\circ} \mathrm{C}-1300{ }^{\circ} \mathrm{C}$ for 4 hour for electrodes and $1300{ }^{\circ} \mathrm{C}$ to $1400{ }^{\circ} \mathrm{C}$ for 4 hours for the electrolytes.

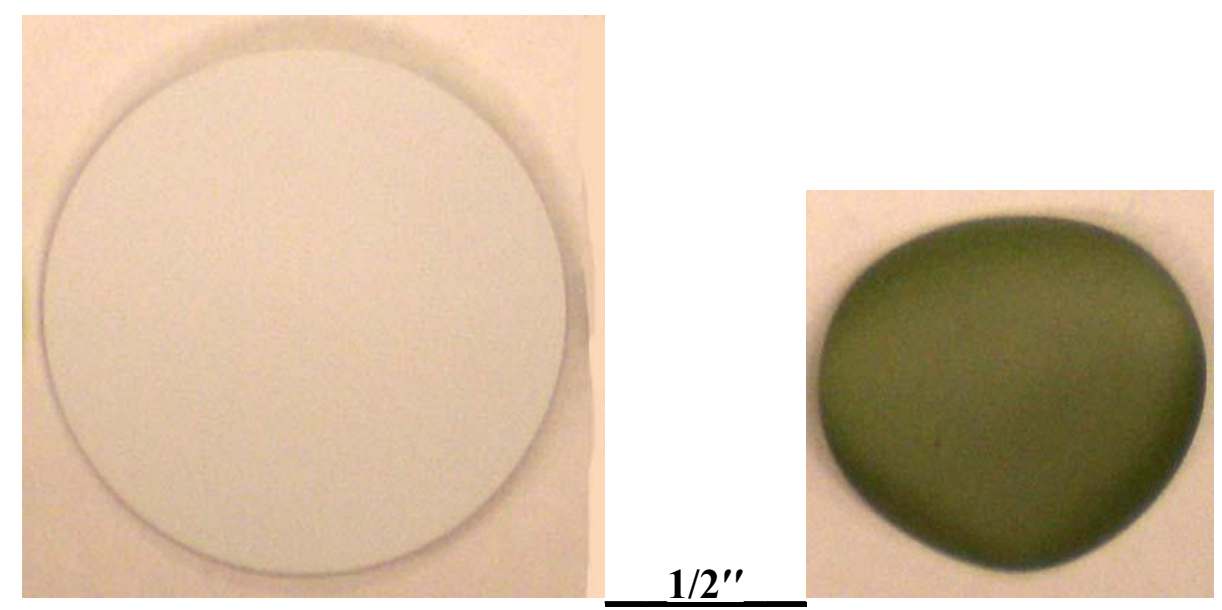

Figure A2. Picture of sprayed and sintered YSZ electrolytes on NiO-YSZ anode supports.

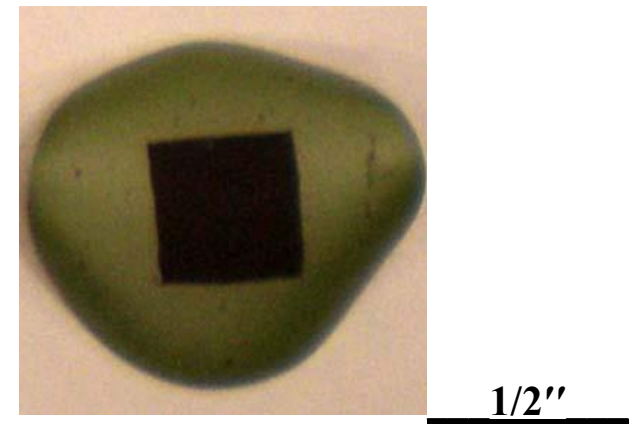

Figure A3. Picture of sintered PYSZ and LSM-YSZ on sintered NiO-YSZ/YSZ anode supports.

\section{A1.2.3 Pt Current Collectors}

For electrochemical testing, Pt mesh current collectors are attached with Pt paste to both electrodes. The cells are then fired at $900{ }^{\circ} \mathrm{C}$ for 30 min to sinter the Pt powder and thus bond the Pt mesh. 


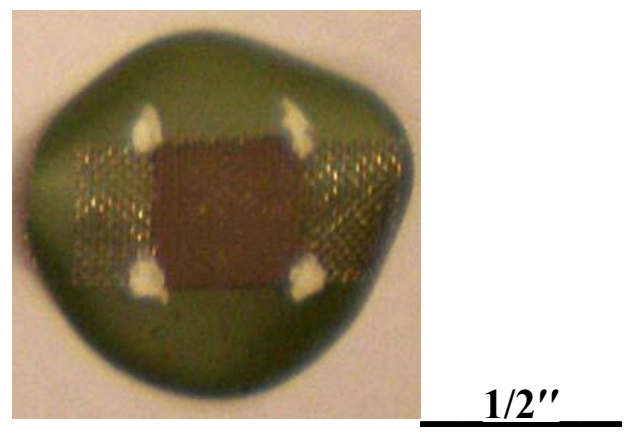

Figure A4. Picture of Pt current collector on cathode of NiO-YSZ/YSZ/LSM-YSZ ASC.

\section{A1.2.4 Infiltration: Nanostructuring}

In this study porous electrodes are enhanced by the addition of a nanostructured electrocatalyst. The electrocatalysts are deposited as a continuous layer of nanoparticles within the electrode, by a novel infiltration method. Appropriate amounts of metal salt and Triton $\mathrm{X}-100$ surfactant were mixed and heated to $\sim 100{ }^{\circ} \mathrm{C}$ and then infiltrated using a vacuum impregnation apparatus (Epovac; Struers), followed by conversion of the precursors by heating at $800^{\circ} \mathrm{C}$ for $0.5 \mathrm{~h}$. A more through description of the novel infiltration process will be given in appendix 2 .

\section{A1.3 Cells}

The production of the three types of SOFC cell configurations will outlined bellow.

\section{A1.3.1 Electrolyte Supported Cells (ESC)}

Electrolyte supports were produced by uniaxially die pressing YSZ powder. The green electrolyte disk was sintered to $1400{ }^{\circ} \mathrm{C}$ for 4 hours, producing a dense support. 
LSM-YSZ and NiO-YSZ electrodes were then sprayed symmetrically in $1 \mathrm{~cm}^{2}$ areas. The electrodes were the fired between $1100^{\circ} \mathrm{C}$ and $1250{ }^{\circ} \mathrm{C}$.

\section{A1.3.2 Anode Supported Cells (ASC)}

Anode supports were produced, either by compaction or tape casting. Compacted samples were created, by uniaxially die-pressing $\mathrm{NiO}$ and YSZ powders in a 50-50 weight ratio. Tape cast samples on the other hand, were created by casting a tape of the identical powders. After drying, the tape is cut into the appropriate shape. The green anode disks are then pre-fired to approximately $1100{ }^{\circ} \mathrm{C}$ for 1 hour. The electrolyte is then added to the support by spraying approximately $10 \mu \mathrm{m}$ or YSZ. The electrolyte and support are then fired to $1400{ }^{\circ} \mathrm{C}$ for 1 hour, producing a dense electrolyte. The cathode is then sprayed on to the electrolyte in a $1 \mathrm{~cm}^{2}$ area, and fired between $1100{ }^{\circ} \mathrm{C}$ and $1300{ }^{\circ} \mathrm{C}$ for 4 hours.

\section{A1.3.3 Cathode Supported Cells (CSC)}

Cathode supports were produced by compacting LSM and YSZ powders in a 50-50 weight ratio. The supports were then pre-fired to $700{ }^{\circ} \mathrm{C}$ for 4 hours. The electrolyte is then added to the support by spraying approximately $10 \mu \mathrm{m}$ or YSZ. The electrolyte and support are then fired to $1300{ }^{\circ} \mathrm{C}$ for 1 hour, producing a dense electrolyte. The NiO-YSZ $(50-50 \mathrm{wt} \%)$ anode is then sprayed on to the electrolyte in a $1 \mathrm{~cm}^{2}$ area and fired at 1300 ${ }^{\circ} \mathrm{C}$. 


\begin{tabular}{|c|c|c|c|c|c|}
\hline Section & Cell Type & $\begin{array}{l}\text { Anode Composition, } \\
\text { Sintering or Pre-firing } \\
\text { Temp, thickness }\end{array}$ & $\begin{array}{l}\text { Electroly te Composition, } \\
\text { Sintering Temp, thickness }\end{array}$ & $\begin{array}{c}\text { Cafhode Composition, } \\
\text { Sintering or Pre-firing } \\
\text { Temp, thickness }\end{array}$ & Infiltration \\
\hline 2.2.1 & ASC & $\begin{array}{l}\text { NiO-YSZ (50-50 wt\%), } \\
1100^{\circ} \mathrm{C} 2 \mathrm{hr}, \sim 500 \mu \mathrm{m}\end{array}$ & YSZ, $1400^{\circ} \mathrm{C}, 4 \mathrm{hrs}, \sim 10 \mu \mathrm{m}$ & YSZ $1300^{\circ} \mathrm{C} 4 \mathrm{hrg}, \sim 10 \mu \mathrm{m}$ & Cafthode: LSM1 \\
\hline $2.2 .2-2.4$ & Asc & $\begin{array}{l}\text { NiO-SSZ (50-50 wt\%), } \\
1100^{\circ} \mathrm{C} 1 \mathrm{hr}, \sim 500 \mu \mathrm{m}\end{array}$ & St:Z, $1350^{\circ} \mathrm{C}$ 4hrs, $10 \mu \mathrm{mm}$ & Sst $1250^{\circ} \mathrm{C} 4 \mathrm{hrs},-10 \mu \mathrm{mm}$ & $\begin{array}{c}\text { Cathode: Ag, LSF or Ag- } \\
\text { LSM1 }\end{array}$ \\
\hline 3.2 & ASC & $\begin{array}{l}\text { NiO-YSZ (50-50 wt\%), } \\
1100^{\circ} \mathrm{C} 1 \mathrm{hr},-500 \mu \mathrm{m}\end{array}$ & $\mathrm{YSZ}, 1400^{\circ} \mathrm{C}, 4 \mathrm{hr}, \sim 10 \mu \mathrm{m}$ & YSZ $1250^{\circ} \mathrm{C} 4 \mathrm{hrg}, \sim 10 \mu \mathrm{m}$ & Cathode: YDC \\
\hline 33 & Asc & $\begin{array}{l}\text { NiO-YSZ (50-50 wt\%), } \\
1100^{\circ} \mathrm{C} 1 \mathrm{hr},-500 \mu \mathrm{m}\end{array}$ & YSSz, $1400^{\circ} \mathrm{C} 4 \mathrm{hrs}, \sim 10 \mu \mathrm{m}$ & $\begin{array}{l}\text { YSZ, LSM or LSM-YSZ } \\
1200^{\circ} \mathrm{C} 4 \mathrm{hrs}, \sim 10 \mu \mathrm{mo}\end{array}$ & Cathode: $\mathrm{CeO}_{2}$ \\
\hline 3.4 & ASC & $\begin{array}{l}\text { NiO-YSZ (50-50 wt\%), } \\
1100^{\circ} \mathrm{C} 1 \mathrm{hr},-500 \mu \mathrm{m}\end{array}$ & YSSE, $1400^{\circ} \mathrm{C} 4 \mathrm{hrs}, \sim 10 \mu \mathrm{m}$ & Yst $1250^{\circ} \mathrm{C} 4 \mathrm{hrs}, \sim 10 \mu \mathrm{m}$ & Cathode: SDC \\
\hline 4.2 & Asc & $\begin{array}{l}\text { NiO-SSZ (50-50 wt\%), } \\
1100^{\circ} \mathrm{C} 1 \mathrm{hr},-500 \mu \mathrm{m}\end{array}$ & St:Z, $1400^{\circ} \mathrm{C}$ 4hrs, $\sim 10 \mu \mathrm{mm}$ & $\begin{array}{c}\text { LSM1-SE (50-50 wt\%) } \\
1200^{\circ} \mathrm{C} 4 \mathrm{hrg}, \sim 10 \mu \mathrm{m}\end{array}$ & Anode: SDC \\
\hline \multirow[t]{5}{*}{ 4.3-4.4 } & \multirow[t]{2}{*}{$\csc$} & $\begin{array}{c}\text { NiO-YSZ (50-50 wt\%), } \\
1300^{\circ} \mathrm{C} 4 \mathrm{hr}, \sim 10 \mu \mathrm{m}\end{array}$ & YSZ, $1300^{\circ} \mathrm{C}, 4 \mathrm{hr}, \sim 10 \mu \mathrm{m}$ & $\begin{array}{c}\text { LSM2-YSZ (50-50 wt\%) } \\
700^{\circ} \mathrm{C} 4 \mathrm{hrs}, \approx 500 \mu \mathrm{m}\end{array}$ & Anode: $\mathrm{CeO}_{2}$ \\
\hline & & & Abbreviations & & \\
\hline & & $\begin{array}{c}\text { ASC }=\text { Anode Supported } \\
\text { Cell }\end{array}$ & $\mathrm{LSM} 2=\mathrm{La}_{0.65} \mathrm{Sr}_{0.3} \mathrm{MnO}_{3-\mathrm{d}}$ & $\mathbf{S S Z}=\mathrm{Sc}_{0.10} \mathbf{Z r}_{0.90} \mathbf{O}_{2}$ & $\mathrm{YDC}=\mathrm{Y}_{0.20} \mathrm{Ce}_{0.80} \mathrm{O}_{2}$ \\
\hline & & $\begin{array}{c}\mathrm{CSC}=\text { Cathode Supported } \\
\text { Cell }\end{array}$ & LSM1 $=\mathrm{L}_{0} \mathbf{b}_{3} \mathrm{Sr}_{01} \mathrm{MnnO}_{3-\mathrm{d}}$ & $\mathbf{Y S Z}=\mathbf{Y}_{00} \mathbf{Z} \mathrm{Z}_{0,9 \mathbf{O}_{2}}$ & $\mathrm{SDC}=\mathrm{Sm}_{020} \mathrm{Ce}_{020_{2}}$ \\
\hline & & & $\mathrm{LSF}=\mathrm{L} a_{0} s_{0} \mathrm{Sr}_{0.20} \mathrm{O}_{2}$ & & \\
\hline
\end{tabular}

Table A1. Processing Index for cells in dissertation.

\section{A1.4 Measurement and Testing Procedure}

\section{A1.4.1 Cell Mounting / Heating}

The single cells are sealed onto an alumina tube using Aremco-552 cement, and current-voltage characteristics are obtained, using $97 \% \mathrm{H}_{2}+3 \% \mathrm{H}_{2} \mathrm{O}$ as the fuel and air as the oxidant. The cells are heated and the cement is simultaneously cured by heating at $3{ }^{\circ} \mathrm{C} / \mathrm{min}$ to $91{ }^{\circ} \mathrm{C}$ for $2 \mathrm{hrs}$, then $3{ }^{\circ} \mathrm{C} / \mathrm{min}$ to $204{ }^{\circ} \mathrm{C}$ for $2 \mathrm{hrs}$, then $3{ }^{\circ} \mathrm{C} / \mathrm{min}$ to $3711^{\circ} \mathrm{C}$ for $2 \mathrm{hrs}$, followed by $3{ }^{\circ} \mathrm{C} / \mathrm{min}$ to $600{ }^{\circ} \mathrm{C}$ or alternatively at $1{ }^{\circ} \mathrm{C} / \mathrm{min}$ to $600{ }^{\circ} \mathrm{C}$.

\section{A1.4.2 Electrochemical Testing}


The cell performance is determined from $600{ }^{\circ} \mathrm{C}$ to $750{ }^{\circ} \mathrm{C}$ with a Solartron 1255 frequency response analyzer combined with a Solartron 1286 electrochemical interface. The impedance spectra were measured under near-open circuit conditions (OCV), using a $10 \mathrm{mV}$ amplitude AC signal over a frequency range of $0.1 \mathrm{~Hz}$ to $1 \mathrm{MHz}$. The DC currentvoltage (I-V) performance is recorded with a potentiostat-galvanostat (Princeton Applied Research Model 371).

\section{A1.4.2.1 Performance Characteristics}

As a current is passed through the fuel cell, the potential deviates from its equilibrium value due to losses in the cell. Cell performance characteristics are obtained by increasing the current density in steps and monitoring the potential as it decreases from OCV. Additionally, the cells power density is also typically included in the performance characteristics and is given by

Power Density $\left(\mathrm{mW} / \mathrm{cm}^{2}\right)=$ Current Density $\left(\mathrm{mA} / \mathrm{cm}^{2}\right) *$ Polarization $(\mathrm{V})$.

A plot of the potential and power density vs current density for a standard cell is given in Figure 5. 


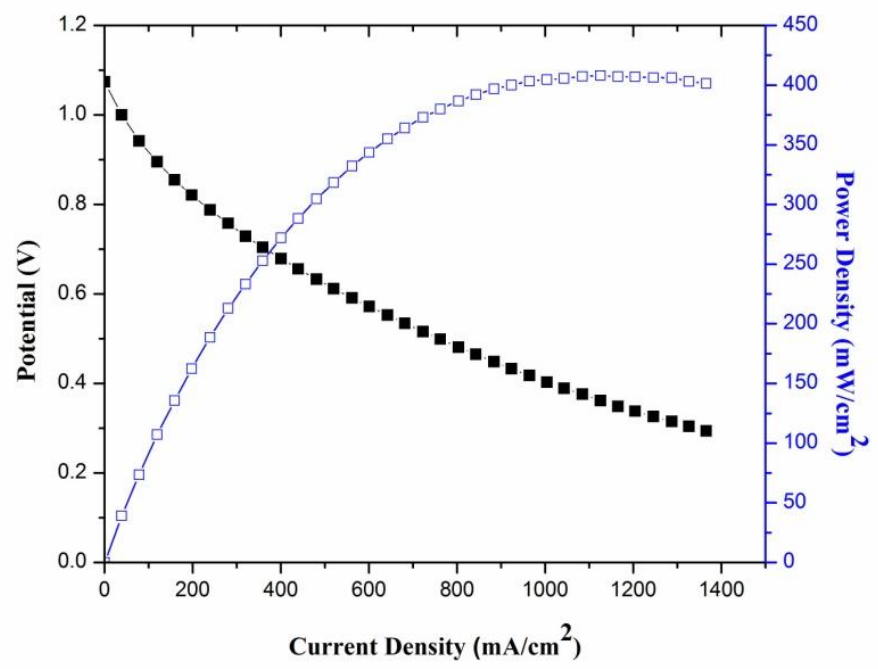

Figure A5. Performance characteristics of anode supported cell with LSM-YSZ cathode at $700^{\circ} \mathrm{C}$.

The potential drop in the cell can be separated out into an electrolyte IR term and electrode polarization terms. The change is potential is give by the following equation

$$
\text { Potential Drop }=\mathrm{IR}+\mathrm{I}\left(\eta_{\text {Cathode }}+\eta_{\text {Anode }}\right)
$$

where $\eta$ is the polarization resistance in each of the electrodes. In an ideal fuel cell the potential drop in the cell is governed simply by the IR losses, i.e. the electrolyte resistance to the flow of $\mathrm{O}^{2-}$ (ohmic resistance). However, since the electrodes are not fully active at the lower temperatures currently targeted for operation, there are additional terms for the polarization resistances in each of the electrodes. As discussed in the background it is specifically the polarization in the cathode that limits the low temperature performance.

A convenient way of analyzing the polarization is by plotting the instantaneous resistance, which is obtained from the performance characteristics. Dividing the change 
in potential by the change in current density, as measured in the current density/ potential measurement. The resistance is given as follows

$$
\text { Resistance }\left(\Omega \mathrm{cm}^{2}\right)=\Delta \text { Potential }(\mathrm{V}) / \Delta \text { Current Density }\left(\mathrm{mA} / \mathrm{cm}^{2}\right) \text {. }
$$

A plot of the instantaneous resistance for the standard cell is given in Figure 6.

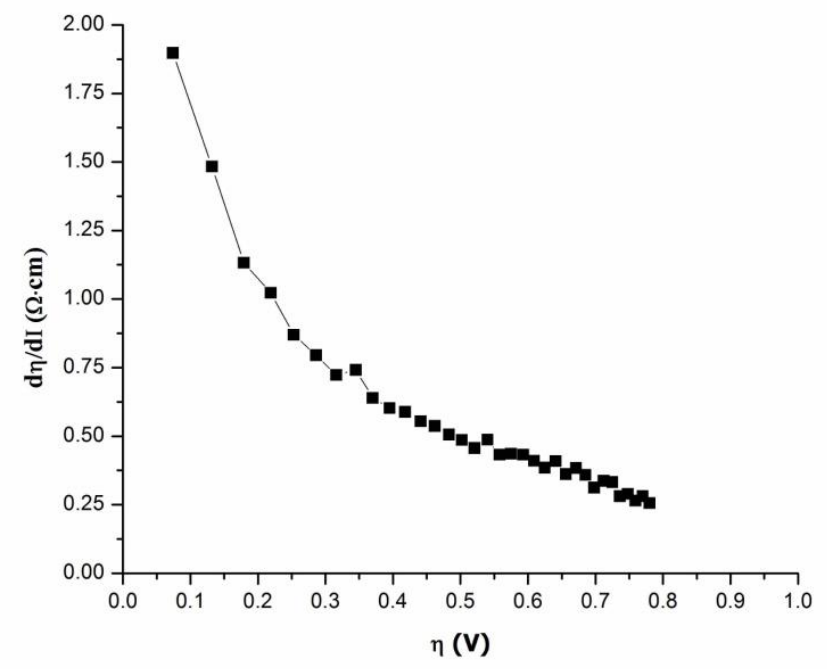

Figure A6. Instantaneous resistance of anode supported cell with LSM-YSZ cathode at $700^{\circ} \mathrm{C}$.

As the cells overvoltage (Potential - OCV) increases the instantaneous resistance decreases and begins to approach the IR losses. The excess instantaneous resistance is due to the electrode polarization resistance. Looking at the change in instantaneous resistance one can monitor change in electrode polarization by infiltration.

\section{A1.4.2.2 AC Impedance Spectroscopy}


While the change in instantaneous resistance conveys the overall change in polarization, AC impedance spectroscopy allows one to probe the change in the molecular level processes within the electrode. A brief review of AC impedance spectroscopy follows.

Impedance describes the measure of opposition of the system (fuel cell) to an applied small amplitude $(\sim 10 \mathrm{mV})$ sinusoidal electrical signal. If the incoming signal is given as

$$
V(t)=|V| e^{i(\omega t)}
$$

where $|\mathrm{V}|$ is the amplitude of the voltage, $\omega$ is the frequency (in radians/sec), and $t$ is the time, then the response of the fuel cell can be given as

$$
\mathrm{I}(\mathrm{t})=|\mathrm{I}| \mathrm{e}^{\mathrm{i}(\omega \mathrm{t}+\phi)} .
$$

where $|\mathrm{I}|$ is the amplitude of the current, and $\phi$ is the phase shift between the input and output signals.

By modifying Ohm's law, we have the relationship

$$
\mathrm{V}=\mathrm{IZ}
$$

where $\mathrm{Z}$ is the impedance (complex resistance). Plugging equations A4 and A5 into A6. We find an expression for the impedance

$$
Z=|V| /|I| e^{-i \phi}=|Z| e^{-i \phi}
$$

where $|\mathrm{Z}|$ is the magnitude of the impedance. The impedance, equation A7, can then be decomposed into real and imaginary components

$$
\begin{aligned}
& Z^{\prime}=\text { Real Impedance }=|Z| \cos (\phi) . \\
& Z^{\prime \prime}=\text { Imaginary Impedance }=|Z| \sin (\phi) .
\end{aligned}
$$

Electrochemical impedance spectroscopy is the measure of a systems response to variation in the frequency $(1 \mathrm{MHz}$ to $0.1 \mathrm{~Hz})$ of the input signal. The response of the 
system can be plotted with $Z^{\prime}$, equation $A 8$, on the $x$-axis and $Z^{\prime \prime}$, equation $A 9$, on the $y$ axis (Nyquist/ Cole-Cole Plot). A Nyquist Plot for the standard cell is given in Figure A7.

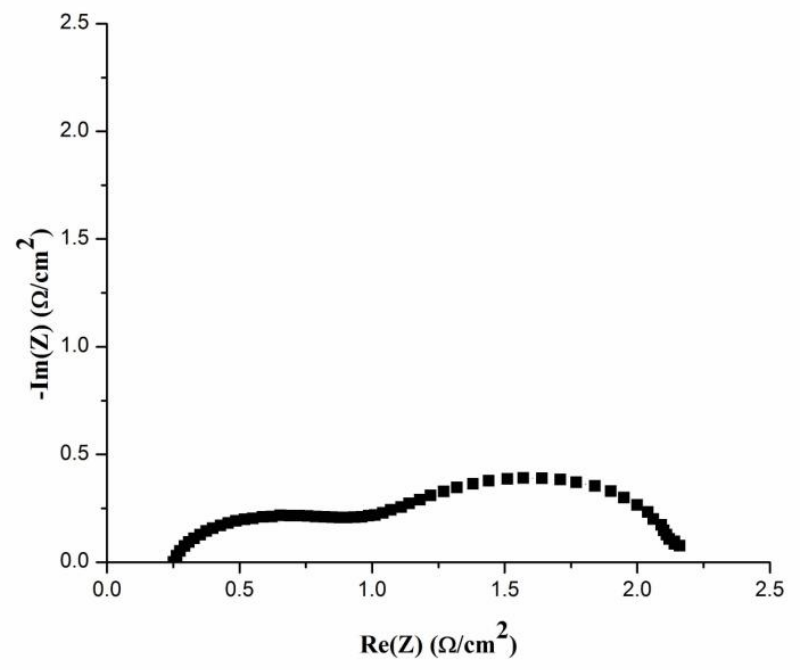

Figure A7. Nyquist Plot of anode supported cell with LSM-YSZ cathode at $700^{\circ} \mathrm{C}$.

In the limit as the frequency approaches 0, the impedance approaches the cell resistance, the high $\mathrm{x}$-intercept. Additionally, the low $\mathrm{x}$-intercept gives the total IR losses (ohmic resistance) for the cell.

A convenient way to separate the limiting reactions in the fuel cell is to determine the frequency at which the processes occur, by plotting the phase angle on the y-axis and the frequency on the $\mathrm{x}$-axis (Bode Plot). Where the phase angle is given by combining equations A8 and A9 as:

$$
\phi=\arctan \left(Z^{\prime \prime} / Z^{\prime}\right)
$$

The Bode Plot for the standard cell is given Figure A8. 


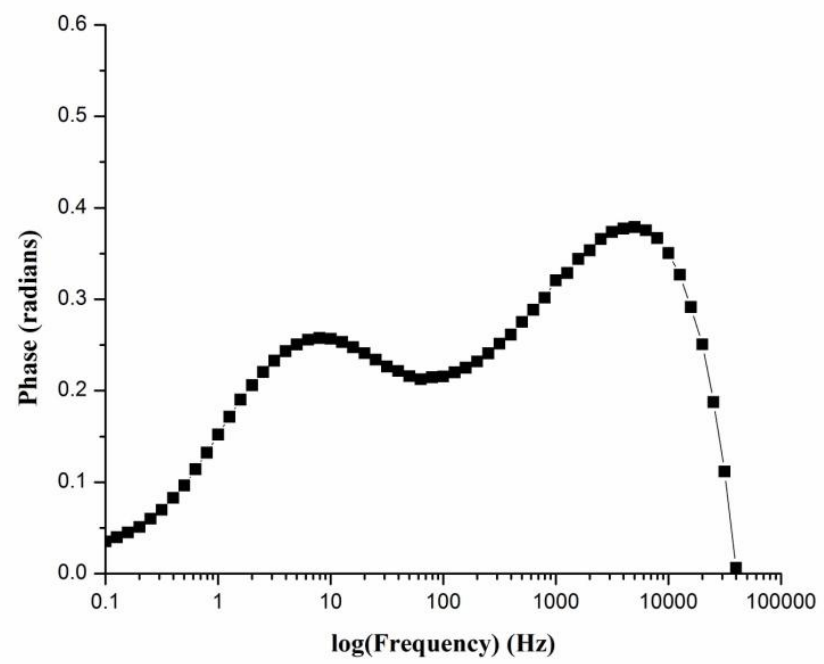

Figure A8. Bode Plot of anode supported cell with LSM-YSZ cathode at $700^{\circ} \mathrm{C}$.

\section{A1.4.3 Microscopy}

After the electrochemical characterization the cells are fractured and the microstructures are examined using a JEOL 6400 scanning electron microscope (SEM).

The cells are further analyzed after fracturing by cross-sectioning and imaging with a dual focused ion and electron beam (FIB/SEM; FEI Strata 235 M) system. SEM images were taken at an angle of $52^{\circ}$ after cross-sectioning with the FIB. Sections were also prepared for transmission electron microscope analysis (TEM; JEOL, JEM-200CX) by a lift-out technique using the above FIB/SEM system. ${ }^{3}$

\section{A1.4.4 XRD}

Phase information was examined using a diffractometer (Siemens D-500) with $\mathrm{Cu}$ Kalpha radiation in the 2 theta range from $20^{\circ}$ to $80^{\circ}$. 


\section{A1.4.5 DSC-TGA}

Precursor decomposition was evaluated using a combined differential scanning calorimetry / thermogravimetric analysis system (DSC/TGA; Netzsch, STA 449C Jupiter), under a flow rate of $25 \mathrm{~mL} / \mathrm{min}$, using technical air, at a ramp rate $1{ }^{\circ} \mathrm{C} / \mathrm{min}$ to $1000{ }^{\circ} \mathrm{C}$.

\section{A1.5 Summary}

Cell processing techniques were reviewed. The specific processing use for the cells in this dissertation was listed in a table at the end of section A1.3. Finally characterization techniques were reviewed. 


\section{References}

1. C. Wang, W. L. Worrell, S. Park, J. M. Vohs, and R. J. Gorte, J. Electrochem. Soc., 148, A864 (2001).

2. S. J. Visco, C. P. Jacobson, and L. C. De Jonghe, U.S. Pat. 6,682,842 (2004).

3. Introduction to Focused Ion Beams, L. A. Giannuzzi and F. A. Stevie, Editors, p. 358, Springer, New York (2005). 


\section{Appendix 2: Infiltration}

\section{A2.1 Introduction}

In this chapter, the infiltration method used to create connected nanostructured SOFC electrodes is reviewed. Typical infiltration techniques use a low concentration precursor and produce random particle size distribution within the electrode. Hence, a large number of repetitions are required to produce a connected network of nanoparticulates, causing pore filling besides the intended coating of pore walls. Progressive filling of the pores has the drawback of causing gas diffusion limitations within the electrodes, which in turn, limit performance at higher current densities. The infiltration method used in this dissertation is unique, since it creates a connected network of nanoparticulates on the surfaces within the electrodes, typically in a single processing step. Additionally, since the method is independent of all other processing steps, it can be preformed at lower temperatures, allowing for the use of otherwise reactive nanoparticulate catalysts.

A through description of the method and science of the infiltration process is given in Section A2.2. Following in Section A2.3 difficulties that are associated with the infiltration process are discussed. A final section is then dedicated to discussing possible scale up scenarios for the process.

\section{A2.2 Method and Science of Infiltration}


Appropriate amounts of metal salt and surfactant are combined to produce the precursor solution for infiltration. Table A1 lists the nitrate weights, yielding 2 grams of final product. The stochiometry is given bellow each of the element names, and in grey the weight of nitrate salt for each element is given. All studies in this dissertation relied on nitrate salts; however, other salts have been tested and found to be equally effective. The typical amount of surfactant added to the precursor is $0.3 \mathrm{~g}$ to $2 \mathrm{~g}$ of final product.

\begin{tabular}{|c|c|c|c|c|c|c|}
\hline & & & $\mathrm{La}$ & $\mathrm{Sr}$ & $\mathrm{Mn}$ & \\
\hline Target material & $W(g)$ & Mole \# & 0.85 & 0.15 & 1.00 & \\
\hline $\mathrm{La}(1-\mathrm{X}) 5 \mathrm{Sr}(\mathrm{X}) \mathrm{MnO} 3$ & 2 & 0.008541 & 0.0073 & 0.0013 & 0.0085 & \\
\hline \multirow[t]{3}{*}{234.1565} & & & 3.144 & 0.271 & 2.452 & \\
\hline & & & $\mathrm{La}$ & $\mathrm{Sr}$ & $\mathrm{Fe}$ & Co \\
\hline & & & 0.6 & 0.4 & 0.8 & 0.2 \\
\hline $\mathrm{La}(1-\mathrm{X}) \mathrm{Sr}(\mathrm{X}) \mathrm{Fe}(1-\mathrm{Y}) \mathrm{Co}(\mathrm{Y}) \mathrm{O} 3$ & 2 & 0.008974 & 0.0054 & 0.0036 & 0.0072 & 0.0018 \\
\hline \multirow[t]{3}{*}{222.86} & & & 2.332 & 0.760 & 2.900 & 0.522 \\
\hline & & & $\mathrm{Sr}$ & $\mathrm{Sm}$ & Co & \\
\hline & & & 0.5 & 0.5 & 1 & \\
\hline $\mathrm{Sm}(1-\mathrm{X}) \mathrm{Sr}(\mathrm{X}) \mathrm{CoO} 3$ & 2 & 0.008853 & 0.0044 & 0.0044 & 0.0089 & \\
\hline \multirow[t]{3}{*}{225.92} & & & 0.937 & 1.967 & 2.576 & \\
\hline & & & $\mathrm{La}$ & $\mathrm{Sr}$ & Co & \\
\hline & & & 0.8 & 0.2 & 1 & \\
\hline \multirow{4}{*}{$\frac{\mathrm{La}(1-\mathrm{X}) \mathrm{Sr}(\mathrm{X}) \mathrm{CoO} 3}{235.582}$} & 2 & 0.008490 & 0.0068 & 0.0017 & 0.0085 & \\
\hline & & & 2.941 & 0.359 & 2.471 & \\
\hline & & & $\mathrm{La}$ & $\mathrm{Sr}$ & $\mathrm{Fe}$ & \\
\hline & & & 0.8 & 0.20 & 1.00 & \\
\hline $\mathrm{La}(1-\mathrm{X}) \mathrm{Sr}(\mathrm{X}) \mathrm{FeO} 3$ & 2 & 0.008602 & 0.0069 & 0.0017 & 0.0086 & \\
\hline \multirow[t]{3}{*}{232.502} & & & 2.980 & 0.364 & 3.475 & \\
\hline & & & $\mathrm{La}$ & $\overline{\mathrm{Ni}}$ & & \\
\hline & & & 1 & 1 & & \\
\hline \multirow{4}{*}{$\frac{\text { LaNiO3 }}{245.61}$} & 2 & 0.008143 & 0.0081 & 0.0081 & & \\
\hline & & & 3.526 & 2.368 & & \\
\hline & & & $\mathrm{La}$ & $\mathrm{Ni}$ & $\mathrm{Fe}$ & \\
\hline & & & 1 & 0.6 & 0.4 & \\
\hline $\mathrm{LaNi}(1-\mathrm{X}) \mathrm{Fe}(\mathrm{X}) \mathrm{O} 3$ & 2 & 0.008181 & 0.0082 & 0.0049 & 0.0033 & \\
\hline 244.47 & & & 3.542 & 1.427 & 1.322 & \\
\hline
\end{tabular}

Table A1. Weight of metal nitrates (grey), in grams, to produce $2 \mathrm{~g}$ of final powder.

The addition of the surfactant to the nitrate precursors facilitates the formation of proper phased material. Figure A1 displays XRD patterns of the decomposition products 
of $\mathrm{La}_{0.85} \mathrm{Sr}_{0.15} \mathrm{MnO}_{3}$ precursors without (Figure A1a), or with (Figure A1b) the additive, Triton X-100. As indicated in Figure 1a, directly decomposing nitrate precursors at 800 ${ }^{\circ} \mathrm{C}$ does not yield a phase-pure LSM perovskite. In contrast, in the presence of the dispersant, the majority of characteristic peaks in Figure A1b correspond to the perovskite phase. Presumably, the surfactant has the effect of complexing the metal ions, so that the individual oxides do not form prematurely. Such complexing effects are well known in sol-gel processes.

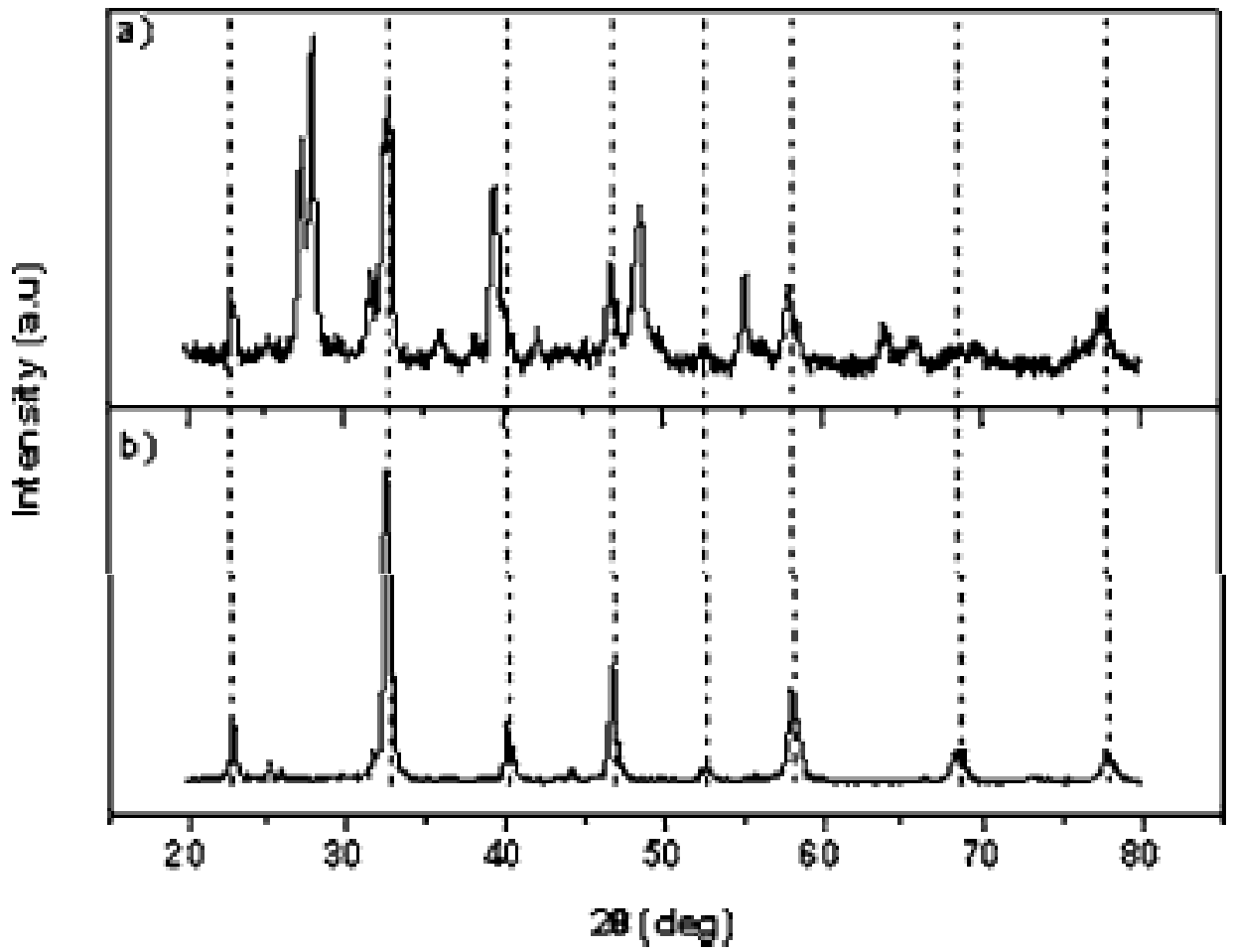

Figure A1. XRD patterns of the decomposition products from LSM precursors (a) without and (b) with the additive sintered at $800{ }^{\circ} \mathrm{C}$ for 1 hour. 
A DSC-TGA scan of LSM and surfactant precursor reveals a number of processes occurring during the decomposition. At the lower temperatures $\left(\sim 100{ }^{\circ} \mathrm{C}\right)$, water is evaporating endothermically, at $\sim 230{ }^{\circ} \mathrm{C}$ the precursor nucleates exothermically to form the oxide product, and finally at $\sim 560{ }^{\circ} \mathrm{C}$ the product undergoes a endothermic ordering reaction. Importantly, the reaction is complete by $600{ }^{\circ} \mathrm{C}$ ensuring that no high temperature processing that may lead to reaction with the substrate is required.

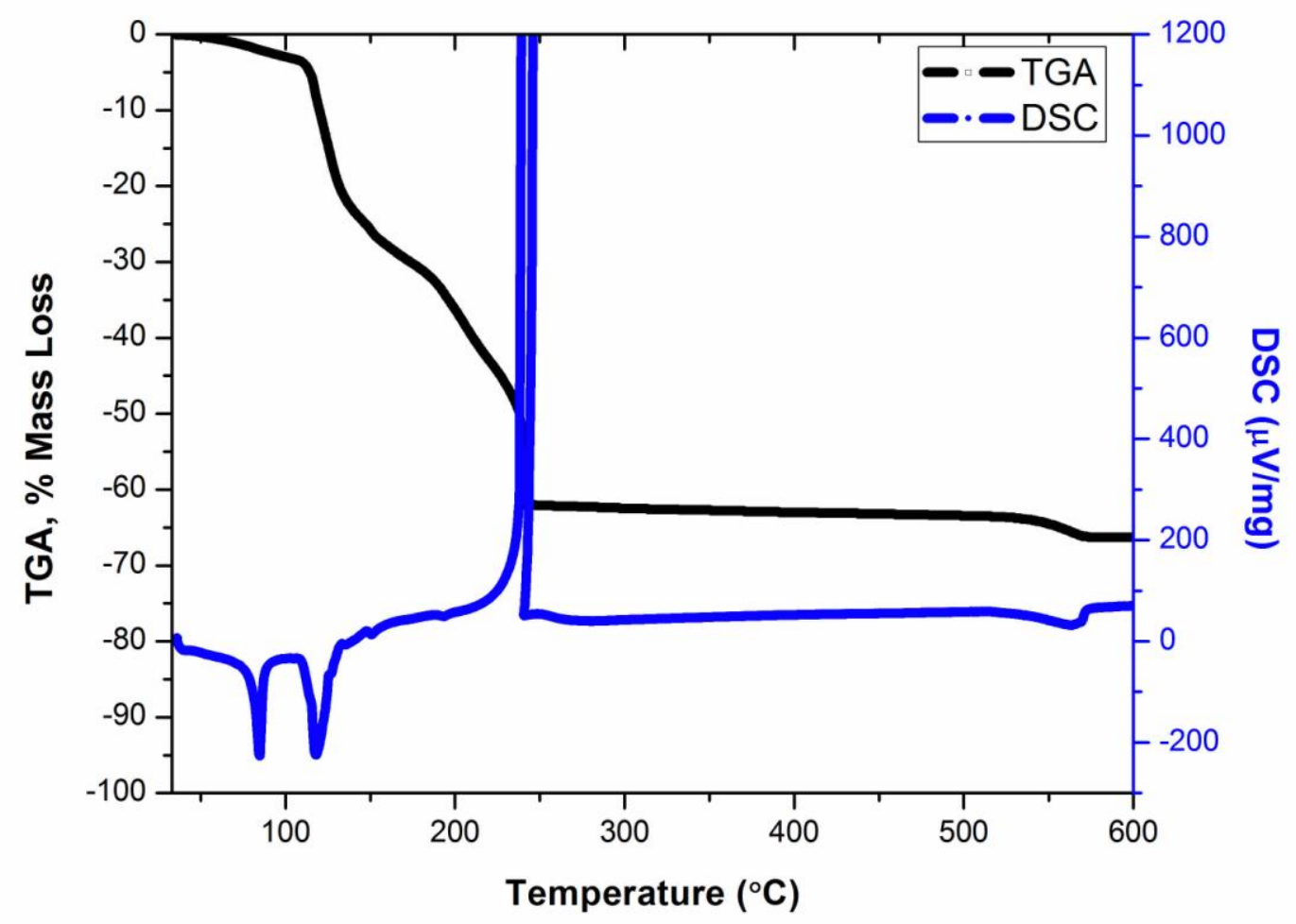

Figure A2. DSC-TGA scan of LSM and surfactant precursor decomposition.

When the alumina crucible, which was placed in the DSC-TGA, is removed after the decomposition, the precursor which was initially only filled up to the bottom $\sim 1 / 5^{\text {th }}$ of the crucible has expanded and overflowed from the crucible, Figure A3. This expansion 
process is believed to be the key to the uniform coating created by the infiltration process. The infiltration process is illustrated in Figure A4. The precursor is first pulled in to the pore by a vacuum; as the system is heated, the precursor expands, forming a uniform layer of nanoparticles. The expansion can be explained by out-gassing during the decomposition.

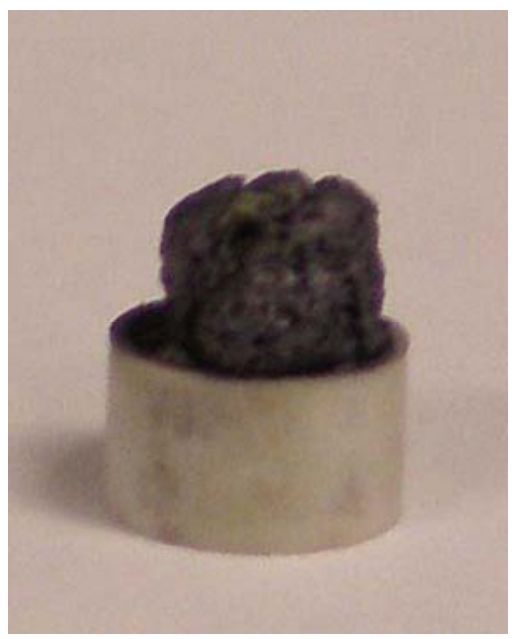

Figure A3. LSM precursor in alumina crucible after DSC-TGA run. The precursor filled $\sim 1 / 5^{\text {th }}$ of the crucible prior to heating.

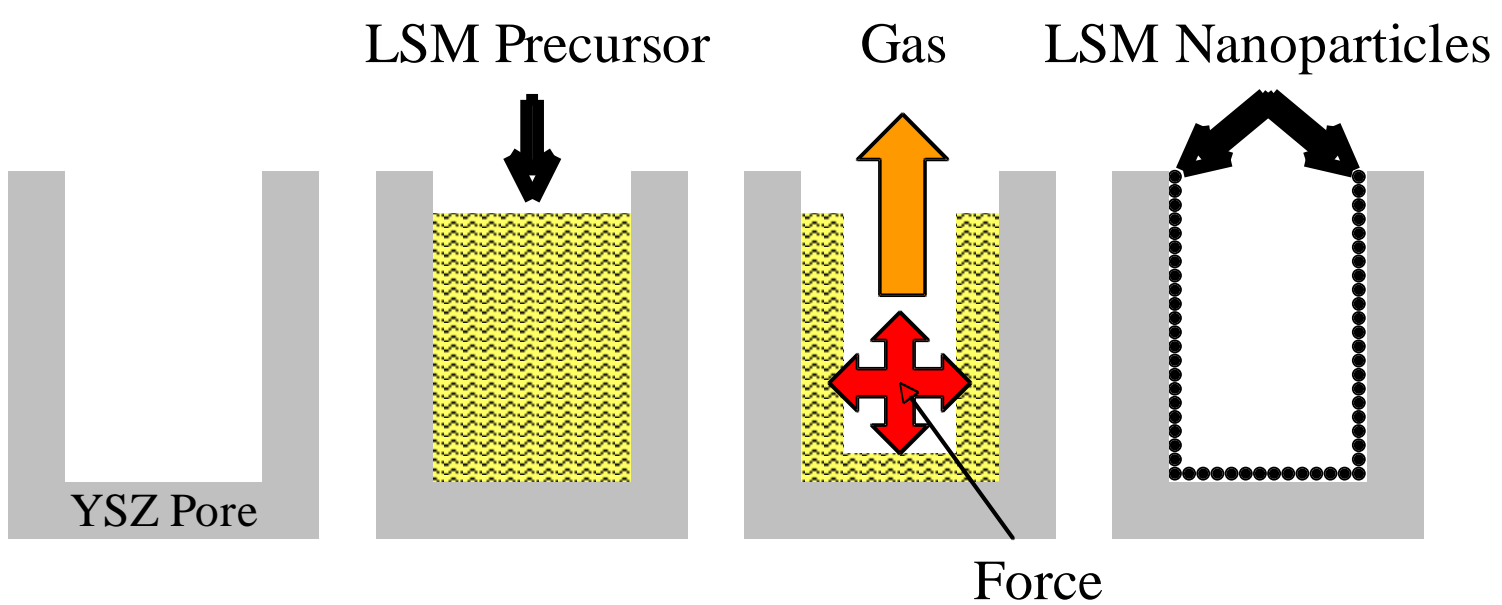

Figure A4. Illustration of infiltration process. 
An SEM image of an LSM infiltrated electrode is given in Figure A5. The YSZ electrolyte is $\sim 10 \mu \mathrm{m}$ thick, the YSZ grains in the electrode are $\sim 1 \mu \mathrm{m}$ in diameter, and the LSM nanoparticles are $~ 50-100 \mathrm{~nm}$ in diameter. The grains are well connected and provide many reaction sites within the electrode.

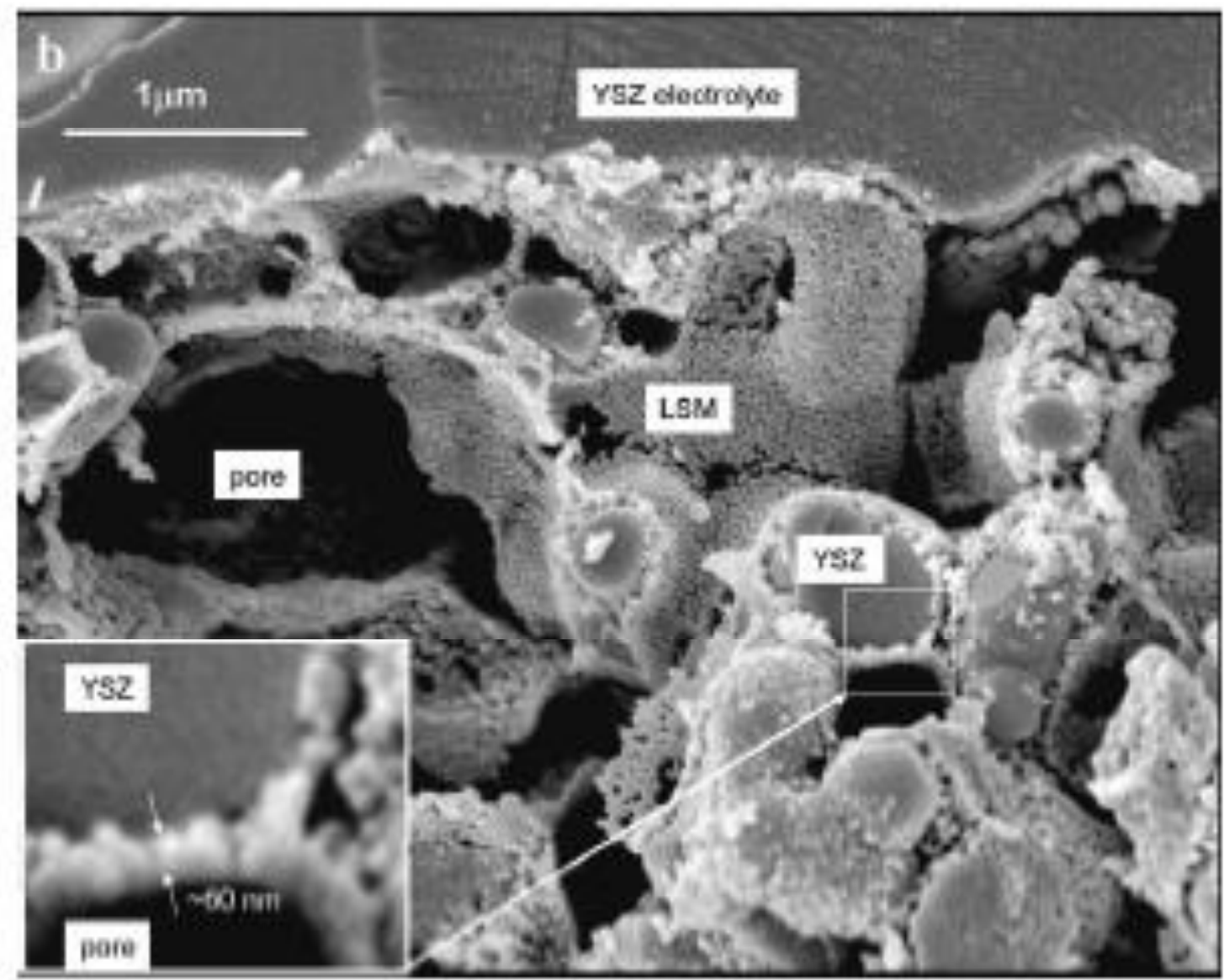

Figure A5. SEM image of YSZ electrolyte backbone infiltrated with LSM.

An important advance in the single-step infiltration procedure involved the modification of the chain length of the surfactant, Triton $\mathrm{X}$, from $\mathrm{n} \sim 10$ for Triton $\mathrm{X}-100$, to $\mathrm{n} \sim 5$ for Triton $\mathrm{X}-45$. Assuming that micelles form in the precursor solutions and that the contents of the micelles are similar, a switch to shorter chain length would yield a 
considerable increase in material deposited by the infiltration. This decrease in surfactant chain length has facilitated the formation of well-connected nanoparticulate networks in a single step within less open electrodes. A conventional LSM-YSZ composite air electrode infiltrated with this improved method is shown in Figure A6, showing nearly complete coverage in a single step as compared to earlier efforts where the infiltrated electrodes were of highly porous electrodes, Figure A5. With the ability to form wellconnected nanoparticulate networks in a single processing step within conventional electrodes, focus can be shifted to decreasing the size of the nanonparticles, so as to exploit further the distinct properties that can be achieved at the nanoscale. For example, changes in infiltration procedure such as decreasing the concentration of the precursor solution, altering reaction rates, modifying the $\mathrm{pH}$, or exploring other surfactants can yield micelles of the proper constitution to synthesize smaller nanoparticles within the porous electrodes. 


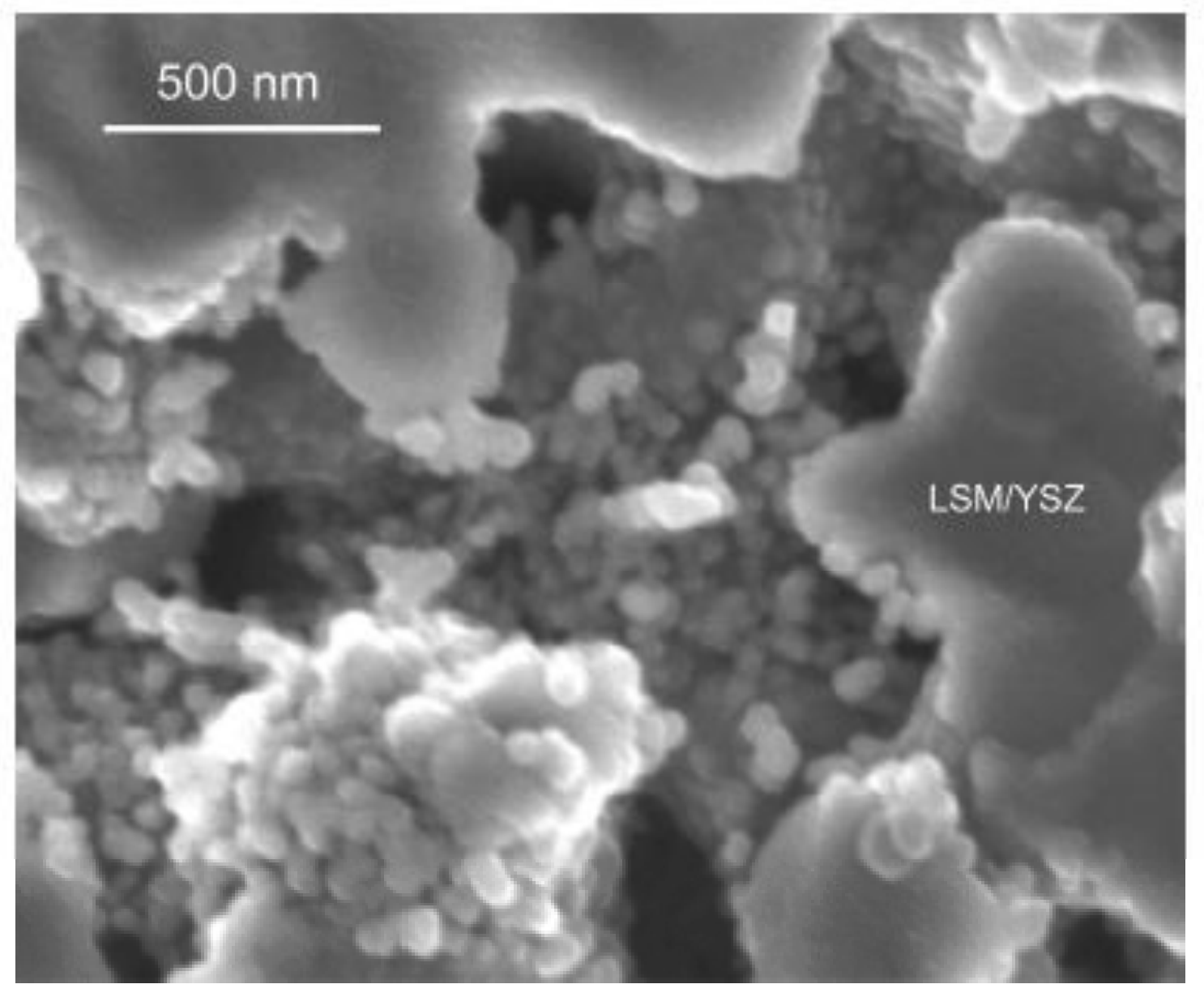

Figure A6. SEM image of conventional LSM-YSZ electrode infiltrated with YDC.

\section{A2.3 Difficulties}

A number of technical difficulties associated with the infiltration will now be discussed.

\section{A2.3.1 Salt}

The vacuum infiltration takes place when the precursor is molten. Hence, it is required that the component salts meet 2 criterion: they must have a liquid phase at low temperatures and must not decompose before $\sim 100{ }^{\circ} \mathrm{C}$. The requirement for having a 
liquid phase can be circumvented if the salt is easily dissolved in $\mathrm{H}_{2} \mathrm{O}$, thus not diluting the precursor solution significantly. A salt that decomposes at low temperatures may also be used if it is the only component; if multiple components are used, it would decompose before the other component salts achieve a low viscosity.

Additional care must also be taken to maintain the appropriate viscosity of the precursor solution. It is beneficial to keep both the precursor and the structure to be infiltrated at the same temperature, in order to prevent temperature gradient induced viscosity variations.

\section{A2.3.2 Phase}

For some of the more complex electrocatalysts, such as LSCF, the infiltration method does not produce a single-phase product. In this case the use of further complexing agents may be needed.

\section{A2.3.3 Electrode Density}

In order to provide sufficient strength in ASC, the anode support is typically highly dense in its oxidized state. In fact, the anode support typically contains no open porosity, preventing infiltration through the electrode, since no percolating path is present in this state. Therefore, for most ASC the performance (Section 3.2) and S tolerance (Section 3.3) cannot be improved.

One possible method allowing infiltration through the dense anode supports is to reduce the $\mathrm{NiO}$ to $\mathrm{Ni}$, thus providing the open pathway for infiltration. However, the use of a reducing atmosphere excludes the use of LSM-YSZ cathodes since LSM 
decomposes in the reducing atmosphere. Alternative cathodes such as LSCF can be used, since they can be sintered at the lower temperatures, allowing for both the reduction step and infiltration to occur before the application of the cathode.

\section{A2.3.4 Volume of Infiltrated Material}

While it has been found that most cathode electrocatlysts can produce a connected nanoparticulate network within a single infiltration step, this is not the case for anode catalysts. The main problem is that the density of cathode electrocatalysts - typically oxides such as LSM-are typically significantly lower than that of anode electrocatalysts - conventionally metals such as Ni. Therefore, a much smaller amount of material is deposited in each infiltration step for anode electrocatalysts. This point is illustrated in Table A2, for LSM and Ni. Furthermore, metal anode electrocatalysts do not wet YSZ as well as oxide electrocatalysts do, and tend to coarsen significantly, making it even more difficult to maintain a connected infiltrated network. ${ }^{1}$

\begin{tabular}{|c|c|c|}
\cline { 2 - 3 } \multicolumn{1}{c|}{} & $\begin{array}{c}\text { Oxide Density } \\
\left(\mathrm{g} / \mathrm{cm}^{3}\right)\end{array}$ & $\begin{array}{c}\text { Infiltrated } \\
\text { Volume } \\
\text { (relative })\end{array}$ \\
\hline $\mathrm{LSM}$ & 6.1 & 4.9 \\
\hline $\mathrm{Ni}$ & 8.9 & 1 \\
\hline
\end{tabular}

Table A2. LSM and Ni final volumes.

\section{A2.4 Scale-up}

While the work on this dissertation focused on lab-scale samples, the infiltration method scales up well for both types of cell geometries (planar and tubular), used in an 
SOFC stack. For planar geometries, the infiltration precursor can be tape cast in its molten state and upon cooling cut into the corresponding shape of the cell electrode. When the cell is heated, the tape will again become molten and can be infiltrated into the desired electrode area.

The scale up has been demonstrated on large metal tubes with a $1570 \mathrm{~cm}^{2}$ area for infiltration. In Figure A7, pictures of one such tube during the infiltration process is shown. A simple way of coating tubes is to simply dip the cell into an appropriate sized vat of the infiltration precursor solution.
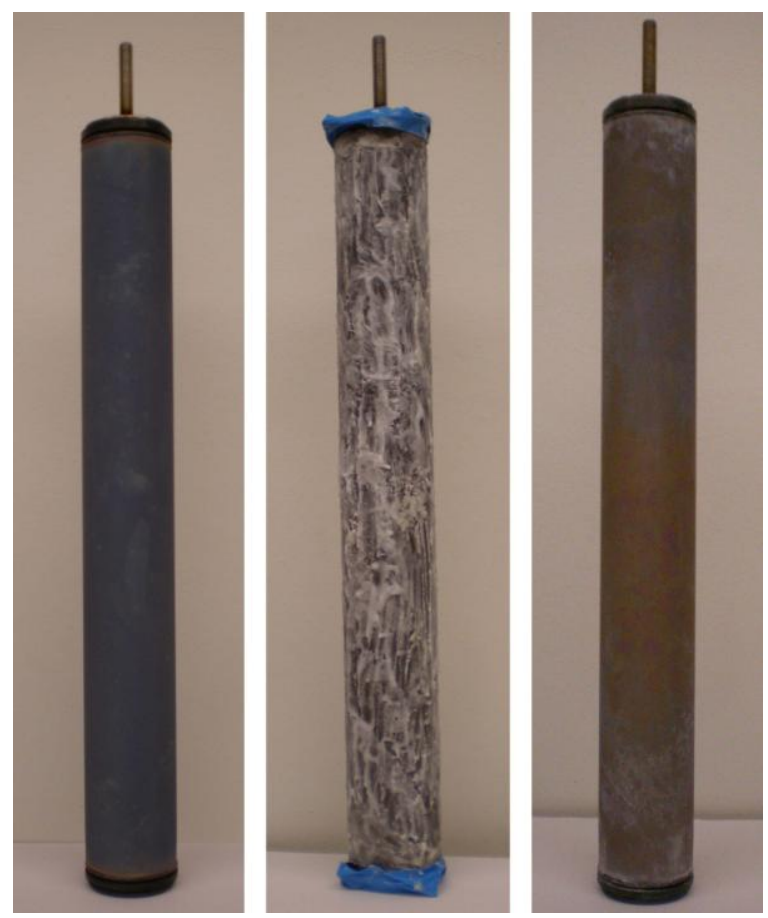

Figure A7. $10 \mathrm{~cm}$ diameter by $50 \mathrm{~cm}$ length metal tube, before infiltration, after addition of precursor to tube surface, and after firing (from left to right).

For both tubular and planar geometries, spraying and tape casting directly onto the cells is an option as well. Each of the scenarios is illustrated tubular geometries in Figures A8 and A9. 


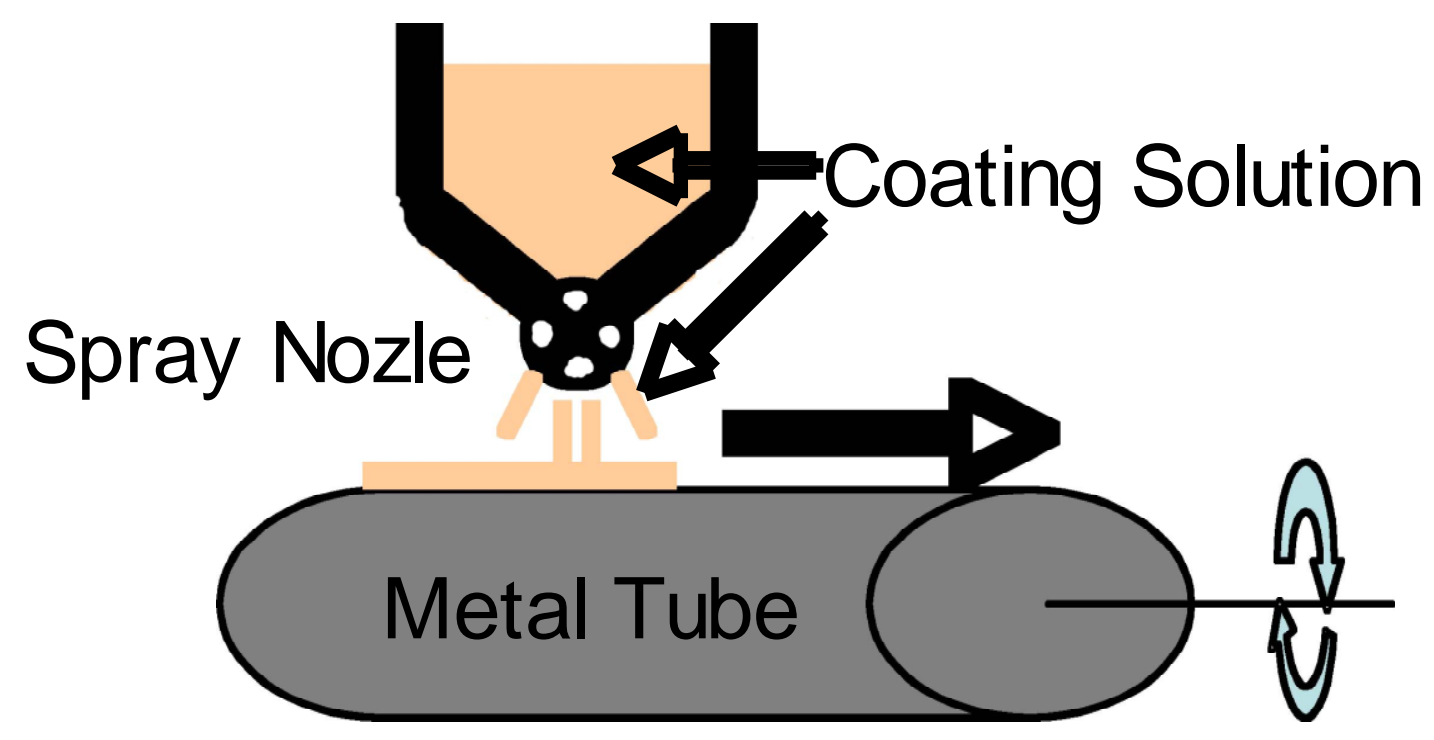

Figure A8. Spray deposition method for precursor solution.

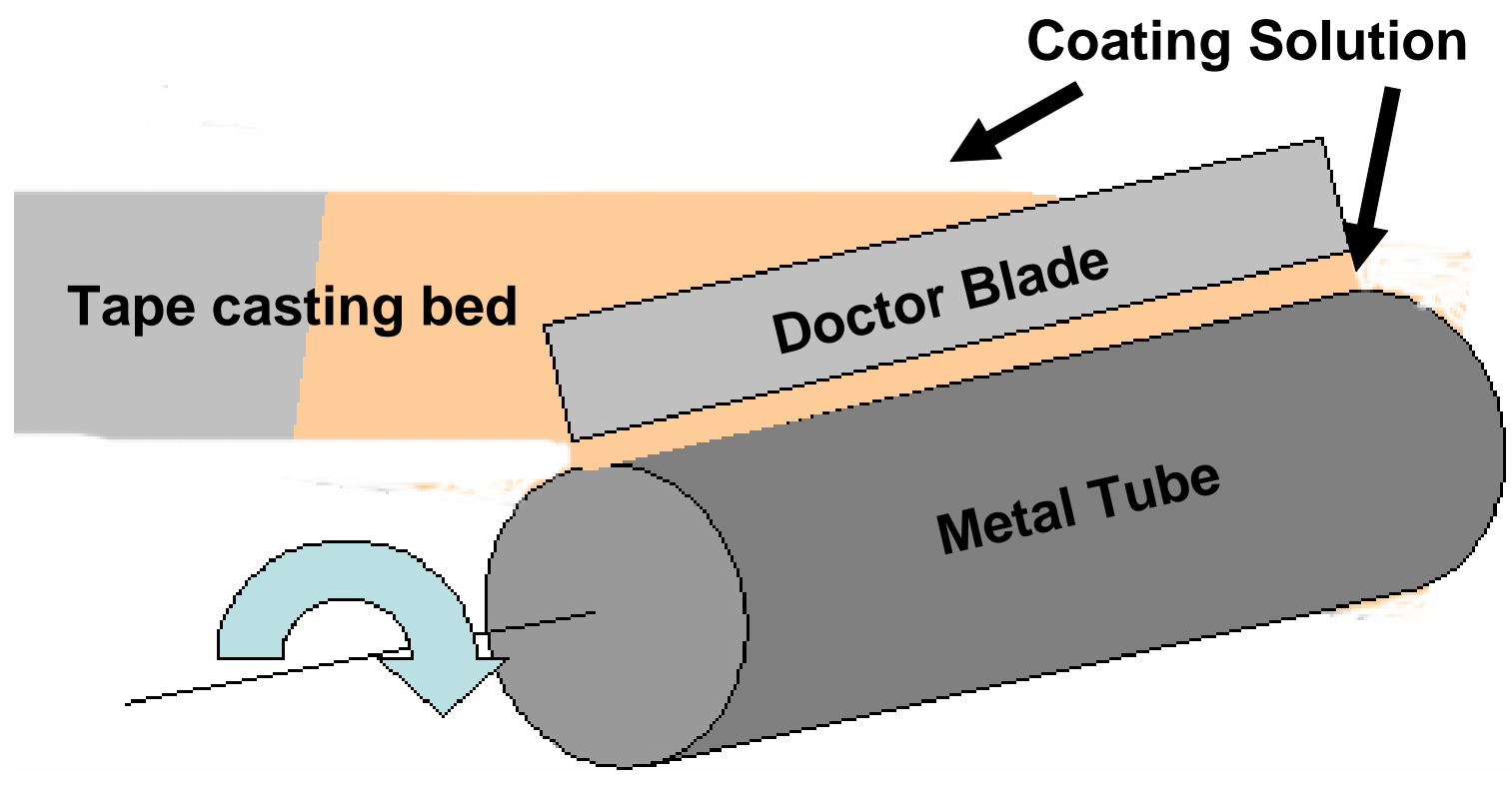

Figure A9. Tape casting deposition method for precursor solution.

\section{A2.5 Summary}


The infiltration method used in this study was evaluated. The process allows for the creation of a connected layer of nanoparticles within a porous electrode within a single processing step. 


\section{References}

1. M.C. Tucker, G.Y. Lau, C.P. Jacobson, L.C. De Jonghe, S.J. Visco, Journal of Power Sources, 171, 2 (2007). 